\title{
Tecnologias Aplicadas a Engenharia Civil
}

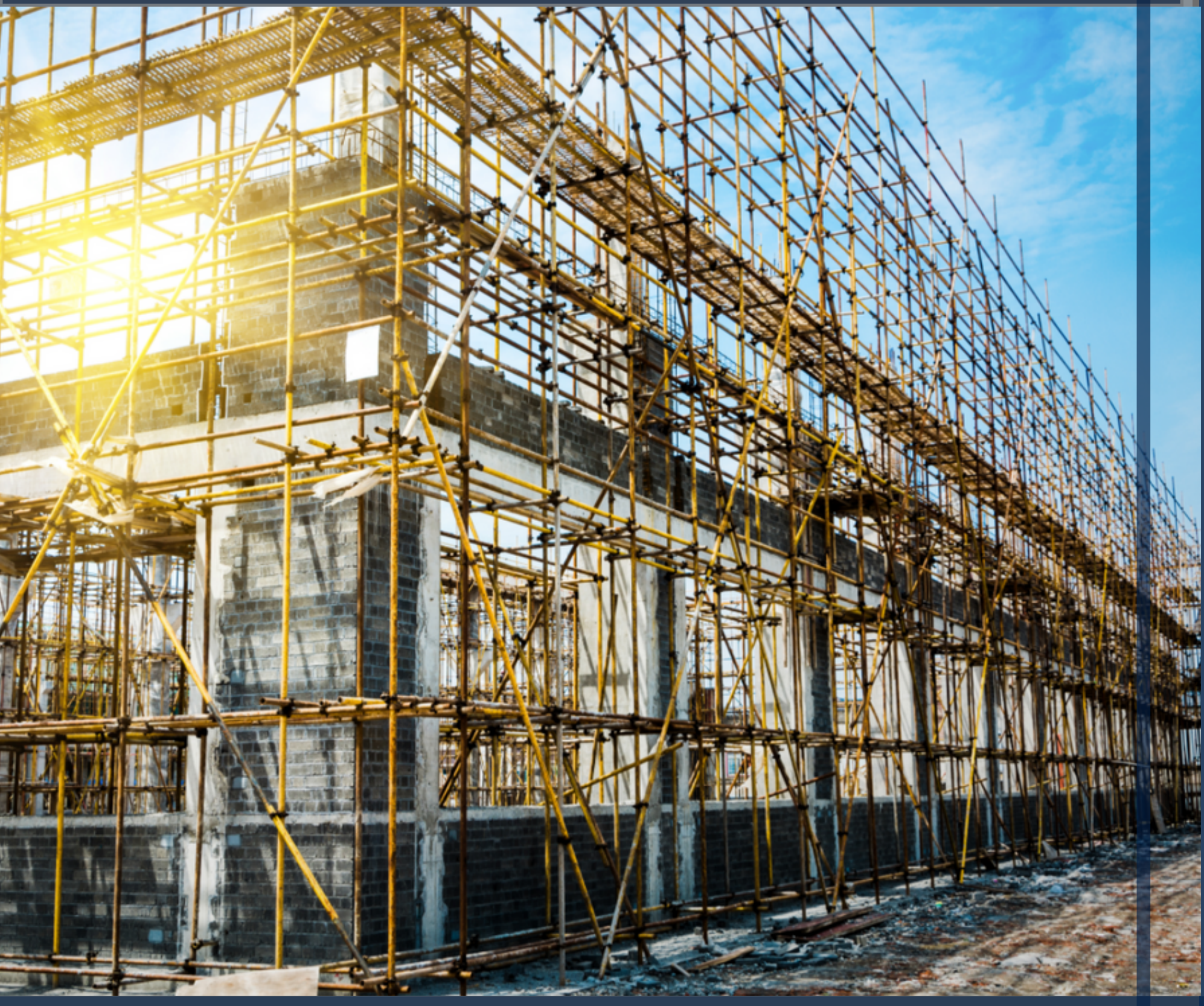

Organizadores

Henrique N. Silva

Everton N. Silva 
TECNOLOGIAS APLICADAS A ENGENHARIA CIVIL

HENRIQUE NOGUEIRA SILVA

EVERTON NOGUEIRA SILVA

(Organizadores)

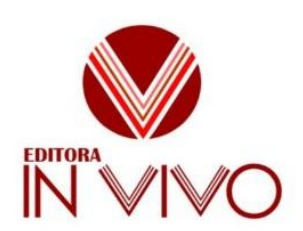

2020 
2020 by Editora In Vivo

Copyright (C) Editora In Vivo

Copyright do Texto (C) 2020 O autor

Copyright da Edição (C) 2020 Editora In Vivo

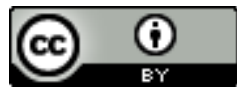

Esta obra está licenciada com uma Licença Creative Commons Atribuição 4.0 Internacional (CC BY 4.0).

O conteúdo desta obra e seus dados em sua forma, correção e confiabilidade são de responsabilidade exclusiva do autor. Permitido o download da obra e o compartilhamento desde que sejam atribuídos créditos ao autor, mas sem a possibilidade de alterá-la de nenhuma forma ou utilizá-la para fins comerciais.

\section{Editor Chefe}

Dr. Everton Nogueira Silva

\section{Colégio de Ciências da Vida 1.1 Ciências Agrárias}

Dr. Aderson Martins Viana Neto Dra. Ana Paula Bezerra de Araújo MSc. Edson Rômulo de Sousa Santos Dr. Fágner Cavalcante P. dos Santos MSc. Filomena Nádia Rodrigues Bezerra Dra. Lina Raquel Santos Araújo Dr. Luis de França Camboim Neto MSc. Maria Emília Bezerra de Araújo

MSc. Yuri Lopes Silva

\subsection{Ciências Biológicas}

Dra. Antonia Moemia Lúcia Rodrigues Portela

1.3 Ciências da Saúde

Dr. Isaac Neto Goes Silva

Dra. Maria Verônyca Coelho Melo

MSc. Paulo Abílio Varella Lisboa

Dra. Vanessa Porto Machado

Dr. Victor Hugo Vieira Rodrigues

\section{Conselho Editorial}

2 Colégio de Humanidades 2.1 Ciências Humanas

Dra. Alexsandra Maria Sousa Silva

MSc. Francisco Brandão Aguiar

MSc. Julyana Alves Sales

2.2 Ciências Sociais Aplicadas

MSc. Cícero Francisco de Lima

MSc. Erivelton de Souza Nunes

Dra. Maria de Jesus Gomes de Lima

MSc. Maria Rosa Dionísio Almeida

MSc. Marisa Guilherme da Frota

3 Colégio de Ciências Exatas, Tecnológica

e Multidisciplinar

3.1 Ciências Exatas e da Terra

Dra. Irvila Ricarte de Oliveira Maia

3.2 Engenharias

MSc. Gilberto Alves da Silva Neto

MSc. Henrique Nogueira Silva

Dados Internacionais de Catalogação na Publicação - CIP

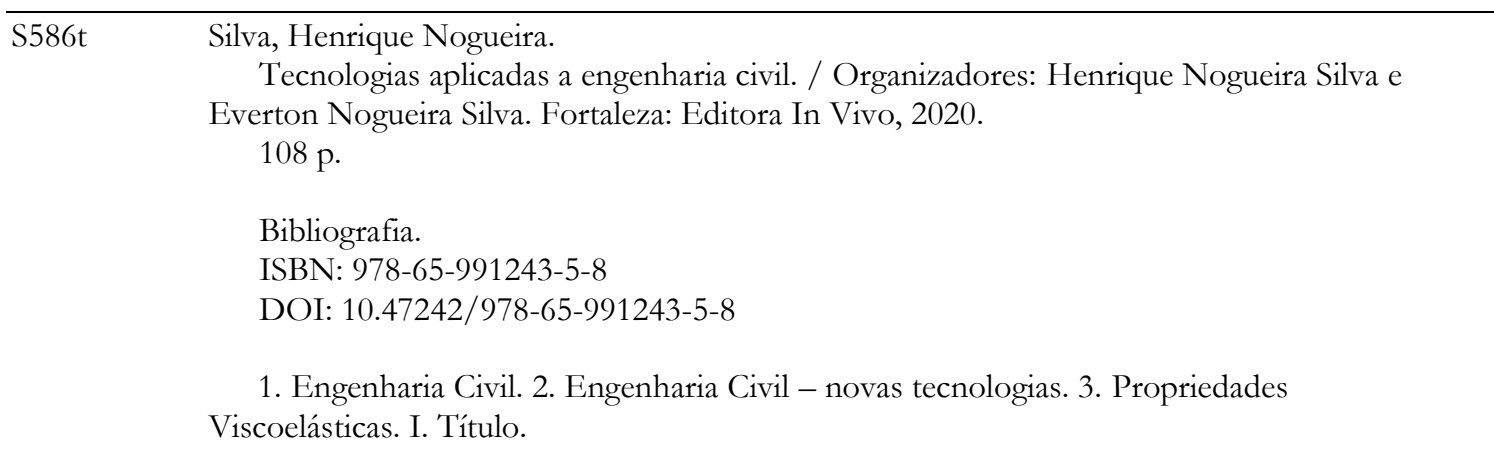




\section{APRESENTAÇÃO}

A engenharia civil tem sido uma das áreas de maior evolução nas sociedades contemporâneas atuais. Destaca-se que ao longo dos séculos, a ciência da engenharia tem se desenvolvimento com avanços tecnológicos sempre alinhado com os outros saberes humanos, tais como a matemática, a geometria, a geologia, a informática etc. Mas uma pergunta surge, quais os avanços necessários na engenharia civil que serão demandados para atender as necessidades futuras em termos técnicos e uso de novos materiais?

Neste sentido, esta obra surge como um norteador a partir da apresentação de trabalhos acadêmicos que buscam expor os mais diversos avanços tecnológicos para que a academia e claro a sociedade de uma forma geral possa ter acesso a informações para o aprimoramento de novas tecnologias para a área da ciência da engenharia civil moderna.

Façam uma boa leitura!

Henrique N. Silva

Everton N. Silva 


\section{Sumário}

Capítulo 1 - VISCOELASTICITY ASPHALT: UMA ABORDAGEM BIBLIOMÉTRICA PARA OS ANOS 2016-2020 5

Capítulo 2 - INFLUÊNCIA DO USO DE ADITIVO REDUTOR DE ÁGUA NO COMPORTAMENTO DE ARGAMASSAS COM AGREGADO MIÚDO RECICLADO CERÂMICO. 17

Capítulo 3 - EFEITOS DE ALTAS TEMPERATURAS NO CONCRETO: REVISÃO BIBLIOGRÁFICA.

Capítulo 4 - CARACTERIZAÇÃO MORFOLÓGICA DE PARTÍCULAS DE GRANITO USANDO METODOLOGIAS DE PROCESSAMENTO E ANÁLISE DE IMAGENS ... 45

Capítulo 5 - EFEITO DA ADIÇÃO DE RESÍDUO DE VIDRO SODA-CAL EM MASSA CERÂMICA PARA INDÚSTRIA DE REVESTIMENTO CERÂMICO

Capítulo 6 - ESTUDO DAS PROPRIEDADES TÉRMICAS E DA INTERAÇÃO COM A ÁGUA NAS BLENDAS DE AMIDO/PBAT E AMIDO/PBAT/PLA

Capítulo 7 - SISTEMA AUTOMATIZADO PARA MONITORAMENTO DO NÍVEL DE ÁGUA NAS CISTERNAS UTILIZANDO PLATAFORMA ARDUINO 80

Capítulo 8 - COMPARATIVO ENTRE ANÁLISES LINEAR E NÃO-LINEAR NA OBTENÇÃO DE FLECHAS EM VIGAS DE CONCRETO ARMADO COM A UTILIZAÇÃO DE SOFTWARE

Capítulo 9 - PROCEDIMENTOS ADOTADOS PARA EXECUÇÃO EM REFORMA DE REVESTIMENTOS INTERNOS EM UM AMBIENTE HOSPITALAR 


\section{VISCOELASTICITY ASPHALT: UMA ABORDAGEM BIBLIOMÉTRICA PARA OS ANOS 2016-2020}

\section{Henrique Nogueira Silva}

Petrobras, Rio de Janeiro, RJ

http://lattes.cnpq.br/3590168850049187

\section{Everton Nogueira Silva}

Universidade Estadual do Ceará, Fortaleza, CE http://lattes.cnpq.br/1111762467064798

Informações sobre o
artigo:

\section{Recebido em:}

$10 / 09 / 2020$

Aceito em:

$15 / 09 / 2020$

Data de publicação:

$23 / 10 / 2020$

Palavras-chave:

\section{Propriedades}

Viscoelásticas

Estudo Bibliométrico

Área de Transportes

\section{RESUMO}

A ciência pode ser estudada, recuperada e avaliada a partir de sua literatura. Partindo deste ponto, cada vez mais insere-se na academia a base científica relacionada ao estudo bibliométrico, em que se é possível construir indicadores por meio de procedimentos estatísticos que avaliam as produções cientificas por áreas de conhecimento. A partir da metodologia bibliométrica, este manuscrito buscará mensurar dados relevantes sob o tema: Viscoelasticity asphalt, extraídos da plataforma Web of Science (WoS) para o período 2016- 2020. A importância do estudo bibliométrico sobre as propriedades viscoelásticas do asfalto torna-se relevante no sentido de se apresentar os avanços da pesquisa acadêmica mais relacionadas a área de transportes. Para tanto, a academia e os mais vastos grupos de estudo e de pesquisa da engenharia civil mais relacionada a área de transportes, tanto a nível nacional como internacional, terão à disposição uma fonte de pesquisa norteadora que servirá de base de acesso para estudos futuros sobre as propriedades do asfalto e seus vários métodos de uso e otimização de vida útil.

\section{VISCOELASTICITY ASPHALT: A BIBLIOMETRIC APPROACH FOR THE YEARS 2016-2020}

\section{ABSTRACT}

Science can be studied, recovered and evaluated from its literature. Starting from this point, the scientific base related to bibliometric study is increasingly inserted in the academy, in which it is possible to build indicators through statistical procedures that evaluate scientific productions by areas of knowledge. From the bibliometric methodology, this manuscript will seek to measure relevant data under the theme: Viscoelasticity asphalt, extracted from the Web of Science (WoS) platform for the period 2016-2020. The importance of the bibliometric study on the viscoelastic properties of asphalt becomes relevant in order to present the advances in academic research more related to the area of transportation. To this end, the academy and the broadest civil engineering study and research groups most related to the transport area, both nationally and internationally, will have at their 
Keywords:

Viscoelastic properties

Bibliometric Study

Transport Area disposal a source of guiding research that will serve as an access base for future studies on the properties of asphalt and its various methods of use and lifetime optimization.

\section{INTRODUÇÃO}

A ciência pode ser estudada, recuperada e avaliada a partir de sua literatura. Partindo deste ponto, cada vez mais insere-se na academia a base científica relacionada ao estudo bibliométrico, em que se é possível construir indicadores por meio de procedimentos estatísticos que avaliam as produções cientificas por áreas de conhecimento. Dentre as aplicações do método de análise bibliométrico podem ser citadas: a seleção de livros e publicações periódicas, a identificação das características temáticas da literatura, a evolução de bibliografias e coleções, entre outros (OKUBO, 1997). A bibliometria então apresenta-se como um método para se avaliar a tipologia, a quantidade e a qualidade das fontes de informação.

A bibliometria tem por proposta ser uma técnica de levantamento estatístico que permite o pesquisador medir índices de produção e disseminação cientifica oferecendo a oportunidade de se avaliar mudanças qualitativas e quantitativas para um determinado tópico ou área de pesquisa, podendo ser estabelecido um perfil das publicações acadêmicas, sendo fornecido informações úteis para especialistas que buscam investigar uma dada área ou assunto científico (ARAÚJO, 2006; REY-MARTÍ, 2016).

A partir da metodologia bibliométrica, este manuscrito buscará mensurar dados relevantes sob o tema: Viscoelasticity asphalt, extraídos da plataforma Web of Science (WoS) para o período 2016-2020. O termo em inglês justifica-se por conta da entrada no sistema WoS para a consulta de trabalhos de relevância internacional relacionado ao tema Viscoelasticity asphalt: uma abordagem bibliométrica para os anos 2016 - 2020.

A importância do estudo bibliométrico sobre as propriedades viscoelásticas do asfalto torna-se relevante no sentido de se apresentar os avanços da pesquisa acadêmica mais relacionada a área de transportes. A academia e os mais vastos grupos de estudo e pesquisas da engenharia civil terão à disposição uma fonte de pesquisa norteadora que servirá de base de acesso para estudos futuros sobre as propriedades do asfalto e seus vários métodos de uso e otimização de vida útil. 


\section{METODOLOGIA}

Para este estudo, foi utilizada a base de dados Web of Science (WoS). A plataforma WoS consiste em ser uma base multidisciplinar internacional que busca indexar os periódicos que são mais citados em suas respectivas áreas, sendo assim permitido identificar as citações recebidas, as referências utilizadas e os registros relacionados ao tema que se busca. Também é possível se realizar uma análise da produção científica com cálculo de índices bibliométricos e o percentual de autocitações, assim como a criação de rankings por inúmeros parâmetros, possuindo atualmente mais de 12.000 periódicos indexados (CAPES, 2012).

A partir de uma base internacional de dados de trabalhos acadêmicos como o WoS, pode-se também se realizar uma análise da situação da pesquisa brasileira em determinado tópico de estudo (VANS e STUMPF, 2010). A análise bibliometrica proposta para este capítulo seguirá as fases propostas por Wang et al (2014): a) definição dos termos de busca; b) consulta à base de dados; c) refinamento da pesquisa e d) análise de indicadores. Para atender o propósito da pesquisa será definido o seguinte termo de busca na plataforma WoS: Viscoelasticity asphalt.

O período selecionado foi a série temporal dos últimos cinco anos. Essa série temporal justifica-se por conta que a academia tem maior nível de interesse em trabalhos publicados nos últimos cinco anos. Na plataforma WoS além do refinamento pela série temporal descrita, foram também utilizados os seguintes critérios: a) categorias de áreas de pesquisa; b) tipos de documentos; c) evolução nos anos de publicação; d) países que mais publicam sobre o tema; e) caracterização das publicações brasileiras existentes na plataforma WoS; f) Idioma mais frequente das publicações; g) evolução no número de citações. Também - através da utilização do programa VOSviewer - foi possível apresentar os elos de ligação das palavras chaves mais recorrentes nos trabalhos acadêmicos mundiais relacionados a temática da viscoelasticidade do asfalto. A apresentação dos resultados será categorizada por Indicadores de Produção Científica e Indicadores de Impacto.

\section{RESULTADOS E DISCUSSÃO}

Nesta seção serão apresentados os indicadores bibliométricos que foram gerados neste estudo. A primeira analise apresentada e discutida será referente aos indicadores de 
produção científica. Em seguida, será apresentado os resultados sobre o aspecto da análise dos indicadores de impacto.

\subsection{Indicadores de produção científica}

A pesquisa parte do interesse da academia ter acesso a um maior nível de informações sobre novas tecnologias que podem ser amplamente aplicáveis para otimização e qualidade para diferentes usos do material asfáltico. Para o critério de economicidade e de durabilidade do material asfáltico, Silva (2009, p.1) destaca que:

Paralelamente aos investimentos necessários, é importante também se aplicar o desenvolvimento de técnicas mais realistas de projeto, de análise mecânica de tensões e deformações, e de construção e reabilitação de pavimentos, que resultem em maior confiabilidade na qualidade destes pavimentos. Particularmente relativo ao desenvolvimento da análise mecânica de tensões e deformações mais próximas da realidade, a comunidade técnico-cientifica brasileira de infraestrutura de transportes deve realizar uma avaliação mecânicoconstitutiva minuciosa dos diferentes materiais de pavimentação.

Para autores como Roberts et al. (1996); Lee e Kim (1998); e Momm (2001), a mistura asfáltica deve ser recuperável pós aplicação de cargas e/ou tensões que possam ocasionar maiores deformações. A título de tipo de análise para a mistura asfáltica, Silva (2009) destaca que os estudos estão mais amplamente relacionados a análises do comportamento mecânico-construtivo das misturas asfálticas - entre elas o concreto asfáltico - onde são avaliados o comportamento elástico linear.

Diante do interesse da academia em apresentar melhores propostas de avaliação da viscoelasticidade para o material asfáltico - existindo uma gama de estudos técnicos de avaliação - foi observado para a série temporal dos últimos cinco anos (2016-2020) a existência de 198 trabalhos de relevância internacional existentes na plataforma WoS. Na Tabela 1, tem-se o ranking das 05 principais categorias/áreas científicas de estudo sobre a temática Viscoelasticity asphalt. Destaca-se as áreas: Engineering Civil; Materials Science Multidisciplinary; e Construction Building Technology. Destaca-se que as áreas apresentadas na referida tabela se correlacionam, sendo os números baseados de um total de 198 trabalhos encontrados na plataforma WoS para o período avaliado.

Tabela 1 - Ranking das categorias relacionadas a temática Viscoelasticity asphalt na plataforma WoS (2016-

$$
\text { 2020) }
$$

\begin{tabular}{l|r}
\hline Categorias WoS & \% de 198 trabalhos \\
\hline $1^{\circ}$ Engineering Civil & 63,64 \\
\hline $2^{\circ}$ Materials Science Multidisciplinary & 57,58 \\
\hline
\end{tabular}




\begin{tabular}{l|r}
\hline $3^{\circ}$ Construction Building Technology & 56,01 \\
\hline $4^{\circ}$ Materials Science Characterization Testing & 12,12 \\
\hline $5^{\circ}$ Mechanics & 9,01 \\
\hline
\end{tabular}

Um dado interessante é que para a área de Materials Science Characterization Testing tem-se um percentual de cerca de $12 \%$, apesar de esta se relacionar com as demais categorias. Esse dado mostra que os estudos para a área da viscoelasticidade para os materiais asfálticos estão sempre inter-relacionados com as demais áreas da engenharia civil. Em atendimento ao segundo indicador bibliométrico relacionado aos tipos de documentos que mais publicam sobre a temática Viscoelasticity asphalt, tem-se no Gráfico 1 a apresentação desta categorização.

Gráfico 1 - Ranking das categorias relacionadas a temática Viscoelasticity asphalt na plataforma WoS (2016-2020)

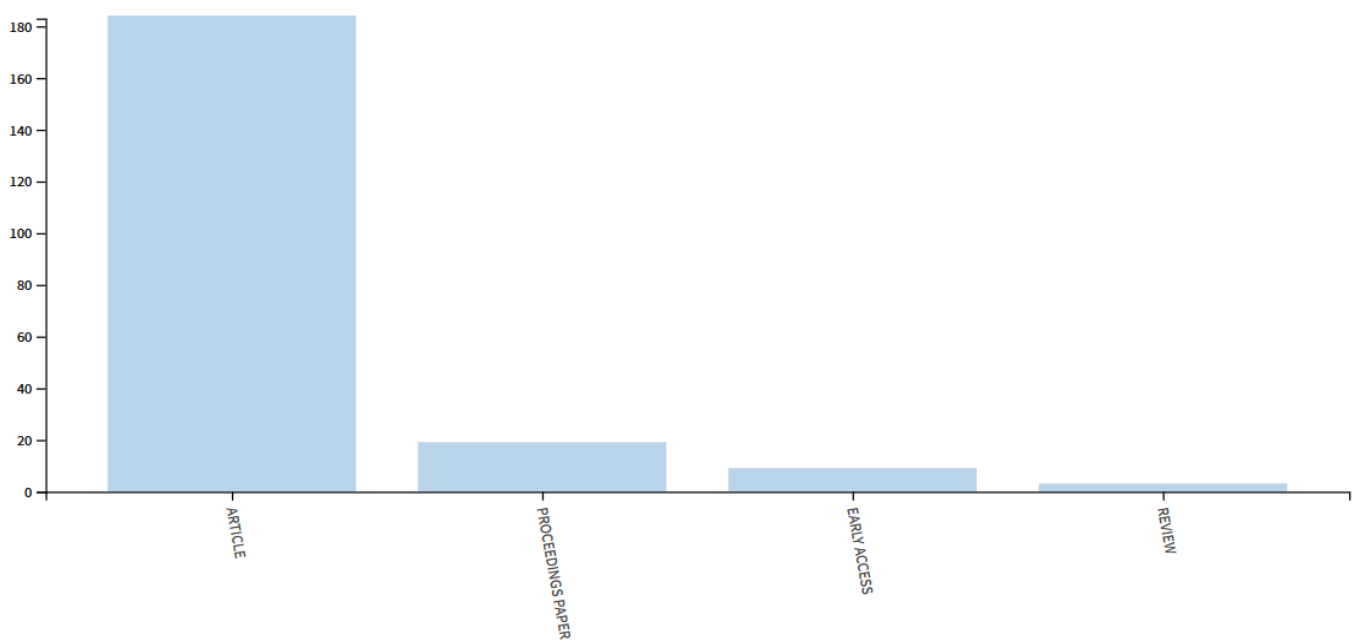

Fonte: Web of Science (2020)

De acordo com o que foi observado no Gráfico 1 para a temática do comportamento da viscoelasticidade do asfalto, as publicações acadêmicas sob este assunto tendem a serem publicadas no formato de artigos científicos em revistas internacionais sendo um total de 183 trabalhos para o período dos últimos cinco anos.

Sob o aspecto da evolução do número de publicações relacionados a temática Viscoelasticity asphalt tem-se uma tendência maior no número de publicações para o ano de 
2017 onde foram publicados cerca de 50 trabalhos acadêmicos sobre a referida temática Gráfico 2.

Gráfico 2 - Número de publicações por ano relacionadas a temática Viscoelasticity asphalt na plataforma WoS (2016-2020)

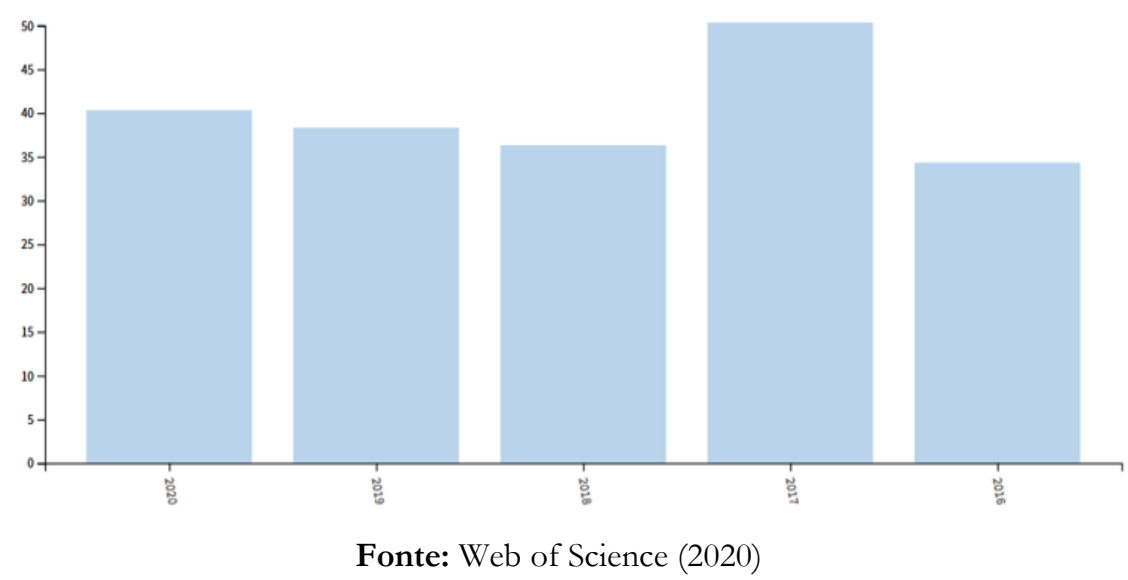

A média de publicações ficou em torno de 39,6 publicações para o período dos últimos cinco anos. Abre-se uma ressalva, o levantamento dos dados na plataforma WoS leva em consideração o período de 2016 até agosto de 2020. Para o ano de 2020 já se acumulam 40 trabalhos sobre a temática Viscoelasticity asphalt.

A análise demográfica dos resultados aponta obtidos na pesquisa (Figura 1) aponta os institutos de pesquisas chineses em primeiro lugar no ranking de publicações internacionais sobre a temática Viscoelasticity asphalt na plataforma WoS nos últimos cinco anos, com uma média de próxima de 14,2 trabalhos/ano. Em segundo lugar vem os Estados Unidos com uma média de 11, 2 trabalhos e em terceiro a França com uma média de 3,6 trabalhos. O Brasil neste ranking está na oitava posição tendo por média aproximadamente 1,4 trabalhos publicados em periódicos internacionais conforme registro no WoS. 
Figura 1 - Distribuição da produção científica por países para a temática Viscoelasticity asphalt na plataforma WoS (2016-2020)

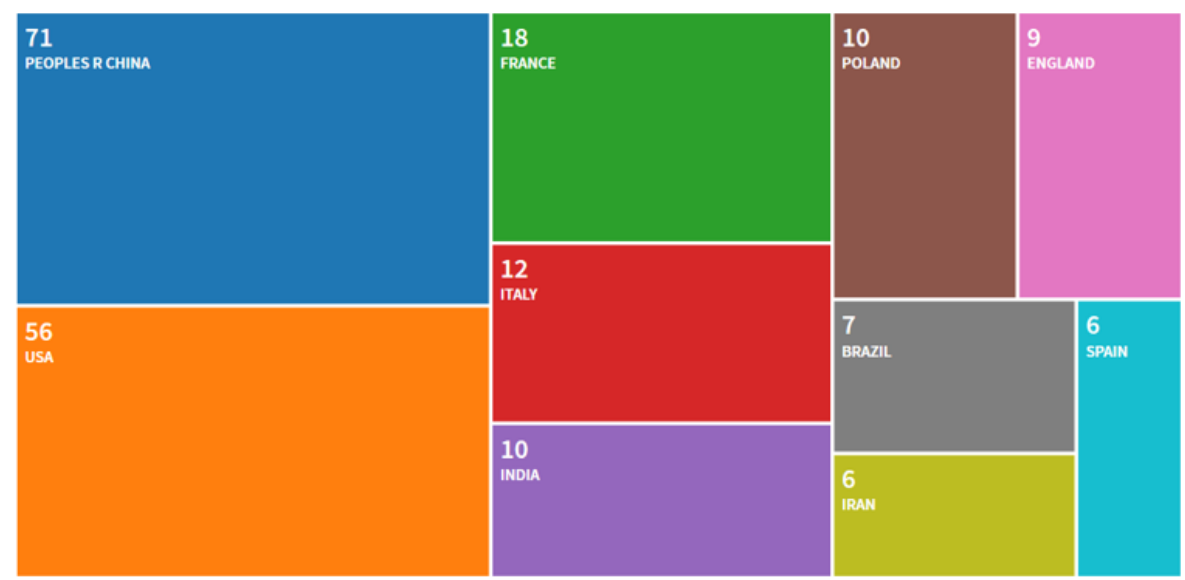

Fonte: Web of Science (2020)

Atendendo ao critério de caracterização das publicações brasileiras na plataforma WoS, tem-se na Tabela 2 a relação dos principais trabalhos brasileiros que são utilizados como referências internacionais, ou seja, os trabalhos brasileiros mais citados em outros manuscritos internacionais de avaliação das propriedades viscoelásticas para o asfalto.

$\mathrm{Na}$ referida tabela, dos trabalhos brasileiros mais citados internacionalmente de acordo com a plataforma WoS para a temática Viscoelasticity asphalt apresenta-se com participação direta ou coparticipação dos pesquisadores do Departamento de Engenharia de Transporte da Universidade Federal do Ceará, demonstrando a vanguarda da referida instituição para o aspecto de pesquisas relacionadas a avaliação das propriedades físicas do asfalto. Somando-se a essa informação, dos 7 trabalhos brasileiros referenciados no Web of Science para o tema Viscoelasticity asphalt, cinco destes tiveram a participação de pesquisadores da Universidade Federal do Ceará - departamento de Engenharia de Transportes. Para o aspecto idioma, foi pertinente em sua totalidade as publicações na língua inglesa sendo $100 \%$ do total dos 198 trabalhos presentes na plataforma WoS. Diante desta informação, é percebido que os manuscritos seguem um padrão de idioma, destacando-se para este critério, a possibilidade da exigência da língua inglesa para a publicação em periódicos internacionais. 
Tabela 2 - Relação dos principais trabalhos brasileiros sobre a temática Viscoelasticity asphalt na plataforma WoS (2016-2020)

\begin{tabular}{|c|c|c|c|c|}
\hline $\begin{array}{c}\text { Ano } \\
\text { Título do trabalho }\end{array}$ & $\begin{array}{l}\text { Número } \\
\text { de } \\
\text { citações }\end{array}$ & Periódico/Evento & Autores & $\begin{array}{c}\text { Instituição(ões) de } \\
\text { Pesquisa(s)/Departamento(s) }\end{array}$ \\
\hline $\begin{array}{l}2016 \text { - An approach to } \\
\text { couple aging to stiffness } \\
\text { and permanent } \\
\text { deformation modeling } \\
\text { os asphalt mixtures }\end{array}$ & 7 & $\begin{array}{l}\text { Materials and } \\
\text { Structures, vol. 49, } \\
\text { edição 12, páginas } \\
\text { 4929-4945. }\end{array}$ & $\begin{array}{l}\text { Babadopulos, } \\
\text { LFDL }^{1} \text {; Ferreira, } \\
\text { JLS}^{2} \text {; Soares, } \\
\text { JB }^{3} \text {. }\end{array}$ & $\begin{array}{c}\text { Universidade Federal do Ceará, } \\
\text { departamento de Engenharia de } \\
\text { Transportes. }\end{array}$ \\
\hline $\begin{array}{l}2017 \text { - Application of } \\
\text { the theory of } \\
\text { viscoelasticity to } \\
\text { evaluate the resilient } \\
\text { modulus test in asphalt } \\
\text { mixes. }\end{array}$ & 7 & $\begin{array}{l}\text { Construction and } \\
\text { building Materials, } \\
\text { vol.149, páginas } \\
648-658 .\end{array}$ & $\begin{array}{l}\text { Spencht, LP'; } \\
\text { Babadopulos, } \\
\text { LFDL }^{2} \text {; Di } \\
\text { Benedetto, } \mathrm{H}^{3} \text { et } \\
\text { al. }\end{array}$ & $\begin{array}{l}\text { Universidade Federal de Santa } \\
\text { Maria (RS), programa de } \\
\text { graduação em Engenharia Civil; } \\
\text { Universidade de Lyon (Fr.), } \\
\text { Ecole Nati Travaux Publ Etat; } \\
\text { Universidade Federal do Ceará, } \\
\text { departamento de Engenharia de } \\
\text { Transportes }\end{array}$ \\
\hline $\begin{array}{l}2018 \text { - Fatigue } \\
\text { cracking simulation of } \\
\text { aged asphalt pavements } \\
\text { using a viscoelastic } \\
\text { continuum damage } \\
\text { model }\end{array}$ & 5 & $\begin{array}{l}\text { Road Materials and } \\
\text { Pavement Design, } \\
\text { vol. 9, edição. 13, } \\
\text { páginas 546-560. }\end{array}$ & $\begin{array}{l}\text { Babadopulos, } \\
\text { LFDL }^{1} \text {; Soares, } \\
\text { JB}^{2} \text {; Ferreira, } \\
\text { JLS }^{3} \text {; do } \\
\text { Nascimento, } \\
\text { LAH. }\end{array}$ & $\begin{array}{l}\text { Universidade Federal do Ceará, } \\
\text { departamento de Engenharia de } \\
\text { Transportes; } \\
\text { Petrobrás, Res. \& Dev. Ctr., Rio } \\
\text { de Janeiro (RJ); } \\
\text { Universidade Federal do Ceará, } \\
\text { Campus Cratéus-CE. }\end{array}$ \\
\hline
\end{tabular}

Fonte: Web of Science (2020)

\subsection{Indicadores de impacto}

Para os últimos cinco anos, conforme apresentado no gráfico 4, tem-se uma tendência crescente no número de citações internacionais para avaliação das propriedades viscoelásticas do asfalto, atingindo um maior nível de citações a partir do ano de 2019. A quantidade de citações apresenta-se como um indicador para se avaliar o impacto dos 
documentos escritos para uma determinada área de pesquisa. O número de citações também está associado, segundo Caldas e Tinoco (2004) ao quanto os pesquisadores de uma área de pesquisa atribuem reconhecimento e/ou importância a um tema de estudo específico.

Gráfico 3 - Evolução no número de citações por ano para a temática Viscoelasticity asphalt

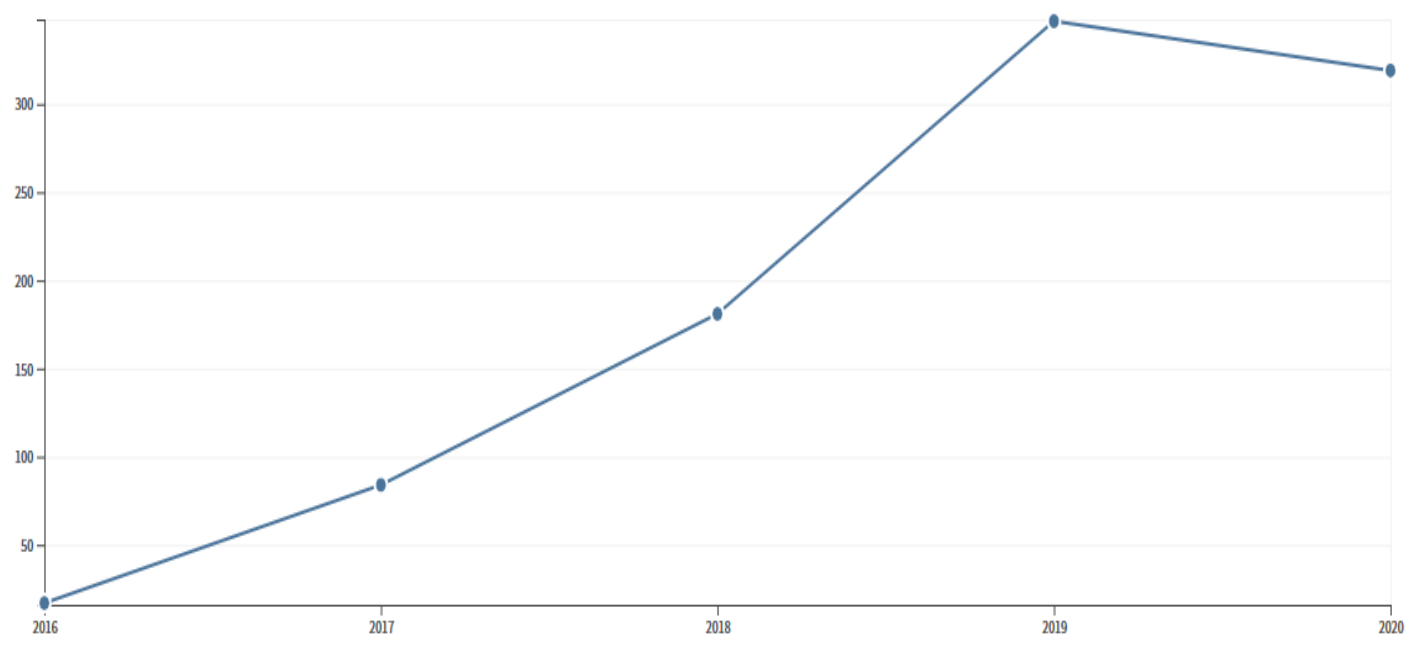

Fonte: Web of Science (2020)

A soma do número de citações foi igual a 948, sendo demonstrado a partir de então o interesse da academia em contribuir com estudos que melhorem a otimização da pavimentação de rodovias e estradas, melhorando assim a eficiência em termos de economia, pois quanto mais se investe em pesquisa para essa área se terá a propensão de se reduzir os gastos com manutenção de estradas e tecnologias mais baratas de pavimentação tendem a surgir.

Outro método bibliométrico para se entender a relevância de uma dada temática cientifica refere-se à avaliação das palavras chave mais citadas nas publicações - Figura 2 permitindo identificar quais assuntos são mais recorrentes e onde há possíveis déficits em termos de pesquisa para uma dada área acadêmica. 
Figura 2 - Palavras chave mais citadas na produção cientifica para a temática Viscoelasticity asphalt na plataforma WoS (2016-2020)

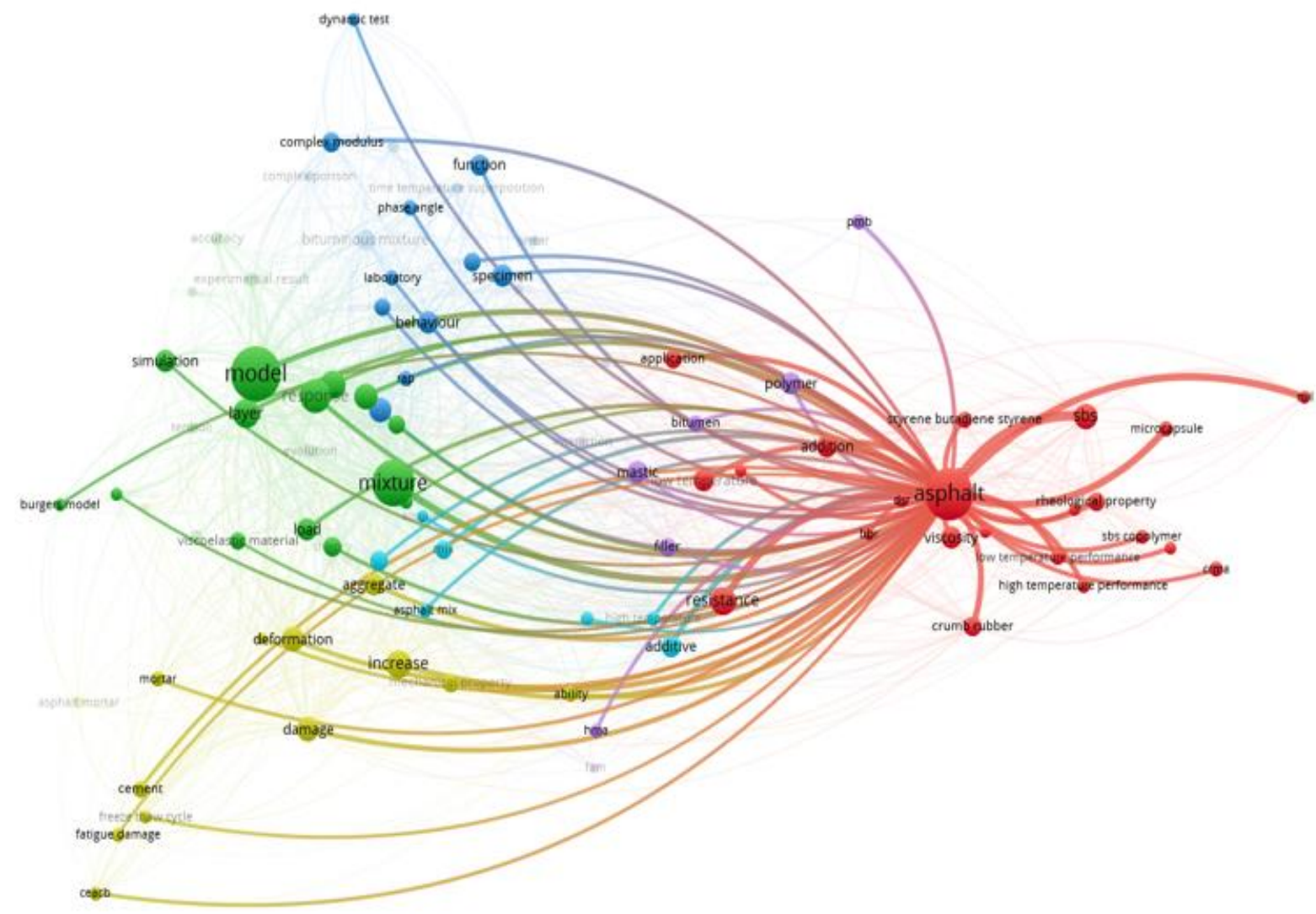

Fonte: Web of Science e VOSviewer (2020)

As palavras chave mais evidentes nos trabalhos acadêmicos sobre a propriedade da viscoelasticidade para o asfalto foram: model, mixture e asphalt. Como comportamento esperado, dado a relevância dos estudos para a área de pavimentação, grande parte das palavras chave gravitaram em torno da palavra asphalt, sendo a mesma um nó e um elo de ligação na rede de palavras chave - as palavras com ligações em vermelho, são as que mais se relacionam com a principal palavra chave principal ou nó de uma rede.

Model e mixture também se apresentaram como nós na rede, porém não formaram um elo forte de ligação com as demais palavras chave expressas. Para tanto, se compreende que para estudos das propriedades físicas do asfalto espera-se que esta palavra forme o principal elo de ligação com as demais palavras chave, pois na lógica as pesquisas buscam avaliar as propriedades viscoelásticas do asfalto, estando as demais palavras chave sob a condição secundária e/ou dependente do termo asfalto. 


\section{CONSIDERAÇÕES FINAIS}

A partir da análise bibliométrica - escopo deste estudo - foi possível apresentar a relevância das mais diversas pesquisas acadêmicas sobre as propriedades viscoelásticas do asfalto, estando o Brasil na vanguarda sob essa temática. Destaca-se a colaboração do Departamento de Engenharia de Transportes da Universidade Federal do Ceará, que de forma direta, ou em parceria com outros institutos de pesquisas mundiais, vem ampliando o conhecimento e o avanço nas pesquisas sob as propriedades viscoelásticas do asfalto.

As propriedades viscoelásticas do asfalto serão constantemente fontes de estudo para a área da Engenharia Civil relacionada ao setor de transportes, sendo cada vez mais recorrente a apresentação de pesquisas que demonstrem meios, métodos e tecnologias para uso do elemento asfalto com maior economicidade e tempo de vida útil.

\section{REFERÊNCIAS}

ARAÚJO, C.A. Bibliometria: evolução histórica e questões atuais. Revista Em Questão, vol.12, n 1, p.11-32, Porto Alegre-RS, 2006.

CAPES. Web of Science lança nova versão de base de dados. Brasília. Coordenação de Aperfeiçoamento de Pessoal de Nível Superior, 2012. Disponível em: http://www.capes.gov.br/servicos/. Acesso em: 01 de set de 2020.

LEE, H; KIM, Y.R. Viscoelastic Constitutive Model for Asphalt Concrete under Cyclic Loading. Journal of Engineering Mechanics. American Society of Civil Engineers ASCE, v. 124, n. 1, p. 32-40, 1998.

MOMM, L. Comportamento Viscoelástico do Concreto Asfáltico. Anais da XXXIII Reunião de Pavimentação, ABPV. Florianópolis- SC, p. 223-231, 2001.

OKUBO, Y. Bibliometric indicators and analysis of research systems: methods and examples. Paris: OCDE/GD, 1997.

REY-MARTÍ, A.; RIBEIRO SORIANO, D; PALACIOS -MARQUÉS, D. A bibliometric analysis of social entrepreneurship. Journal of Business Research, v.69, n.5, p. 1651-1655, 2016.

ROBERTS, F. L. et al. Hot Mix Asphalt Materials, Mixture Design and Construction. Ed. NAPA, Education Foundation. Lanham, Maryland, USA, 1996. 
SILVA, H.N. Caracterização viscoelástica linear de misturas asfálticas: operacionalização computacional e análise pelo método de elementos finitos. Dissertação. Programa de Mestrado em Engenharia de Transportes, Universidade Federal do Ceará, Fortaleza-CE, 2009.

VANZ, S.A.S; STUMPF, I.R.C. Procedimentos e ferramentas aplicados aos estudos. Revista Informação \& Sociedade, v.20, n.2, p. 67-75, maio/ ago., João Pessoa-PB, 2010.

WANG, B. et al. An overview of climate change vulnerability: A Bibliometric Analysis based on Web of Science Database. Natural Hazards, v. 74, n.3, p. 1649-1666, 2014. 


\section{INFLUÊNCIA DO USO DE ADITIVO REDUTOR DE ÁGUA NO COMPORTAMENTO DE ARGAMASSAS COM AGREGADO MIÚDO RECICLADO CERÂMICO}

\section{Gilberto Alves da Silva Neto}

Universidade Federal de Minas Gerais, Departamento de Engenharia de Materiais e Construção, Belo Horizonte, MG

http://lattes.cnpq.br/3217090207726291

\section{Juliano de Freitas Dutra}

Universidade Federal de Minas Gerais, Departamento de Engenharia de Materiais e Construção, Belo Horizonte, MG

http://lattes.cnpq.br/7464843657319971

\section{White José dos Santos}

Universidade Federal de Minas Gerais, Departamento de Engenharia de Materiais e Construção, Belo Horizonte, $\mathrm{MG}$

http://lattes.cnpq.br/6929801431620076

\section{Adriana Guerra Gumieri}

Universidade Federal de Minas Gerais, Departamento de Engenharia de Materiais e Construção, Belo Horizonte, MG

http://lattes.cnpq.br/8727172704273748

Informações sobre o
artigo:

Recebido em:

$17 / 08 / 2020$

Aceito em:

20/08/2020

Data de publicação:

$23 / 10 / 2020$

Palavras-chave:

Aditivo redutor de água

Argamassa

Agregado miúdo

reciclado

Resíduo cerâmico

\section{RESUMO}

A indústria da construção civil é responsável pela grande extração de recursos naturais não-renováveis e pela geração de um número significativo de resíduos, cuja destinação final causa grandes preocupações, impulsionando constantes pesquisas quanto ao seu reaproveitamento em diversas áreas. O setor ceramista é um dos setores que descartam grandes quantidades de resíduos, tanto na fabricação de produtos cerâmicos em si, quanto na execução de obras. Estes podem ser incorporados como insumo no processo de fabricação de novos compósitos cimentícios, substituindo na maioria das vezes à areia. No entanto, a elevada porosidade desses agregados reciclados (AR) ainda é um problema que tem trazido efeitos negativos no desempenho mecânico e na durabilidade do produto final. Alguns estudos, portanto, já vêm obtendo bons resultados ao utilizar aditivos redutores de água em concretos e argamassas recicladas com AR de concreto. Portanto, o objetivo desse trabalho é analisar a influência do aditivo redutor de água no comportamento de argamassas recicladas com substituição parcial do agregado miúdo natural (AMN) pelo agregado miúdo reciclado (AMR, originado de resíduos de blocos cerâmicos de vedação e $\mathrm{d}_{\text {máx }}=4,8 \mathrm{~mm}$ ), ao manter-se constantes a relação a/c e a trabalhabilidade das misturas. As argamassas no estado endurecido foram submetidas aos ensaios: de resistência à compressão axial, que revelou uma melhora nessa propriedade com o uso do AMR, sobretudo quando se adotou o superplastificante na mistura; de absorção de água por capilaridade, que apresentou uma redução dessa propriedade ao se incorporar o AMR à mistura, tendo um 
comportamento semelhante com e sem aditivo; e de absorção por imersão, que não apresentou uma alteração expressiva na propriedade ao substituir 50\% do AMN pelo AMR, mas que sofreu um acréscimo ao utilizar o superplastificante, devendo ser melhor investigado por ser contraditório.

INFLUENCE OF USING WATER-REDUCING ADMIXTURE ON THE BEHAVIOR OF MORTARS WITH CERAMIC FINE RECYCLED AGGREGATE

\section{ABSTRACT}

The civil construction industry is responsible for the large extraction of non-renewable natural resources and the generation of a significant quantity of waste, whose the final destination has been causing great concern, promoting constant research on the reuse of this material in several areas. The ceramic sector is one of the sectors that discard large quantities of waste, both in the manufacture of ceramic products, and in the execution of constructions. Such waste can be incorporated as an input in the production of new cementitious composites, mostly replacing the sand. However, the high porosity of these recycled aggregates (RA) is still a problem that has brought about negative effects on the mechanical performance and durability of the final product. Some studies, therefore, have already been successful using waterreducing admixtures in recycled concrete and mortars with concrete RA. Therefore, the aim of this paper is to analyze the influence of the water-reducing admixture on the behavior of recycled mortars with partial replacement of the fine natural aggregate (FNA) by the fine recycled aggregate (FRA, originated from ceramic block waste and with $\mathrm{d}_{\max }=4.8 \mathrm{~mm}$ ), keeping constant the water/cement ratio and the workability of the mixtures. The mortars in the hardened state were submitted to the following tests: compressive strength, which showed an improvement in this property with the use of FRA, especially when the superplasticizer was used in the mixture; capillary water absorption, which presented a reduction of this property when incorporating the FRA to the mixture, having a similar behavior with and without admixture; and absorption by immersion, which did not show an expressive change in this property, when replacing $50 \%$ of the FNA by the FRA, but which was increased when using the superplasticizer, which should be better investigated once it is contradictory. 


\section{INTRODUÇÃO}

A quantidade de resíduos de construção e demolição (RCD) gerados mundialmente e no Brasil aproxima-se de 3 bilhões e de 70 milhões de toneladas por ano, respectivamente, influenciado pelo índice de desenvolvimento humano (AKHTAR; SARMAH, 2018; CONTRERAS, 2016). O RCD tem uma composição bastante heterogênea, sendo um dos seus componentes principais o material cerâmico (cerca de 54\%), gerado pela própria indústria cerâmica, ou na execução de obras (JUAN et al., 2010).

Os resultados obtidos por alguns autores, referente à estas substituições, mostram que o aumento nos percentuais de agregado reciclado utilizados para produção de concretos, acarreta uma diminuição na densidade da mistura e um aumento na absorção de água (DEBIEB; KENAI, 2008; ETXEBERRIA; VEGAS, 2015). Esse aumento da absorção, pode ser explicado devido à alta porosidade do bloco que originou esse agregado (DEBIEB; KENAI, 2008) podendo afetar principalmente a durabilidade das matrizes cimentícias (CORREIA et al. 2006).

A alta capacidade de absorção de água pode reduzir a resistência à compressão dos compósitos cimentícios (DEBIEB; KENAI, 2008). Porém os resultados nos diversos estudos são bem variados e apontam que o aumento do teor de resíduo cerâmico, pode pouco alterar (GOMES; DE BRITO, 2009), gerar reduções de 10 a 45\% (DE BRITO, et al., 2005), ou até mesmo aumentar a resistência, em cerca de 11\% (MEDINA et al., 2013).

Uma alternativa, para melhorar os indicadores de durabilidade e resistência mecânica com a utilização desses agregados reciclados, que vem sendo estudada, é a utilização de aditivos redutores de água nas misturas. Pereira et al., 2012 e Barbudo et al., 2013, produziram concreto reciclado inserindo aditivos e encontraram um efeito positivo no comportamento desse material. Vale destacar que as ações dos aditivos plastificantes não se resumem a melhorar a trabalhabilidade das misturas, eles ainda tendem à reduzir o volume de vazios em concretos, beneficiando assim o desempenho mecânico desse material. No entanto, nos estudos que avaliaram o efeito destes aditivos em concretos reciclados, utilizouse agregados reciclados de resíduos de concretos, sendo necessário avaliar diferentes resíduos, como o cerâmico.

Assim, o presente trabalho busca avaliar o efeito da utilização de um aditivo superplastificante, juntamente com a adição de agregado miúdo reciclado cerâmico em argamassas, visando melhorar alguns indicadores de durabilidade desse material, seu 
comportamento mecânico, e ao mesmo tempo, buscar uma alternativa para uma destinação adequada desse resíduo.

\section{METODOLOGIA}

O cimento utilizado para a produção das argamassas foi o CP V-ARI, de massa específica $3,07 \mathrm{~g} / \mathrm{cm}^{3}$, com baixo teor de adições, garantindo uma melhor análise da influência do resíduo cerâmico na matriz cimentícea.

Adotou-se como agregado miúdo natural (AMN) a areia lavada fina peneirada de dimensão máxima característica (DMC) de 4,8 mm, originada em Esmeralda e Inhaúma (Minas Gerais). Como agregado miúdo reciclado (AMR), foi utilizado resíduo oriundo de blocos cerâmicos, também com DMC de 4,8 mm. Como a heterogeneidade e presença de contaminantes nesses resíduos são as principais dificuldades encontradas para realização de sua reciclagem (SILVA et al., 2009), podendo interferir nas propriedades físicas e mecânicas do agregado produzido, optou-se nesse estudo por se produzir o AMR partindo de blocos cerâmicos novos de mesmo lote, obtendo um maior controle do resíduo utilizado.

O processo de cominuição consistiu inicialmente numa etapa manual, na qual os blocos cerâmicos de vedação de dimensões 14x19x29 cm e 5,55 Kg foram quebrados com auxílio de uma marreta para geração do resíduo, que posteriormente passou pelo britador de mandíbula e foi peneirado na peneira de abertura de $4,8 \mathrm{~mm}$, repetindo todo esse procedimento para as frações retidas nesta peneira $\left(1^{\circ} \mathrm{Ciclo}\right)$. Em seguida as partículas de resíduo que se manteve com dimensões maiores que 4,8 $\mathrm{mm}$, passaram pelo moinho de rolos, seguindo o mesmo procedimento utilizado no $1^{\circ}$ Ciclo. A Tabela 1 apresenta as propriedades dos agregados miúdos, utilizados para a produção das argamassas.

Tabela 1 - Propriedades físicas dos agregados miúdos utilizados

\begin{tabular}{|c|c|c|c|}
\hline \multicolumn{2}{|l|}{ Propriedade Avaliada } & \multirow{2}{*}{$\begin{array}{l}\text { AMN } \\
4,8\end{array}$} & \multirow{2}{*}{$\begin{array}{l}\text { AMR } \\
4,8\end{array}$} \\
\hline Dimensão máxima caracterí & & & \\
\hline Módulo de finura a & & 2,14 & 3,30 \\
\hline \multirow{3}{*}{ Massa específica $\left(\mathrm{g} / \mathrm{cm}^{3}\right)^{b}$} & Seca & 2,57 & 1,91 \\
\hline & Saturada superfície seca & 2,69 & 2,27 \\
\hline & Real & 2,91 & 2,98 \\
\hline Massa unitária $\left(\mathrm{kg} / \mathrm{m}^{3}\right)^{\mathrm{c}}$ & & 1200 & 930 \\
\hline Material pulverulento $(\%) \mathrm{d}$ & & 7,4 & 12,0 \\
\hline Absorção de água (\%) ${ }^{\mathrm{e}}$ & & 4,4 & 16,0 \\
\hline
\end{tabular}

Fonte: a ABNT, 2003a; b ABNT, 2009a; c ABNT, 2006; d ABNT, 2003b; e ABNT, 2001 
Como se observa, tanto a massa unitária quanto a massa específica seca do AMR são menores $(22,50 \%$ e $25,68 \%$, respectivamente) do que as do $A M N$, dada a maior porosidade do resíduo cerâmico, como pode ser observado ao comparar Figura 1 (b) e (d).

No entanto, as massas específicas reais dos dois materiais deram equivalentes com uma diferença de 2,4\%. Portanto, devido a essa equivalência, optou-se por não fazer a correção da massa de material utilizada na produção das argamassas, inserindo a mesma quantidade de AMR e AMN nas misturas. Foi observada uma expressiva capacidade de absorção de água do AMR de 16\%, quase 4 vezes maior que a do $\mathrm{AMN}$ (4,4\%), o que influencia na redução da relação a/c efetiva e consequentemente, na trabalhabilidade da mistura. Tanto as massas específicas (seca, saturada superfície seca e real), quanto a absorção de água dos AMR foram semelhantes ao encontrado por outro estudo (ETXEBERRIA; VEGAS, 2015), que trabalharam com o mesmo resíduo e com DMC de $5 \mathrm{~mm}$, próximo à utilizada neste presente artigo $(4,8 \mathrm{~mm})$. Percebe-se grande variabilidade entre os materiais estudados. Logo, é importante avaliar estes parâmetros em relação ao comportamento das argamassas no estado fresco e endurecido.

A Figura 2 apresenta as curvas granulométricas dos agregados miúdos utilizados nessa pesquisa, bem como as curvas dos limites determinados pela NBR 7211 (ABNT, 2009a). Pode-se observar que a curva granulométrica do AMN encontra-se mais próxima da zona utilizável superior, enquanto a curva do AMR se encontra mais próxima da zona utilizável inferior. Além disso, verifica-se que as curvas desses dois agregados são bem distintas, porém ambas podem ser classificadas como contínuas (bem distribuídas). Através das curvas granulométricas observou-se também que a combinação desses dois agregados, gerou uma curva que caracteriza uma granulometria melhor distribuída, se comparada ao AMN e AMR individualmente, com módulo de finura igual a 2,72, o que a enquadra na zona ótima (módulo de finura entre 2,20 e 2,90 (ABNT, 2009a)).

A relação a/c foi fixada em 0,8 garantindo a argamassa de referência um índice de consistência de $240 \mathrm{~mm}$, atendendo ao limite de $250 \pm 15 \mathrm{~mm}$ previamente estabelecido por ser adequado para a produção desse material. Além disso, com o intuito de se corrigir a trabalhabilidade da argamassa com AMR e devido à maior demanda de água desta, dada à alta capacidade de absorção de água do resíduo cerâmico e teor de finos, adotou-se um aditivo superplastificante a base de policarboxilados, no teor de $2,0 \%$ em relação à massa de cimento. 
Figura 1 - Imagem de microscopia digital dos agregados adotados: visão geral das diferentes frações granulométricas do (a) AMN (b) AMR; grãos de dimensão 4,8 mm do (c) AMN (d) AMR

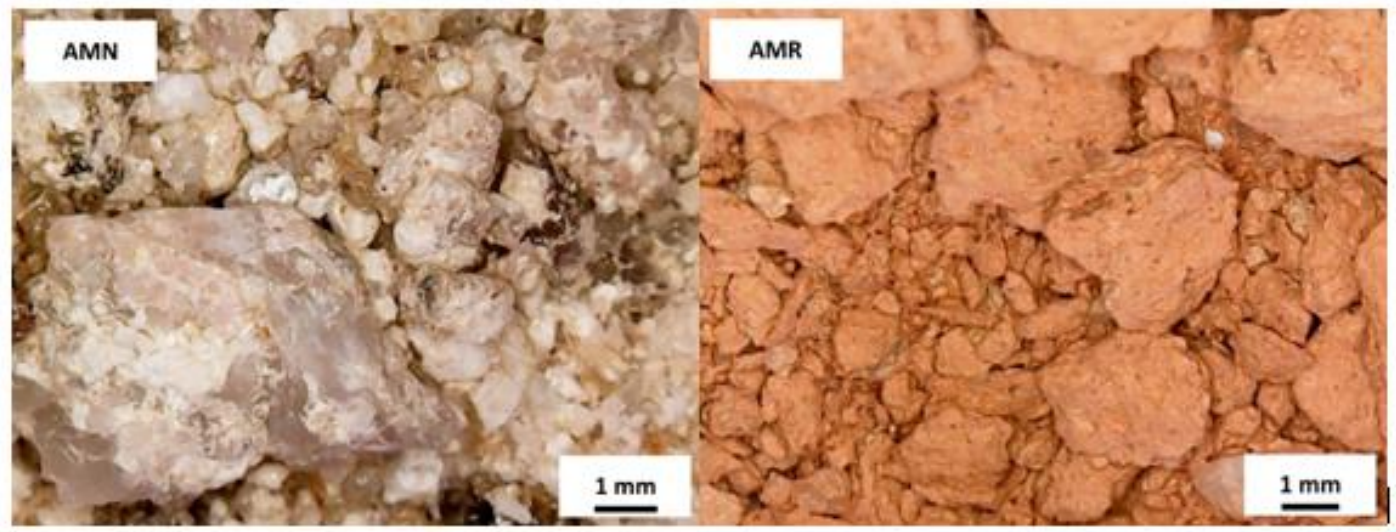

(a)

(b)

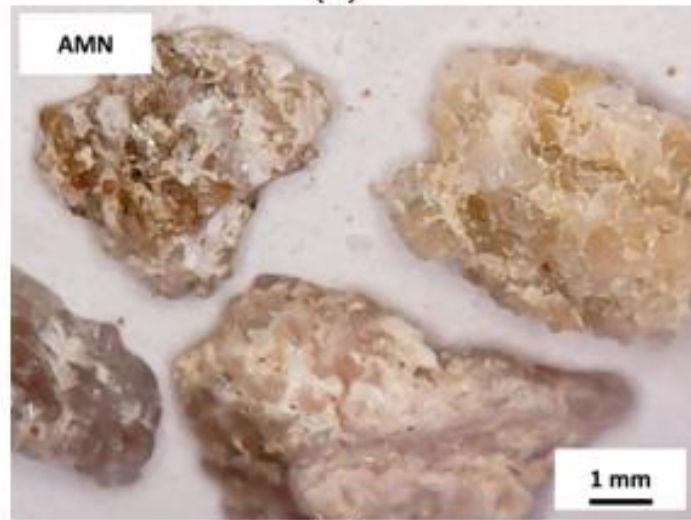

(c)

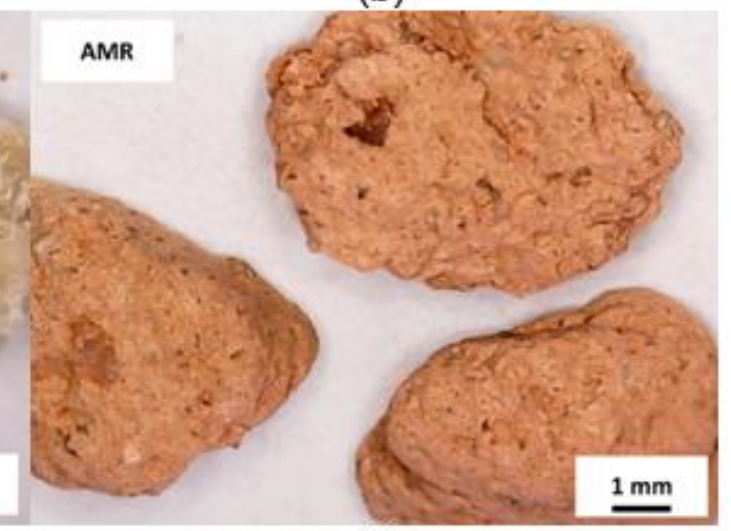

(d)

Figura 2 - Curva granulométrica dos agregados miúdos e as curvas limites na NBR 7211:2009

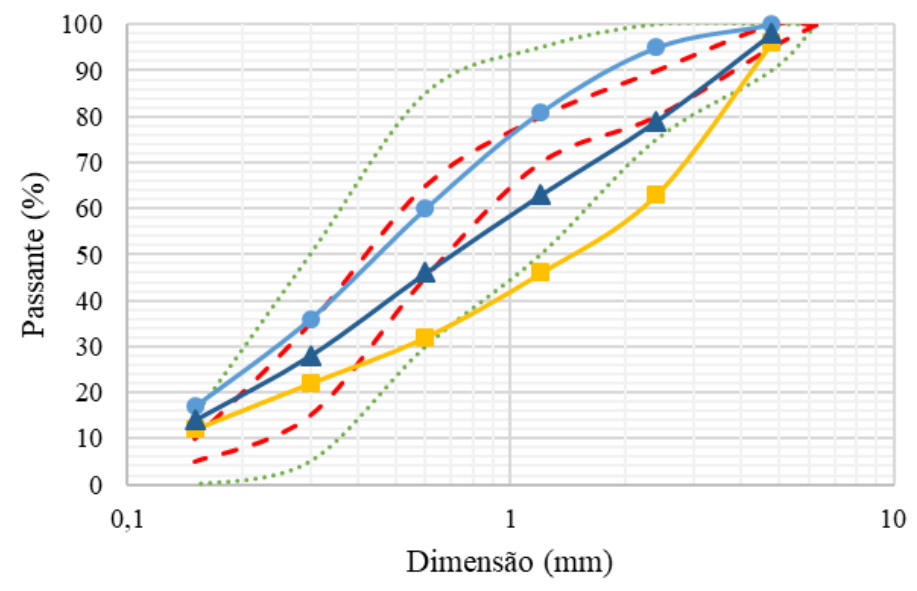

…..... Zona Utilizável (Sup.)

........ Zona Utilizável (Inf.)

- - - Zona Ótima (Sup.)

- - - Zona Ótima (Inf.)

$\longrightarrow \mathrm{AMN}$

$-\mathrm{AMR}$

$\longrightarrow$ Composição (AMN + AMR)

Para o conhecimento do comportamento das argamassas produzidas realizou-se inicialmente a determinação do índice de consistência (ABNT, 2016) dos três traços estabelecidos (Tabela 2): argamassas de referência (REF), argamassa com resíduo cerâmico e sem aditivo (RSA) e argamassa com resíduo cerâmico e com aditivo (RCA). Feito isso, 
preparou-se as argamassas por meio do método de mistura da NBR 7215 (ABNT, 1991) e moldou-se 4 CPs para determinação da absorção de água por capilaridade (ABNT, 20120), absorção de água por imersão, massa específica e índice de vazios (ABNT, 2009b), e outros 4 CPs para a determinação da resistência à compressão axial (ABNT, 2018), todos de dimensões 5 x $10 \mathrm{~cm}$. Os corpos de prova foram mantidos em câmara úmida imergidos em água com cal até as idades de ensaio.

Tabela 2 - Detalhamento dos traços adotados

\begin{tabular}{llll}
\hline Mistura & Agregado Miúdo & Relação a/c & Aditivo \\
\hline REF & $100 \%$ AMN & 0,8 & - \\
\multirow{2}{*}{ RSA } & $50 \%$ AMN & 0,8 & - \\
& $50 \%$ AMR & & \\
RCA & $50 \%$ AMN & 0,8 & $2,0 \%$ \\
& $50 \%$ AMR & & \\
\hline
\end{tabular}

\section{RESULTADOS E DISCUSSÃO}

\subsection{Estado Fresco}

A Figura 3 apresenta os resultados obtidos na determinação do índice de consistência das três argamassas produzidas.

Figura 3 - Determinação do índice de consistência das argamassas produzidas (a) REF (b) RSA (c) RCA

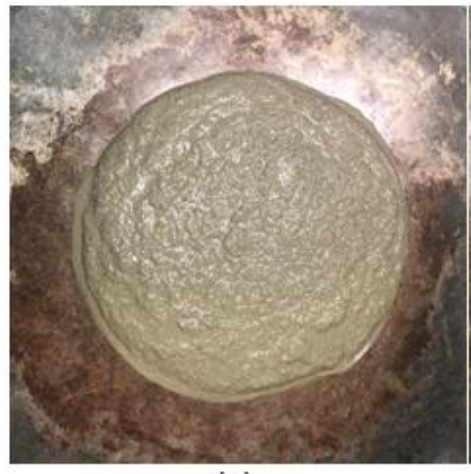

(a)

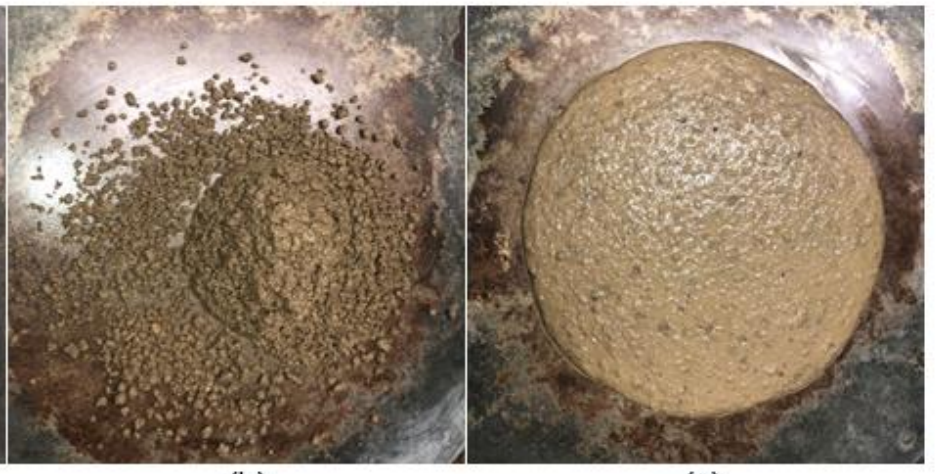

(b) (c) 
A partir do observado na Figura 3, a REF mostrou-se trabalhável, com índice de consistência de $240 \mathrm{~mm}$, e com exsudação pouco expressiva. Já a RSA, apresentou-se bastante seca, não sendo possível determinar seu índice de consistência, e tendo sua moldagem dificultada. E o índice de consistência da RCA, $260 \mathrm{~mm}$, enquadrou-se no limite pré-estabelecido, sendo maior que a REF.

A expressiva redução da trabalhabilidade, quando se substituiu $50 \%$ do AMN pelo AMR, está atrelada a elevada capacidade de absorção de água deste último (16,0\%), que reduziu consideravelmente a relação a/c efetiva da mistura (KHATIB, 2005; SILVA NETO; LEITE, 2018), deixando-a seca e de difícil manuseio; além do seu elevado teor de material pulverulento (1,6 vezes maior que o do $\mathrm{AMN}$ ), aumentando a demanda de água de amassamento.

\subsection{Absorção de Água por Capilaridade}

$\mathrm{Na}$ Figura 4 constam as curvas da absorção de água por capilaridade em função do tempo, das três argamassas produzidas e ensaiadas aos 18 dias.

Figura 4 - Curva da absorção de água por capilaridade versus tempo

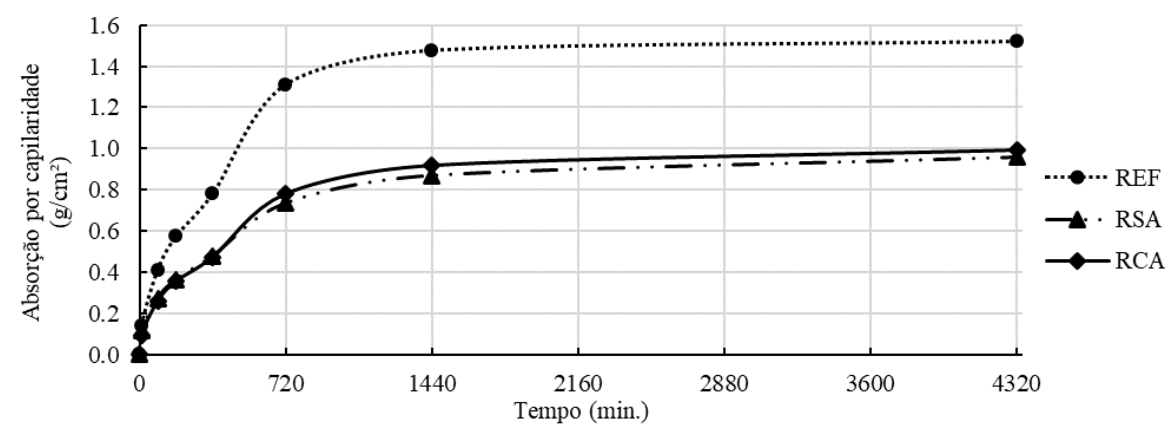

Foi possível observar que as argamassas com resíduo cerâmico, RSA e RCA, apresentaram um comportamento bastante semelhante, com suas curvas quase sobrepostas. Ambas apresentaram uma menor capacidade de absorção de água por capilaridade, quando comparadas à REF. Tal comportamento pode ser explicado pelo alto teor de material pulverulento do agregado miúdo reciclado cerâmico (12,0\%), bem como pela granulometria mais contínua da composição com o agregado miúdo natural (50\% AMN + 50\% AMR) que beneficiam o empacotamento da mistura (SILVA NETO; LEITE, 2018) e assim a redução dos valores desta propriedade. O material fino presente no AMR cerâmico tem a capacidade de preencher os poros, impedindo assim que os mesmos se interconectem, e 
consequentemente, reduzindo a absorção de água por capilaridade das argamassas recicladas. Esse comportamento foi diferente ao observado em demais estudos que utilizaram esse resíduo (DEBIEB; KENAI, 2008; ETXEBERRIA; VEGAS, 2015; CORREIA et al., 2006). No entanto, Debieb e Kenai (2008) constataram que a utilização de aditivos plastificantes tem efeito benéfico em concretos reciclados, uma vez que se reduz a capacidade de absorção de água dos mesmos.

\subsection{Absorção de Água por Imersão, Massa Específica e Porosidade}

A Tabela 3, apresenta os resultados médios dessas propriedades com os desvios padrões e coeficientes de variação. A Figura 5 apresenta os resultados das referidas propriedades das argamassas ensaiadas na idade de 24 dias.

Tabela 3 - Resultados médios da absorção de água por imersão, índice de vazios e massa específica real

\begin{tabular}{lccc}
\hline Propriedades & \multicolumn{3}{c}{ Misturas } \\
\cline { 2 - 4 } & REF & RSA & RCA \\
\hline $\begin{array}{l}\text { Absorção por Imersão (\%) } \\
\mathrm{A} \pm \mathrm{SD}(\mathrm{CV})\end{array}$ & $13,54 \pm 0,49(3,6)$ & $14,19 \pm 1,08(7,6)$ & $15,62 \pm 1,67(10,7)$ \\
\hline $\begin{array}{l}\text { Porosidade }(\%) \\
\mathrm{P} \pm \mathrm{SD}(\mathrm{CV})\end{array}$ & $25,0 \pm 0,68(2,7)$ & $26,2 \pm 1,52(5,8)$ & $27,9 \pm 2,57(9,2)$ \\
\hline $\begin{array}{l}\text { Massa Específica Real }\left(\mathrm{g} / \mathrm{cm}^{3}\right) \\
\varrho \pm \mathrm{SD}(\mathrm{CV})\end{array}$ & $2,47 \pm 0,00(0,1)$ & $2,51 \pm 0,01(0,5)$ & $2,48 \pm 0,01(0,2)$ \\
\hline
\end{tabular}

SD - Desvio Padrão; CV - Coeficiente de Variação

Constata-se pela Figura 5 e Tabela 3 que a presença de 50\% de resíduo em substituição ao agregado miúdo não promoveu um aumento expressivo na absorção de água por imersão e nem na porosidade aberta (comparando REF com RSA). Este resultado se justifica pelo maior empacotamento das partículas (Figura 2) na mistura, o que promoveu após adensamento, um compósito mais denso e com tendências de um material durável. 
Figura 5 - Resultados referentes à absorção de água e porosidade das misturas

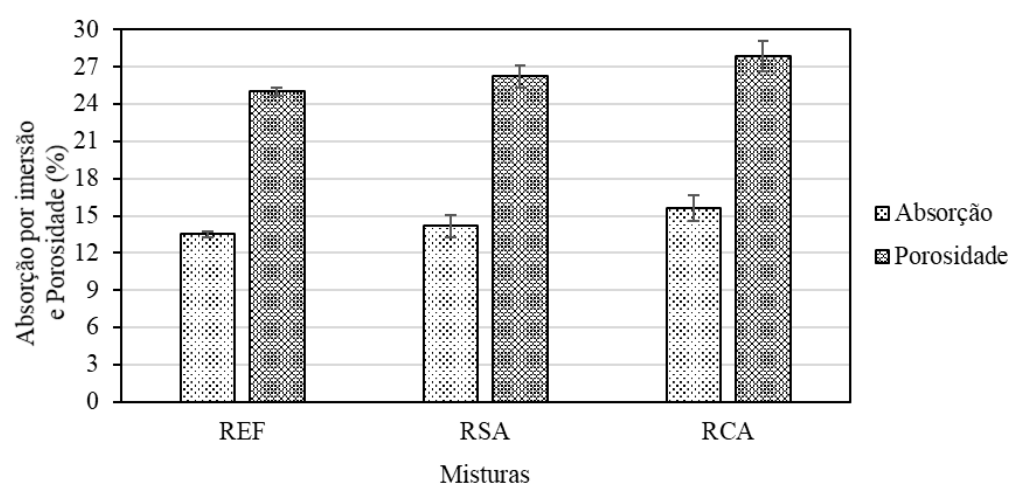

Comparando as RSA e RCA, nota-se um aumento da porosidade (6\%) e, da absorção de água por imersão (10\%), contradizendo o observado por Barbudo et al. (2013) onde os autores afirmam uma tendência do aditivo superplastificante aumentar a compacidade da mistura ao reduzir os poros da mesma. Portanto, tal comportamento contraditório deve ser melhor estudado, para um melhor entendimento das possíveis causas influenciadoras. Em relação à massa específica das argamassas no estado endurecido, não houve variação significativa dessa propriedade nas três misturas, estando esta variando entre 2,47 e $2,51 \mathrm{~g} / \mathrm{cm}^{3}$. Demonstrando que apesar do material ser mais leve (massa especifica seca e maior porosidade) a melhor estruturação das partículas impediu a redução desta propriedade.

\subsection{Resistência à Compressão}

A Tabela 4 apresenta os resultados médios da resistência à compressão das argamassas produzidas, juntamente com o desvio padrão e coeficiente de variação. A Figura 6 apresenta a resistência à compressão relativa comparando as RSA e RCA, com a REF, ensaiadas na idade de 20 dias.

Com os resultados obtidos, observou-se que com a substituição do AMN pelo AMR no teor de 50\% houve um ganho de $31 \%$ na resistência à compressão das argamassas, aumentando de $24,81 \mathrm{MPa}(\mathrm{REF})$ para $32,42 \mathrm{MPa}$ (RSA), o aumento pode ser explicado pela redução da relação a/c efetiva da mistura, dada à elevada capacidade de absorção de água do AMR (SILVA NETO; LEITE, 2018) o que foi visivelmente constatado pela perda total de trabalhabilidade da mistura. 
Tabela 4 - Resultados médios da resistência à compressão

\begin{tabular}{lccc}
\hline \multirow{2}{*}{ Propriedades } & \multicolumn{3}{c}{ Misturas } \\
\cline { 2 - 4 } & REF & RSA & RCA \\
\hline Compressão Axial (MPa) & $24,81 \pm 2,32(9,4)$ & $32,42 \pm 0,25(0,8)$ & $40,33 \pm 1,40(3,4)$ \\
$\sigma \pm$ SD $(\mathrm{CV})$ & & & \\
\hline
\end{tabular}

SD - Desvio Padrão; CV - Coeficiente de Variação

Figura 6 - Resistência à compressão relativa

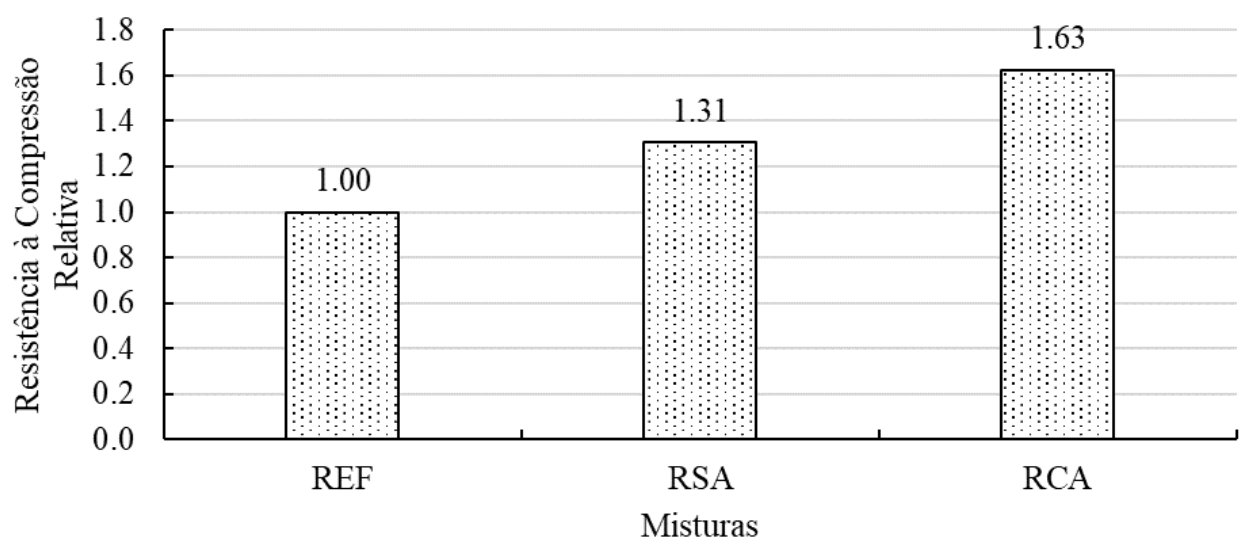

Tal resultado positivo para as argamassas produzidas não foram condizentes com o obtido em demais estudos que trabalharam com o AMR cerâmico (DE BRITO et al., 2005; CORREIA et al., 2006; DEBIEB; KENAI, 2008). Já nas argamassas recicladas, com a adição do aditivo superplastificante, a resistência aumentou ainda mais, chegando à 40,33 MPa que corresponde à um aumento de 63\% em relação à argamassa de referência (REF) e $24 \%$ em relação a argamassa reciclada sem aditivo (RSA). Esse aumento poderia ser explicado pela ação do aditivo utilizado, que além da melhoria na trabalhabilidade, o superplastificante tende a reduzir os poros da mistura, proporcionando assim uma melhoria no comportamento mecânico do material (BARBUDO et al., 2013). Porém, não se constatou essa redução dos poros na mistura e sim um aumento, comparando as argamassas recicladas com a de referência (item 3.3). No entanto, tais poros não se mostraram conectados, o que daria origem à capilares, confirmado pela redução da absorção de água por capilaridade das argamassas recicladas (item 3.2), o que é benéfico, portanto, para o desempenho mecânico das argamassas. 


\section{CONCLUSÃO}

A partir dos resultados obtidos frente à substituição parcial da areia natural por resíduo cerâmico de granulometria semelhante, e à utililização de superplastificante nestas misturas, pode-se concluir que:

- Houve uma redução da relação a/c efetiva e da trabalhabilidade das misturas, quando substituiu 50\% do AMN pelo AMR, devida a alta capacidade de absorção de água do AMR em relação ao AMN;

- Os resultados obtidos com o teor de substituição de 50\%, foram positivos devido ao melhor empacotamento promovido pela combinação granulométrica do AMN com o AMR;

- As misturas RSA e RCA, apresentaram uma menor capacidade de absorção de água por capilaridade, ao compará-las com a REF, destacando a influência do elevado teor de finos do AMR e da combinação granulométrica do AMN e AMR, na melhoria do empacotamento das misturas;

- Observou-se um aumento de $6 \%$ da porosidade, e consequentemente, um aumento de $10 \%$ da absorção de água por imersão, quando se comparou as misturas RSA e RCA. O que deve ser melhor investigado, uma vez que autores afirmam uma tendência do aditivo superplastificante aumentar a compacidade da mistura ao reduzir os poros da mesma. Acredita-se que o processo de adensamento (apiloamento do soquete) pode ter incluído ar e este virado poros posteriormente. Indica-se alterar o processo de adensamento de argamassas plásticas para vibração mecânica ou similar ao realizado no processo de argamassa de revestimento;

- Com a substituição do AMN pelo AMR, observou-se um aumento de 31\% e 63\%, respectivamente, na resistência à compressão, quando se comparou RSC e RCA com a mistura REF.

Os resultados apresentados apontam indícios da possibilidade da utilização do superplastificante juntamente com a substituição do agregado miúdo natural pelo agregado miúdo reciclado cerâmico, para a produção de argamassas para fins estruturais. Porém, mais estudos são necessários para entender melhor o comportamento das argamassas produzidas com esta combinação. É necessária uma maior atenção em como o superplastificante pode afetar a durabilidade das argamassas produzidas com AMR. 


\section{REFERÊNCIAS}

AKHTAR, A; SARMAH, A. K. Construction and demolition waste generation and properties of recycled aggregate concrete: A global perspective. Journal of Cleaner Production, v. 186, p. 262-281, 2018.

ASSOCIAÇÃO BRASILEIRA DE NORMAS TÉCNICAS. NBR 13276: argamassa para assentamento e revestimento de paredes e tetos - Preparo da mistura e determinação do índice de consistência. Rio de Janeiro, 2016.

NBR 5739: concreto - ensaio de compressão de corpos de prova cilíndricos. Rio de Janeiro, 2018.

NBR 7211: agregados para concreto - Especificação. Rio de Janeiro, 2009a.

NBR 7215: cimento Portland - Determinação da resistência à compressão. Rio de Janeiro, 1991.

NBR 9778: argamassa e concreto endurecidos - Determinação da absorção de água, índice de vazios e massa específica. Rio de Janeiro, 2009b.

NBR 9779: argamassa e concreto endurecidos - Determinação da absorção de água por capilaridade. Rio de Janeiro, 2012.

NBR NM 248: agregados - Determinação da composição granulométrica. Rio de Janeiro, 2003a.

NBR NM 45: agregados - Determinação da massa unitária e do volume de vazios. Rio de Janeiro, 2006.

NBR NM 46: agregados - Determinação do material fino que passa através da peneira $75 \mu \mathrm{m}$, por lavagem. Rio de Janeiro, 2003b.

NBR NM 52: agregado miúdo - Determinação de massa específica e massa específica aparente, Rio de Janeiro, 2009c.

2001.

NBR NM 52: agregado miúdo - Determinação da absorção de água. Rio de Janeiro,

BARBUDO, A. et al. Influence of water-reducing admixtures on the mechanical performance of recycled concrete. Journal of Cleaner Production, v. 59, p. 93-98, 2013.

CONTRERAS, M. et al. Recycling of construction and demolition waste for producing new construction material (Brazil case-study). Construction and Building Materials, v. 123, p. 594-600, 2016.

CORREIA, J. R.; DE BRITO, J; PEREIRA, A. S. Effects on concrete durability of using recycled ceramic aggregates. Materials and Structures, v. 39, p. 151-158, 2006. 
DE BRITO, J.; PEREIRA, A. S.; CORREIA, J. R. Mechanical behaviour of non-structural concrete made with recycled ceramic aggregates. Cement \& Concrete Composites, v. 27, p. $429-433,2005$.

DEBIEB, F.; KENAI, S. The use of coarse and fine crushed bricks as aggregate in concrete. Construction and Building Materials, v. 22, p. 886-893, 2008.

ETXEBERRIA, M.; VEGAS, I. Effect of fine ceramic recycled aggregate (RA) and mixed fine RA on hardened properties of concrete. Magazine of Concrete Research, v. 67, n. 12, p. 645-655, 2015.

GOMES, M; DE BRITO, J. Structural concrete with incorporation of coarse recycled concrete and ceramic aggregates: Durability performance. Materials and Structures, v. 42, n. 5, p. 663-675, 2009.

JUAN, A., et al. Re-Use of Ceramic Wastes in Construction In: WUNDERLICH, W., Ceramic Materials. Rijeka, Croatia: InTech, 2010. p. 197-214.

KHATIB, J. M. Properties of concrete incorporating fine recycled aggregate. Cement \& Concrete Composites, v. 35, p. 763-769, 2005.

MEDINA, C; SÁNCHEZ DE ROJAS, M. I; FRÍAS, M. Properties of recycled ceramic aggregate concretes: Water resistance. Cement and Concrete Composites, v. 40, p. 21-29, 2013.

PEREIRA, P.; EVANGELISTA, L.; DE BRITO, J. The effect of superplasticisers on the workability and compressive strength of concrete made with fine recycled concrete aggregates. Construction and Building Materials, v. 28, n. 1, p. 722-729, 2012.

SILVA NETO, G. A., LEITE, M. B., Study of the influence of the mortar fine recycled aggregate ratio and the mixing sequence on the behavior of new mortars. Ambiente Construído, v.18, n.2, p. 53-69, 2018.

SILVA, J; BRITO, J; VEIGA, R. Incorporation of fine ceramics in mortars, Construction and Building Materials, v. 23, n. 1, p. 556-564, 2009. 


\section{Capítulo 3}

\section{EFEITOS DE ALTAS TEMPERATURAS NO CONCRETO: REVISÃO BIBLIOGRÁFICA}

Max Taylo Araújo Lima

Centro Universitário Maurício de Nassau, Recife, PE http://lattes.cnpq.br/9378711524464308

\section{Arthur Vinicius Matias Barreto}

Centro Universitário Maurício de Nassau, Recife, PE http://lattes.cnpq.br/8362679832504791

\section{José Wellyngton Nunes Floro}

Centro Universitário Maurício de Nassau, Recife, PE http://lattes.cnpq.br/7867060015915634

\section{Amanda Agripina Costa Ramos Dias}

Centro Universitário Maurício de Nassau, Recife, PE http://lattes.cnpq.br/2787130900386655

\section{Ana Helena Souza de Barros Correia}

Centro Universitário Maurício de Nassau, Recife, PE http://lattes.cnpq.br/8073899951739327

\section{Ricardo Alexandre da Silva Lopes}

Centro Universitário Maurício de Nassau, Recife, PE http://lattes.cnpq.br/6777431988006550

\section{Caio Vinicius Ribeiro Cavalcanti}

Centro Universitário Maurício de Nassau, Recife, PE http://lattes.cnpq.br/2356128876702825

\section{Gisele Paiva Cavalcanti}

Centro Universitário Maurício de Nassau, Recife, PE http://lattes.cnpq.br/1308294552828809

\section{Yuri Brainner Silva Morais}

Universidade Católica de Pernambuco, Recife, PE http://lattes.cnpq.br/5849961441578113

\section{José Allef Ferreira Dantas}

Centro Universitário Maurício de Nassau, Recife, PE http://lattes.cnpq.br/4753211933090768

\section{Marina Corral de Abreu}

Centro Universitário Maurício de Nassau, Recife, PE http://lattes.cnpq.br/2050777338486002

\section{Raimundo Rômulo Martins Junior}

Centro Universitário Maurício de Nassau, Recife, PE http://lattes.cnpq.br/1199880523026219 
Informações sobre o

artigo:

Recebido em:

$17 / 08 / 2020$

Aceito em:

$20 / 08 / 2020$

Data de publicação:

$23 / 10 / 2020$

Palavras-chave:

\section{Concreto}

Altas temperaturas

Propriedades

\section{RESUMO}

O concreto é o material mais utilizado para construções no Brasil, que, em condições normais de trabalho ou em acidentes, pode ser submetido a altas temperaturas. Nessas circunstâncias, seu desempenho está relacionado às características térmicas dos seus materiais constituintes. O objetivo deste trabalho é identificar os efeitos da exposição a altas temperaturas na estrutura, nos componentes e nas propriedades do concreto. A metodologia definida para este estudo foi uma revisão bibliográfica exploratória de caráter descritivo, por meio de artigos originais, relatos de caso, revisões bibliográficas e capítulos de livros, publicados entre 2010 e 2020 na língua inglesa e portuguesa, pesquisados nas bases de dados Scielo (Scientific Eletronic Library Online) e ScienceDirect. Os efeitos de altas temperaturas no concreto podem ser analisados através da macroestrutura, pois o aspecto visual é o fator mais acessível, visto que a mudança de coloração inicia conforme a exposição e elevação da temperatura. $\mathrm{Na}$ microestrutura, as principais reações ocorrem nas fases da pasta de cimento hidratada, quando toda a água evaporável é removida, o que ocorre entre 200 ${ }^{\circ} \mathrm{C}$ e $300{ }^{\circ} \mathrm{C}$. Neste momento, intensifica-se a desidratação do gel do C-S-H que afetam as ligações com a pasta de cimento e a deixam mais suscetível à fissuração. Os agregados se comportam de forma distinta diante do aumento de temperatura de acordo com sua composição mineralógica. $\mathrm{Na}$ zona de transição ocorre um processo de retração da pasta de cimento e de expansão dos agregados. As propriedades mecânicas do concreto exposto a altas temperaturas são decorrentes das reações físico-químicas derivadas do fluxo e distribuição do calor. Outras alterações nas propriedades estão relacionadas ao gel de C-S-H e do C2S, que fazem a resistência variar de acordo com parâmetros relacionados aos constituístes do concreto, como o consumo de cimento, o tipo de agregado e o teor de umidade.

\section{EFFECTS OF HIGH TEMPERATURES ON CONCRETE BIBLIOGRAPHIC REVIEW}

\section{ABSTRACT}

Concrete is the most used material for construction in Brazil, which, under normal working conditions or in accidents, can be subjected to high temperatures. In these circumstances, its performance is related to the thermal characteristics of its constituent materials. The objective of this work is to identify the effects of exposure to high temperatures on the structure, components and properties of concrete. The methodology defined for this study was an exploratory bibliographic review of a descriptive character, through original articles, case reports, bibliographic reviews and book chapters, published between 2010 and 2020 in English and Portuguese, searched in Scielo databases ( Scientific Eletronic Library Online) and ScienceDirect. The effects of high temperatures on the concrete can be analyzed through the macrostructure, since the visual aspect is the most 
Keywords:

\section{Concrete}

High temperatures

Properties accessible factor, since the color change starts as the exposure and temperature rise. In the microstructure, the main reactions occur in the hydrated cement paste phases, when all the evaporable water is removed, which occurs between $200{ }^{\circ} \mathrm{C}$ and $300{ }^{\circ} \mathrm{C}$. At this moment, the dehydration of the $\mathrm{C}-\mathrm{S}-\mathrm{H}$ gel intensifies, affecting the bonds with the cement paste and making it more susceptible to cracking. The aggregates behave differently due to the temperature increase according to their mineralogical composition. In the transition zone there is a process of retraction of the cement paste and expansion of the aggregates. The mechanical properties of concrete exposed to high temperatures are due to the physicochemical reactions derived from the flow and distribution of heat. Other changes in properties are related to the C-S-H and $\mathrm{C} 2 \mathrm{~S}$ gel, which cause the resistance to vary according to parameters related to concrete constituents, such as cement consumption, type of aggregate and moisture content.

\section{INTRODUÇÃO}

O desenvolvimento humano, assim como as contínuas mudanças no seu cotidiano, requer cada vez mais materiais aprimorados e com elevados desempenhos para o suprimento dessas novas necessidades. O concreto, segundo Mehta e Monteiro (2014), é o material mais utilizado para construções no Brasil. Em decorrência da diversidade de aplicações, este material pode ser submetido a situações que afetam suas propriedades e estrutura de diferentes formas e com impactos variados, como é o caso da sua exposição a altas temperaturas.

O fogo foi a primeira energia natural utilizada de forma intencional pelo homem e ainda hoje é aplicado em larga escala na gênese de diferentes processos. Quando é tido de forma acidental, o fogo começa com a ignição em um material e continua até que a chama se espalhe por todas as superfícies combustíveis, atingindo a fase de inflamação generalizada no ambiente de origem, promove gradativamente, em função de sua severidade, a fragilização gradual dos elementos estruturais e assume, em condições críticas, a capacidade de promover o colapso estrutural da edificação. Esta capacidade se amplia na medida em que maiores porções da estrutura são afetadas por sua ação.

O concreto pode estar sujeito acidentalmente a altas temperaturas ou estas podem fazer parte de suas condições normais de trabalho (FERREIRA, 2011). O bom desempenho do concreto, quando submetido a temperaturas elevadas, está relacionado às características 
térmicas dos seus materiais constituintes, como a condutividade térmica, baixo coeficiente de dilatação e incombustibilidade.

Costa e Figueiredo (2002) citam que a elevação gradual da temperatura provoca alteração na coloração, perda da resistência mecânica e desagregação da estrutura, através da manifestação de fenômenos como esfarelamento da superfície, separação parcial de pequenas camadas superficiais do material (sloughing ou spalling) e fissuração.

Portanto, conhecer a composição e comportamento do concreto, assim como, de seus componentes, é imprescindível para identificar os efeitos que a exposição a altas temperaturas podem causar no desempenho das suas propriedades e no comprometimento da segurança das estruturas.

\section{ESTRUTURA DO CONCRETO EM ALTAS TEMPERATURAS}

\subsection{Macroestrutura do Concreto}

Sob o aspecto visual, considerando a macroestrutura, a elevação da temperatura ocasiona uma série de mudanças na coloração do concreto, especialmente se os agregados forem silicosos e calcários, devido a presença de componentes ferrosos nos mesmos (FERNANDES, et al., 2017).

Fernandes el at. (2017) adverte que as alterações calorimétricas são mais acentuadas para os agregados ricos em sílica do que nos calcários. Até $200^{\circ} \mathrm{C}$ a cor do concreto é cinza e não ocorrem reduções significativas da resistência, entre $300{ }^{\circ} \mathrm{C}$ e $600{ }^{\circ} \mathrm{C}$ a cor muda de rosa a vermelho, baixando a resistência à compressão até valores de $50 \%$ do seu original. Acima de $600{ }^{\circ} \mathrm{C}$ até $950^{\circ} \mathrm{C}$ a cor muda novamente para um segundo cinza com pontos avermelhados, dando indício de friabilidade e alta sucção da água, sendo a resistência à compressão muito pequena. De $950^{\circ} \mathrm{C}$ a $1000^{\circ} \mathrm{C}$ a cor muda para amarelo alaranjado e o concreto começa a sintetizar-se. Entre $1000^{\circ} \mathrm{C}$ e $1200^{\circ} \mathrm{C}$ o concreto sofre sinterização, sua cor se torna amarelo claro e suas resistências são totalmente anuladas, restando só um material calcinado e mole. A figura 1 relaciona a perda de resistência e a alteração da coloração em função do aumento da temperatura. 
Figura 1 - Alteração na coloração e na resistência do concreto

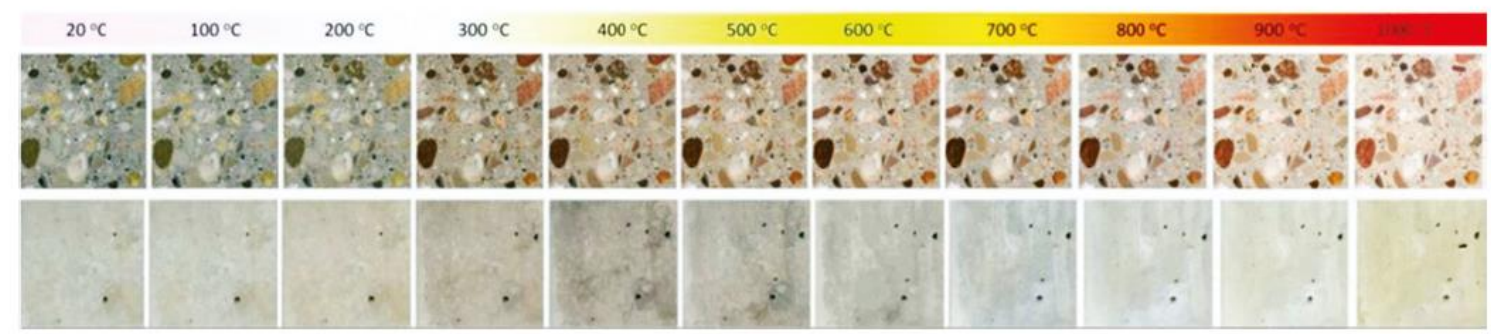

Fonte: FERNANDES et al. (2017)

O concreto quando submetido ao aquecimento apresenta diversas fissuras, sendo estas, devido as pressões internas e a desidratação dos silicatos de cálcio hidratados (C-S-H). Isso pode fazer com que fragmentos de concreto se desprendam. Este efeito é conhecido como explosive spalling, onde os agregados ricos em sílica, tais como os granitos, arenitos, gnaisses entre outros, quando superaquecidos, proporcionam manifestações patologias no concreto. (XIAO; XIE, Q; XIE, W, 2018; COELHO et al., 2020 e HOLAN et al., 2020).

\subsection{Microestrutura do Concreto}

De acordo com Mehta e Monteiro (2014), a pasta de cimento hidratado é composta por fases sólidas, sendo as principais: silicato de cálcio hidratado, conhecida como C-S-H, que corresponde de 50\% a 60\% do volume de sólidos; hidróxido de cálcio $(\mathrm{Ca}(\mathrm{OH}) 2)$, chamado de portlandita, que corresponde de $20 \%$ a $25 \%$ do volume de sólidos; sulfoaluminatos de cálcio, conhecido como etringita, encontrados de 15\% a 20\% no volume dos sólidos e grãos de clínquer não hidratados.

Em seu estado natural, o concreto possui em sua composição grande quantidade de água livre e água capilar, além de água adsorvida. Quando exposta ao fogo, a temperatura do concreto não se eleva até que toda a água evaporável tenha sido removida (MEHTA \& MONTEIRO, 2014). As águas livres e capilares presentes na pasta de cimento começam a evaporar após a temperatura de $100^{\circ} \mathrm{C}$, retardando o aquecimento do concreto. A evaporação total da água capilar ocorre entre $200^{\circ} \mathrm{C}$ e $300^{\circ} \mathrm{C}$, mas neste patamar ainda não são significativas as alterações na estrutura do cimento hidratado, bem como seu reflexo na resistência do concreto. O gel do C-S-H sofre um processo de desidratação durante o aquecimento, que inicia em $100^{\circ} \mathrm{C}$, se intensifica aos $300^{\circ} \mathrm{C}$ e termina próximo aos $400^{\circ} \mathrm{C}$. Neste período ocorre uma redução progressiva da água de gel, com formação de silicatos 
anidros. Isto resulta em um considerável decréscimo na resistência e causa o aparecimento de fissuras superficiais (FERNANDES el at., 2017).

A quantidade de portlandita decresce até $100^{\circ} \mathrm{C}$, devido à desidratação e à carbonatação, que se acelera em atmosferas ricas em dióxido de carbono $\left(\mathrm{CO}_{2}\right)$, como é o caso de muitos incêndios. $\mathrm{Na}$ temperatura de $530^{\circ} \mathrm{C}$, a portlandita rapidamente se decompõe e é transformada em óxido de cálcio $(\mathrm{CaO})$. Durante o processo de resfriamento, este óxido pode se reidratar, formando novamente a portlandita com um arranjo cristalino menos estável e que sofre processo de decomposição a temperaturas mais baixas que a original (SOUZA; AZERÊDO; SILVA, 2018; SOUZA, 2016).

Os agregados ocupam de $60 \%$ a $80 \%$ do volume do concreto e, portanto, a variação de suas propriedades durante o aquecimento pode influenciar significativamente as características do material. As rochas carbonáticas são estáveis até $700^{\circ} \mathrm{C}$, quando o $\mathrm{CaCO}_{3}$ começa a se transformar em $\mathrm{CaO}$ e liberar $\mathrm{CO}_{2}$. Durante o resfriamento, o $\mathrm{CaO}$ pode se reidratar, apresentando uma expansão de 40\%. Os agregados calcários e os leves são os menos afetados pelo calor, este desempenho favorável ocorre devido aos baixos coeficientes de dilatação térmica, às reações endotérmicas que se produzem ao elevar-se a temperatura e à criação de uma película superficial de $\mathrm{CO}_{2}$ que atua como isolante térmico (PAZDERA et al., 2017 e WRÓBLEWSKA; KOWALSKI, 2020).

\section{COMPONENTES DO CONCRETO EM ALTAS TEMPERATURAS}

\subsection{Aglomerante}

Segundo Mehta e Monteiro (2014), a utilização de cimento Portland para concretos submetidos a altas temperaturas é limitada a aproximadamente $500{ }^{\circ} \mathrm{C}$, visto que, quando submetido a temperaturas elevadas, o hidróxido de cálcio $(\mathrm{C}-\mathrm{H})$ se decompõe dando origem ao óxido de cálcio $(\mathrm{CaO})$ livre que leva a deterioração do concreto exposto à umidade ou água. Já o cimento Portland branco, apresenta baixo teor de álcalis solúveis e é produzido a partir da mistura de caulim, que contém baixos teores de óxido de ferro e manganês, com giz ou calcário livres de determinadas impurezas e custa cerca de 3 vezes o preço do cimento Portland comum. Além dele, é produzido o cimento branco especial de aluminato de cálcio que pode suportar temperaturas ainda mais elevadas, pois é produzido contendo entre $70 \%$ e $80 \%$ de óxido de alumínio (Al2O3), 20\% a 30\% de cálcio e apenas 1\% de ferro e sílica, 
porém, com custo bastante elevado (NEVILLE, 2016).

Oliveira (2019) aponta que para exposição a elevadas temperaturas, de forma a manter grande parte de suas características mecânicas e reológicas, é mas utilizado concretos que possuam cimento de aluminato de cálcio (CAC) porque sua alta pureza, impede a formação de fases indesejadas, como óxido de cálcio e hidróxido de cálcio $\left(\mathrm{Ca}(\mathrm{OH})_{2}\right)$, a temperaturas inferiores à $1000^{\circ} \mathrm{C}$.

\section{2 Água}

O principal agente para a hidratação do concreto na ligação hidráulica do aglomerante é a água, ela possui papel imprescindível nas propriedades do concreto fresco e endurecido, além de atuar na fluidez da pasta e continuidade dos constituintes, da matriz e demais componentes do concreto (FERNANDES, 2017).

A água pode existir de várias formas na pasta de cimento hidratada e, de acordo com o grau de facilidade com que ela pode ser removida, é classificada em água interlamelar que é retida pelas ligações de pontes de hidrogênio entre as camadas do C-S-H, água capilar que está presente nos maiores vazios e está livre da influência das forças de atração, água adsorvida que se encontra próximo à superfície sólida dos produtos de hidratação e a água quimicamente combinada que integra parte da microestrutura de vários produtos de hidratação do cimento, conforme figura 2 (MEHTA e MONTEIRO, 2014).

Figura 2 - Esquematização dos tipos de água na pasta de cimento hidratada

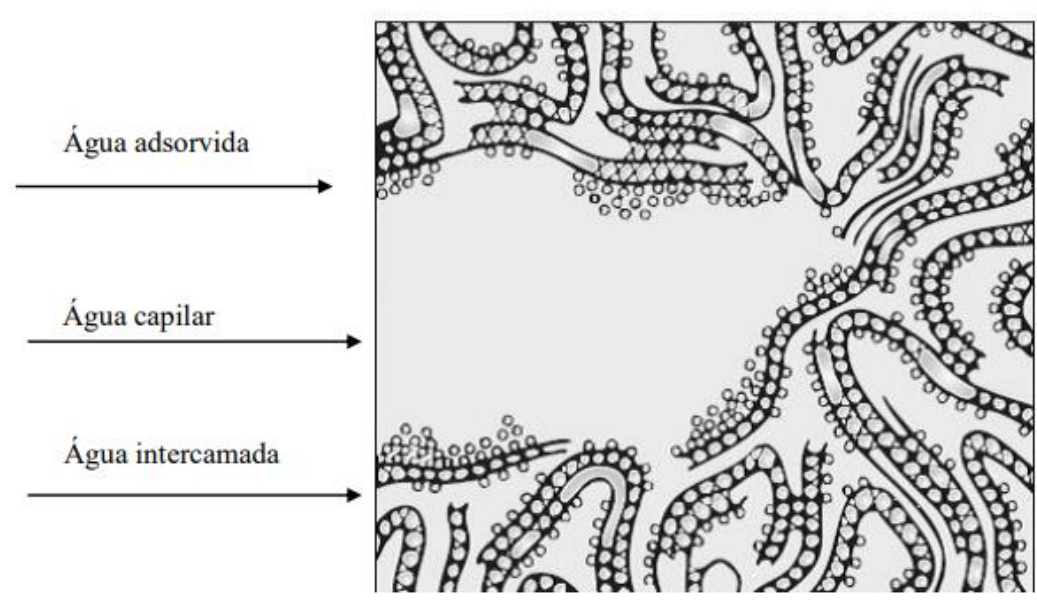

Fonte: MEHTA e MONTEIRO (2014) 


\subsection{Agregado}

O efeito da temperatura no agregado varia de acordo com a sua composição. Os agregados silicosos apresentam alta expansão térmica e favorecem o aumento da fissuração e consequentemente redução da resistência na interface térmica (SOUZA, 2016).

Segundo Neville (2016), a diferença na perda da resistência em concretos com agregados silicosos, calcários ou leves é desconsiderada quando submetidos a temperaturas acima de $800{ }^{\circ} \mathrm{C}$, como pode ser observado na figura 3 que apresenta o resultado de ensaio realizados em concretos de resistência inicial de $25 \mathrm{MPA}$ com tipos distintos de agregados ensaiados a quente e sem aplicação de carga.

Figura 3 - Redução da resistência à compressão em função do tipo de agregado adotado.

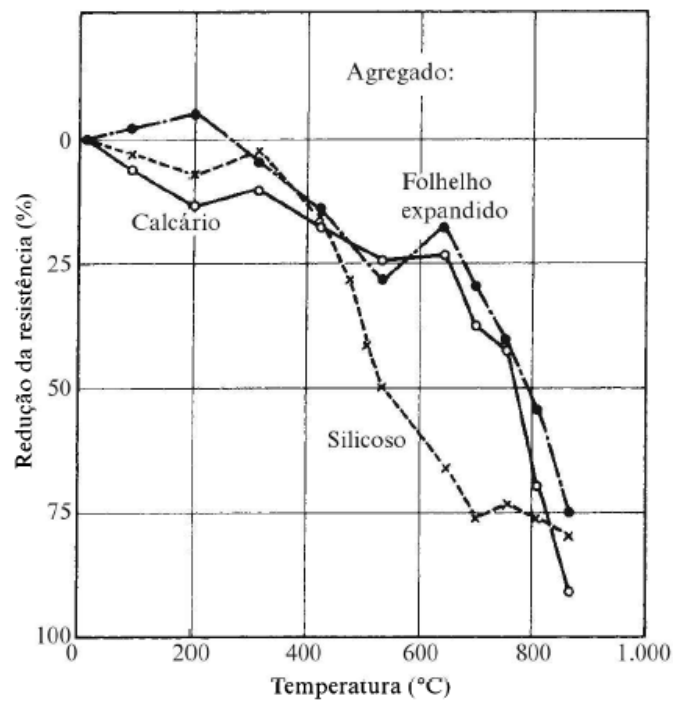

Fonte: NEVILLE (2016)

Agregados silicosos que contém quartzo em sua composição, sofrem transformações significativas como expansão volumétrica de $5,7 \%$ aos $570{ }^{\circ} \mathrm{C}$, devido à transformação da forma cristalina do quartzo de $\alpha \mathrm{em} \beta$ o que causam fissuras radiais ao redor dos agregados. Os agregados calcários possuem menor diferença nos coeficientes de dilatação térmica entre a matriz e o agregado, reduzindo a possibilidade do surgimento de fissuras e consequente redução da resistência. Porém, tornam-se instáveis em torno dos $600^{\circ} \mathrm{C}$ quando começa sua decomposição (NEVILLE, 2016 e GURUPRASAD; RAMASWAMY, 2018). 


\subsection{Pasta de Cimento}

A consequência do aumento de temperatura na pasta de cimento hidratada depende do grau de hidratação e da umidade, pois o fator água/cimento interfere diretamente na permeabilidade e na umidade (SOGBOSSI; VERDIER; MULTON, 2020). A pasta de cimento apresenta grande quantidade de água livre, capilar e adsorvida, quando bem hidratada consiste, principalmente, em silicatos de cálcio hidratados (C-S-H), hidróxido de cálcio e sulfoaluminatos de cálcio hidratados. As alterações iniciais na pasta de cimento são predominantemente físicas e começa a sofrer desgaste químico a partir dos $200{ }^{\circ} \mathrm{C}$ com a redução das forças de Van Der Walls entre as camadas do C-S-H. Aos $300{ }^{\circ} \mathrm{C}$, a água intermelar do C-S-H e parte da água quimicamente combinada do C-S-H e dos sulfatos aluminatos hidratados será perdida, provocando a evolução dos poros. Aproximadamente aos $500{ }^{\circ} \mathrm{C}$, verifica-se uma desidratação da pasta do cimento devido à decomposição do hidróxido de cálcio (portlandita) e, aos $900{ }^{\circ} \mathrm{C}$ com a perda completa da água intermelar, ocorre a decomposição completa do C-S-H (tobermorita), que é responsável pela perda de resistência do concreto e pela redução de volume da pasta aumentando a fissuração (SOUZA, 2016 e YIMA; PARK; JUN, 2019). Acima de $800{ }^{\circ} \mathrm{C}$, a pasta sofre reações cerâmicas e, entorno de $1100{ }^{\circ} \mathrm{C}$, ocorre derretimento total dos diferentes géis ou componentes cristalinos (FERNANDES, 2017).

\subsection{Zona de Transição}

O aquecimento do concreto leva a uma expansão térmica diferencial entre o agregado e a matriz cimentícia, pois, durante o aquecimento, a pasta sofre um intenso processo de retração devido à desidratação, enquanto os agregados sofrem um processo de expansão, conforme figura 4. Esse fator resulta em fissuras que surgem inicialmente na zona de transição devido à sua maior fragilidade, o que pode também pode introduzir processo de desplacamento (FERNANDES, 2017). 
Figura 4 - Incompatibilidade térmica entre o agregado e pasta de cimento hidratada.

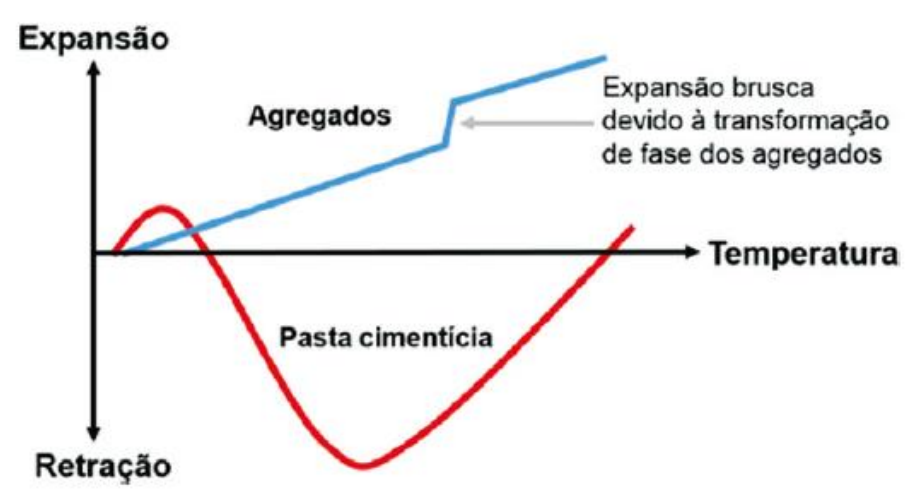

Fonte: FERNANDES (2017)

À temperatura ambiente, a zona de transição apresenta uma matriz intacta, constituída por etringita, portlandita e silicato de cálcio hidratado. É possível notar, na figura 5 , que os cristais de etringita e portlandita desapareceram aos $350{ }^{\circ} \mathrm{C}$ e aos $550{ }^{\circ} \mathrm{C}$, respectivamente.

Figura 05 - Micrografia da zona de transição de concreto convencional submetido a $550{ }^{\circ} \mathrm{C}$.
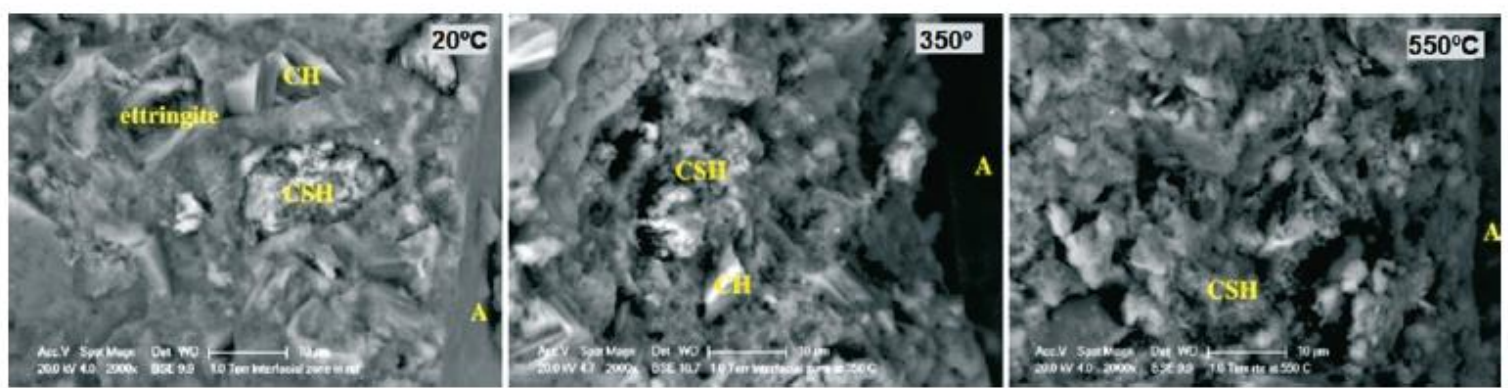

Fonte: FERNANDES (2017)

\section{COMPORTAMENTO DAS PROPRIEDADES DO CONCRETO EM ALTAS TEMPERATURAS}

De acordo com Argenton (2011), quando exposto ao fogo, o concreto pode apresentar alterações nas suas propriedades mecânicas e térmicas. Esses problemas decorrem de reações físico-químicas provenientes do fluxo de calor submetido e da distribuição da temperatura no interior do elemento que depende: do tipo de cimento, agregado, adições, dimensão da seção transversal, relação água/cimento e da porosidade do elemento de 
concreto (BRITZ, 2011).

\subsection{Propriedades Mecânicas do Concreto}

A resistência à compressão do concreto varia com a situação de exposição a altas temperaturas. Os efeitos nas propriedades do concreto são decorrentes do gel de C-S-H e do $\mathrm{C}_{2} \mathrm{~S}$. Neville (2016) aponta que, após a exposição a uma alta temperatura, a resistência varia:

a) Misturas com menor consumo de cimento sofrem uma perda na resistência, após a exposição a uma alta temperatura, menor do que misturas mais ricas;

b) A perda da resistência à compressão é menor em concretos com agregados leves do que em concretos convencionais;

c) Concretos de alta resistência perdem mais resistência do que concretos convencionais.

d) Devido ao teor de umidade no momento de aplicação da carga, a perda de resistência é maior em concretos saturados do que em concretos secos.

Segundo Kirchhof et al. (2020), a redução da resistência à compreensão do concreto ocorre gradualmente com o aumento da temperatura, diferentemente do concreto de alta resistência, que sofre uma considerável perda de força a partir de $400{ }^{\circ} \mathrm{C}$.

Segundo Caspeelo e Botte (2017), o resfriamento é outro fator que influencia a redução da resistência do concreto, até os $400^{\circ} \mathrm{C}$ o resfriamento brusco provoca grandes perdas de resistências, isto se deve a maior quantidade de fissuras provenientes do choque térmico ao ser submerso em água. Após $600^{\circ} \mathrm{C}$, a diferença torna-se insignificante.

Segundo LI at el. (2020), as propriedades mecânicas e a estrutura dos poros das estruturas danificadas pelo fogo no concreto podem ser recuperados após a cura pósincêndio. A recuperação é com base na reidratação dos produtos desidratados durante exposição a altas temperaturas. 


\section{CONSIDERAÇÕES FINAIS}

Os efeitos de altas temperaturas no concreto podem ser analisados a partir de diversas ópticas, partindo desse princípio, convém avaliar o conjunto da mistura através da macroestrutura e microestrutura. $\mathrm{O}$ aspecto visual, é o fator mais acessível e indicativo das alterações que estão ocorrendo macroscopicamente no material, visto que a mudança de coloração inicia e continua a ser alterada conforme a exposição e elevação da temperatura. Essas alterações são acentuadas quando os agregados são silicosos ou calcárias, por apresentarem componentes ferrosos. Esse aumento de temperatura é inversamente proporcional à resistência a compressão até o ponto no qual o material sofre sinterização e suas resistências não totalmente anuladas.

Microscopicamente, as principais reações devido à elevação da temperatura ocorrem nas fases da pasta de cimento hidratada, no qual a água presente é evaporada conforme o nível em que se encontra.

Os componentes do concreto reagem de formas diferentes e conforme suas particularidades químicas e físicas, quando submetidas a temperaturas elevadas. O cimento Portland comum, possui suas limitações quanto as suas propriedades e desempenho, existem outros tipos de cimento que possuem melhores desempenhos à altas temperaturas, por possuírem aluminato de cálcio e/ou baixos teores de óxido de ferro e manganês. A água presente no concreto é eliminada conforme o aumento da temperatura, seguindo um padrão. Primeiro é eliminada a água adsorvida e em seguida a água livre nos interstícios, essa evaporação causa uma retração da pasta de cimento resultando no aparecimento de fissuras. Os agregados se comportam de forma distinta diante do aumento de temperatura de acordo com sua composição mineralógica. Porém, acima de $800^{\circ} \mathrm{C}$ é desconsiderada a diferença de perda de resistência do concreto em relação aos que são constituídos por agregados silicosos, calcários e leves. Além disso, os agregados silicosos que possuem quartzo sofrem expansões volumétricas relevantes em relação ao coeficiente de dilatação dos agregados calcários. O concreto se torna mais vulnerável na zona de transição, onde ocorre um processo de retração da pasta de cimento e de expansão dos agregados devido a desidratação causada pela evaporação da água submetida ao aumento da temperatura.

As propriedades mecânicas do concreto exposto a altas temperaturas são decorrentes das reações físico-químicas decorrentes do fluxo e distribuição do calor no interior do material. Esse efeito varia conforme a intensidade, duração e situação de exposição. 


\section{REFERÊNCIAS}

ARGENTON, M. B. Efeito das variações do teor de umidade e condições de aquecimento no comportamento de concreto de alta compacidade. Escola de Engenharia da Universidade Federal do Rio Grande do Sul, Rio Grande do Sul, 2011.

BOTTE, W., CASPEELE, R. Post-cooling properties of concrete exposed to fire. Fire Safety Journal, 92, 142-150, 2017.

BRITZ, A. C. Avaliação de pilares de concreto armado colorido de alta resistência, submetidos a elevadas temperaturas. Escola Politécnica da Universidade de São Paulo, São Paulo, 2011.

COELHO, A.R.; CAMPOS, G. C. R.; SANTOS, C. C., et al. Influência do choque térmico por resfriamento brusco do concreto após exposição a elevadas temperaturas em simulação de incêndio. Revista Matéria, v.25, n.1, 2020.

COSTA, C.N.; FIGUEIREDO, A.D.; SILVA, V.P. Aspectos tecnológicos dos materiais de concreto em altas temperaturas. Núcleo de Pesquisa em Tecnologia da Arquitetura e Urbanismo, São Paulo, 2002.

FERNANDES, B.; GIL, A.M.; BOLINA, F. L.; TUTIKIAN. B.F. Microestrutura do concreto submetido a altas temperaturas: alterações físico-químicas e técnicas de análise. São Paulo, IBRACON, v. 4, 2017.

FERREIRA, A. P. G. Modelagem dos fenômenos de transporte termo-hídricos em meio porosos submetidos a temperaturas elevadas: aplicação a uma bicamada rochaconcreto. Programa de Pós-graduação em Modelagem Computacional da Universidade Federal de Juiz de Fora, Juiz de Fora, 2011.

GURUPRASAD, Y.K.; RAMASWAMY, A. Micromechanical analysis of concrete and reinforcing steel exposed to high temperature. Department of Civil Engineering, Indian Institute of Science, Bangalore 560012, India.

HOLAN, J., NOVÁK, J., MÜLLER, P., \& ŠTEFAN, R. Experimental investigation of the compressive strength of normal-strength air-entrained concrete at high temperatures. Construction and Building Materials, 248,2020.

LI, L., SHI, L., WANG, Q., LIU, Y., DONG, J., ZHANG, H., \& ZHANG, G. A review on the recovery of fire-damaged concrete with post-fire-curing. Construction and Building Materials, 237, 117-564, 2020.

KIRCHHOF, LD; LIMA, RCA; SANTOS NETO, ABS, et al. Effect of Moisture Content on the Behavior of High Strength Concrete at High Temperatures. Revista Matéria, v.25, n.1, 2020.

MEHTA, P.K.; MONTEIRO, P.J.M. Concreto: Microestrutura, Propriedades e Materiais. 2a . Ed. São Paulo, IBRACON, 2014. 
NEVILLE, A. M. Propriedades do Concreto. 5. Ed. São Paulo, Bookman, 2016.

OLIVEIRA, J. de A., RIBEIRO, J. C. L., PEDROTI, L. G., FARIA, C. S. de, NALON, G. H., \& OLIVEIRA JÚNIOR, A. L. Durability of Concrete After Fire Through Accelerated Carbonation Tests. Materials Research, 2019.

PAZDERA, L., TOPOLAR, L., MIKULASEK, K., SMUTNY, J., \& SEELMANN, H. Non-Linear Characteristics of Temperature Degraded Concrete at High Temperature. Procedia Engineering, 190, 2017.

SOGBOSSI, H., VERDIER, J., \& MULTON, S. Permeability and damage of partially saturated concrete exposed to elevated temperature. Cement and Concrete Composites, 2020.

SOUZA, L. D. P. S. Análise do comportamento estrutural de vigas de concreto armado submetidos às altas temperaturas utilizando a metodologia do planejamento fatorial. Programa de Pós-Graduação em Engenharia Civil e Ambiental da Universidade Federal da paraíba, João Pessoa, 2016.

SOUZA, L. D. P.; AZERÊDO, G. A. de; SILVA, F. de A. Comportamento do concreto sob altas temperaturas via planejamento experimental fatorial com configuração estrela. Ambiente Construído, Porto Alegre, v. 18, n. 1, p. 327/344, jan./mar. 2018.

WRÓBLEWSKA, J.; KOWALSKI, R. Assessing concrete strength in fire-damaged structures. Warsaw University of Technology, Civil Engineering Faculty, Institute of Building Structures, Al. Armii Ludowej 16, 00-637 Warsaw, Poland, 2020.

XIAO, J., XIE, Q., \& XIE, W. Study on high-performance concrete at high temperatures in China (2004-2016) - An updated overview. Fire Safety Journal, 95, 1124, 2018.

YIMA, H. J., PARK, S. J., \& JUN, Y. Physicochemical and mechanical changes of thermally damaged cement pastes and concrete for re-curing conditions. Cement and Concrete Research, 125, 2019. 


\title{
CARACTERIZAÇÃO MORFOLÓGICA DE PARTÍCULAS DE GRANITO USANDO METODOLOGIAS DE PROCESSAMENTO E ANÁLISE DE IMAGENS
}

\author{
Natália de Macedo do Lago \\ Universidade Federal Rural do Rio de Janeiro, Seropédica, RJ \\ http://lattes.cnpq.br/7479856630580574 \\ Tessie Gouvêa da Cruz Lopes \\ Universidade Federal Rural do Rio de Janeiro, Seropédica, RJ \\ http://lattes.cnpq.br/3115368259632031
}

\section{Belmira Benedita de Lima-Kühn}

Universidade Federal Rural do Rio de Janeiro, Seropédica, RJ http://lattes.cnpq.br/2717561428282678

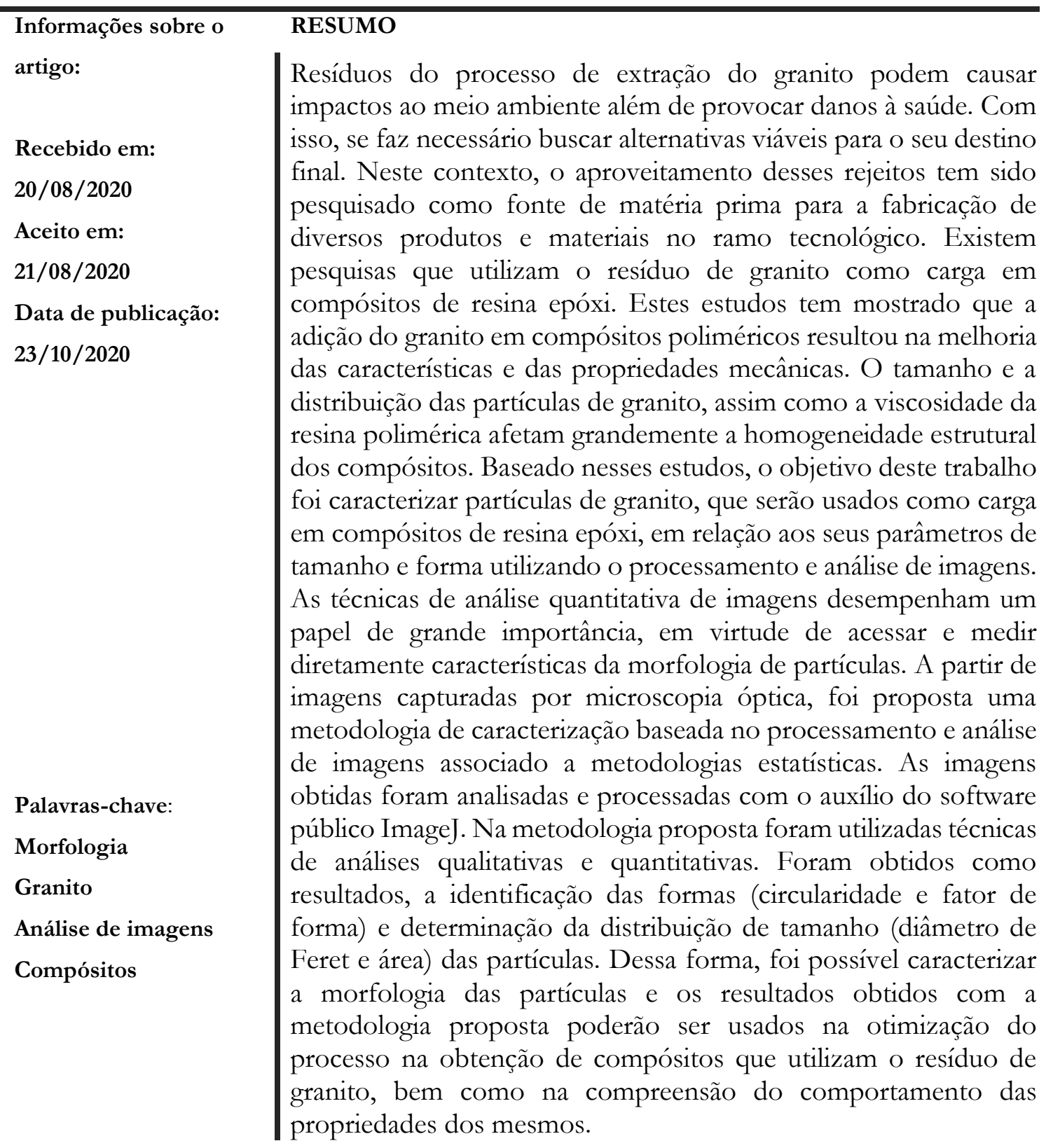




\section{MORPHOLOGICAL CHARACTERIZATION OF GRANITE PARTICLES USING IMAGE PROCESSING}

\section{ABSTRACT}

Residues from the granite extraction process can cause impacts to the environment as well as damage to health. Therefore, searches of viable alternative for its final destination are necessary. In this context, the use of these residues has been researched as a source of raw material for the production of several products and materials in the technological field. There are researches that use the granite residue as filled in epoxy resin composites. These studies have shown that the addition of granite in polymeric composites has resulted in improved characteristics and mechanical properties. The size and distribution of granite particles, as well as the viscosity of the polymeric resin greatly affect the structural homogeneity of composites. Based on these studies, the objective of this work was to characterize granite particles, which will be used as fillers in epoxy resin composites, in relation to their size and shape parameters using image processing and analysis. The techniques of quantitative image analysis play a role of great importance, due to the direct access and measurement of particle morphology characteristics. From images captured by optical microscopy, a characterization methodology based on image processing and analysis associated with statistical methodologies was proposed. The images obtained were analyzed and processed with the help of ImageJ public software. Qualitative and quantitative analysis techniques were used in the proposed methodology. The results were obtained by identifying the shapes (circularity and shape factor) and determining the size distribution (Feret diameter and area) of particles. Thus, it was possible to characterize the morphology of particles and the results obtained with the proposed methodology can be used in the optimization of the process in obtaining composites that use the granite residue, as well as in understanding the behavior of their properties.

\section{INTRODUÇÃO}

Com o passar dos anos, tem crescido as atividades industriais de serragem de blocos de granito e consequentemente o aumento da quantidade dos resíduos proveniente desse tipo de processo. Devido a enorme quantidade de rejeitos gerados, esses são muitas vezes descartados no meio ambiente e acabam por fim gerando um enorme impacto ambiental. Dessa forma, está sendo feito cada vez mais estudos para o emprego dos resíduos do pó de granito (ALMEIDA et al. 2015; PINHEIRO et al. 2019).

Desde o momento em que se começou a desenvolver técnicas com o intuito de beneficiamento, as partículas do pó de granito passaram a ser aplicadas em diferentes áreas 
tecnologicas. Na construção civil, por exemplo, estas partículas tem sido usadas em revestimentos por conter facilidades na aplicação, além da sua utilização em pisos e paredes (ALVES et al. 2015; AMARAL et al. 2018). Existem pesquisas que utilizam o resíduo de granito como carga em compósitos de resina epóxi. Estes estudos tem mostrado que a adição do granito em compósitos poliméricos resultou na melhoria das características e das propriedades mecânicas (NALLUSAMY \& KARTHIKEYAN, 2017; PAWAR et al. 2015; SUBHASH et al. 2018).

O reaproveitamento dessas partículas de granito estão ligadas as características físicas e químicas do resíduo (JAIN et al. 2020; ZAFAR et al. 2020). O tamanho e a distribuição das partículas de granito afetam grandemente a homogeneidade estrutural dos compósitos poliméricos que utilizam o granito como carga (SUBHASH et al. 2018). Neste contexto, o processamento e analise de imagens tem sido utilizada como técnica na caracterização morfológica de partículas (PIRATELLI-FILHO \& SHIMABUKURO, 2008; COELHO et al. 2019; ATKINSON \& SHI, 2003).

Para o presente trabalho foi proposta uma metodologia de caracterização baseada no processamento e análise de imagens obtidas por microscopia optica associado a metodologias estatísticas. Na metodologia proposta foram utilizadas técnicas de análises qualitativas e quantitativas para a identificação das formas e determinação da distribuição de tamanho das partículas com o objetivo de otimização na obtenção de compósitos que utilizam o resíduo de granito.

\section{METODOLOGIA}

\subsection{Materiais}

Para obtenção de partículas de granito foi utilizado como matéria prima uma pedra de granito cedido pela Marmoraria Jardim LTDA sediada na cidade de Cruzeiro-SP. A pedra de granito foi fragmentada manualmente com o auxílio de um martelo para facilitar o processo de moagem. Para o processo de Cominuição foi utilizado um Moinho de Martelo modelo TE-330 da marca Tecnal. Para uma pré-classificação foram utilizadas peneiras de 20\#, 28\#, 42\#, 60\# e 270\#. As partículas do pó retidas nas peneiras 42\#, 60\# e 270\# foram maceradas por intermédio de um almofariz de ágata. As partículas maceradas foram 
separadas para a caracterização morfológica usando a metodologia de processamento e análise de imagens proposta neste trabalho.

\subsection{Caracterização morfológica das partículas de granito}

As partículas de granito foram observadas no Microscópio Metalográfico BEL modelo MTM-1A. As imagens foram capturadas através de uma câmera digital acoplada no microscópio. O número de imagens a serem capturadas foi baseado no modelo probabilístico proposto por Mainy (MAINY, 1996).

A determinação do número de campos de amostragem $(\mathrm{N})$, isto é, número de imagens a serem capturadas foi calculado com base no número médio de partículas (n) capturadas em cada imagem. Neste tratamento estatístico, os objetos de interesse (no caso, as partículas de granito) apresentam amostragem aleatória e é possível assumir uma distribuição normal. Para esse tipo de distribuição probabilística o intervalo de confiança associado a quantidade de amostragem é definido pela equação:

$$
\mathrm{N} \geq\left[\left(\frac{4}{\mathrm{E}_{\mathrm{r}}}\right) * \frac{1}{\mathrm{n}}\right]
$$

Onde:

$\mathrm{N}$ = Número de campos da amostragem (número de imagens capturadas);

$\mathrm{E}_{\mathrm{r}}=$ Intervalo de confiança;

$\mathrm{n}$ = Número médio de partículas na imagem capturada no microscopio óptico.

Para a definição do número de imagens necessárias para um intervalo de confiança $\left(\mathrm{E}_{\mathrm{r}}\right)$ de $95 \%$ na análise morfológica proposta foram capturadas 8 imagens microscópica das partículas de granito. Essas imagens foram processadas e foi extraído o número médio de partículas presentes em cada imagem. Com base no número de partículas presentes nas imagens capturadas (n) e usando a Equação (1) foi determinado o número de amostragem $(\mathrm{N})$, isto é, o número de imagens a serem analisadas para a caracterização morfológica das partículas.

As imagens obtidas na microscopia foram processadas e analisadas usando o software público ImageJ. As imagens foram segmentadas com o objetivo de separar os objetos de interesse (partículas de granito). Para isso foram segmentadas utilizando o thresolding (programa ImageJ) com os níveis que destacavam as partículas. Utilizando as ferramentas do 
programa ImageJ, o plugin "Analyzer Particle", as imagens foram processadas e os parâmetros de tamanho (área, diâmetro de Feret) e forma (circularidade, razão de aspecto e fator de forma) foram calculados.

\section{RESULTADOS E DISCUSSÃO}

\subsection{Caracterização morfológica das partículas de granito}

Para a definição do número de imagens necessárias para um intervalo de confiança $\left(\mathrm{E}_{\mathrm{r}}\right)$ de $95 \%$ na análise morfológica proposta foram capturadas 8 (oito) imagens das partículas de granito. A Figura 1(a) apresenta um exemplo das imagens capturadas no microscópio. Todas as imagens capturadas no microscópio foram segmentadas [exemplo de segmentação Figura 1 (b)] e com a utilização de ferramentas do programa ImageJ foi calculado o número médio de partículas de granito para cada imagem.

Figura 1 - (a) Exemplo de imagem das partículas de granito obtida por microscopia óptica; (b) Exemplo de Imagem Segmentada.
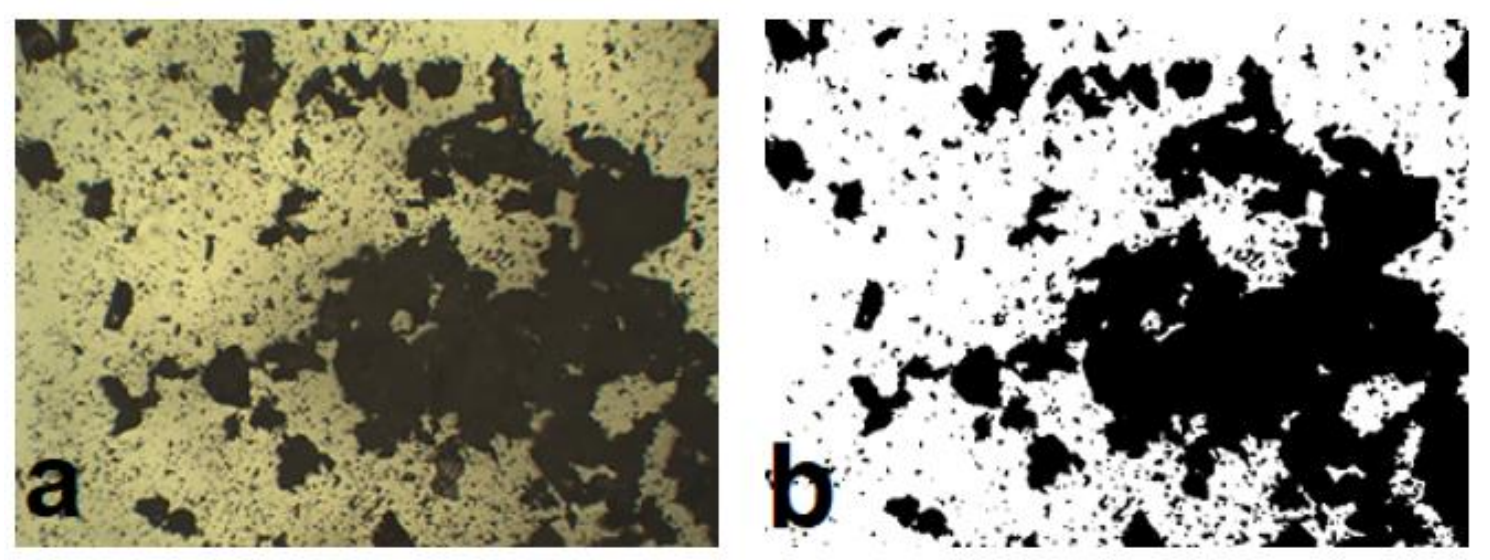

Os resultados para o número médio de partículas de granito por imagem $\left(\mathrm{n}_{\mathrm{i}}\right)$, obtidos para todas as imagens capturadas (total de 8 imagens), estão apresentados na Tabela 1. 
Tabela 1 - Número médio de partículas de granito por imagem capturada.

\begin{tabular}{|c|c|}
\hline Imagem Capturada & Número Médio de Partículas $\left(\mathbf{n}_{\mathbf{i}}\right)$ \\
\hline 1 & 756 \\
\hline 2 & 1157 \\
\hline 3 & 583 \\
\hline 4 & 585 \\
\hline 5 & 630 \\
\hline 6 & 464 \\
\hline 7 & 627 \\
\hline 8 & 180 \\
\hline Média Aritmética & 622 \\
\hline
\end{tabular}

Para o número médio de partículas na imagem capturada no microscopio óptico (n) da equação (1) foi calculada a média aritmética para as 8 (oito) imagens capturadas (Tabela 1). A partir do valor de número médio de partículas (n), utilizando a Equação (1) foi determinado, com 95\% de confiabilidade, um número total de amostragem $(\mathrm{N})$ igual 0,13 . Este resultado demonstra que o processamento e análise de imagens de apenas uma imagem capturada no microscópio seria necessária para o processamento e análise dos parâmetros de tamanho e forma.

Foi definido um total de 8 (oito) imagens para o processamento e análise dos parâmetros a serem extraídos, no qual uma das imagens está sendo apresentada pela Figura 2(a).

Figura 2 - Etapas do processamento e análise de imagens. (a) Imagem obtida por microscopia óptica (detalhe das partículas indicadas pelas setas vermelha e azul); (b) Imagem segmentada e grupo de partículas agregadas (detalhe das partículas indicadas pelas setas vermelha e azul); (c) Utilização do operador morfológico 'watershed' para separar as partículas (detalhe das partículas indicadas pelas setas vermelha e azul); (d) Partículas separadas e contabilizadas na análise e extração dos parâmetros (detalhe das partículas indicadas pelas setas vermelha e azul).
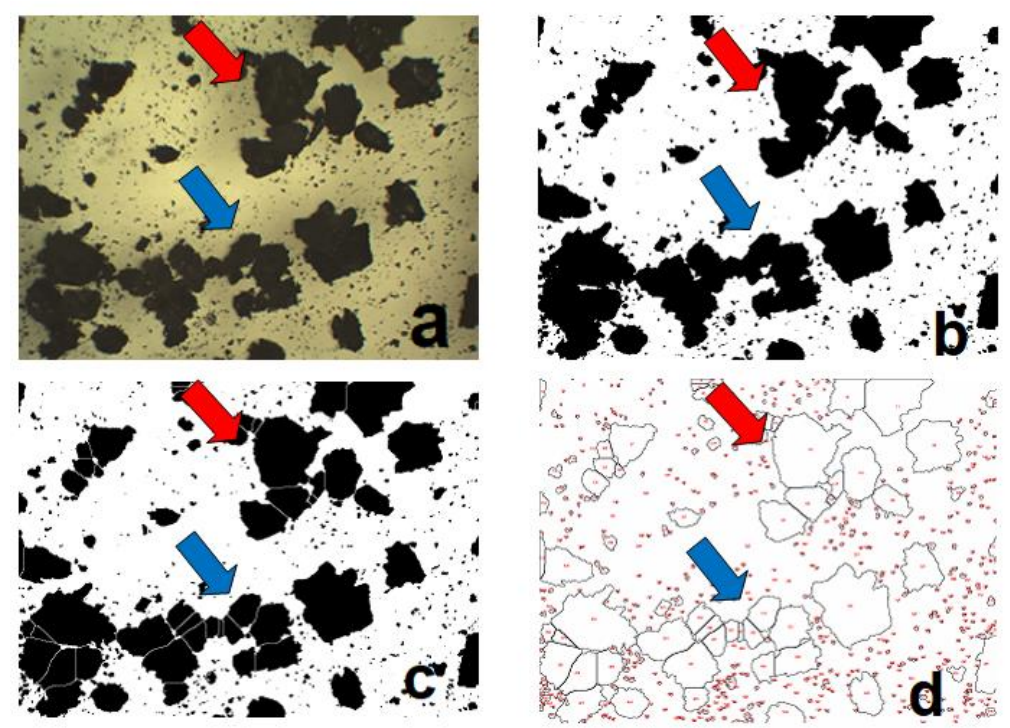

As imagens foram segmentadas e as partículas de granito identificadas como objeto de interesse [Figura 2(b)]. Neste tipo de segmentação, pode acontecer que algumas partículas tendam a se agregar (detalhe das partículas indicadas pelas setas vermelha e azul na [Figura 
2(a)] e consequentemente essas serão consideradas como um único objeto (detalhe das partículas indicadas pelas setas vermelha e azul na [Figura 2(c)]. Na etapa de extração dos parâmetros a análise e cálculo não representariam o número real de partículas (CRUZ, 2011). Com o objetivo de diminuir a quantidade de agregados das partículas e imputação de erro no cálculo dos parâmetros, foi utilizado o operador 'watershed' no programa ImageJ [Figura 2(d)]. O operador 'watershed' ressalta o contorno dos objetos, produzindo bordas em pontos de descontinuidade de nível de cinza, efeito geralmente desejado em segmentação de imagens (CRUZ, 2011).

Após o processamento das imagens os parâmetros específicos (tamanho e forma) foram extraídos. Na metodologia proposta, usando as ferramentas de caracterização e análise do software IMAGEJ foram calculados os parâmetros de caracterização morfológica.

Para os parâmetros relacionados a tamanho foram calculados: área (A) e diâmetro de Feret (DF). Para os parâmetros relacionados a forma foram calculados: circularidade (C), razão de aspecto (RA) e arredondamento (A). Os valores médios, desvio padrão e valores de máximo e mínimo são apresentados para cada parâmetro na Tabela 2.

Tabela 2 - Parâmetros de tamanho e forma do pó de granito

\begin{tabular}{|c|c|c|c|c|}
\hline Parâmetros & Média & Desvio Padrão & Máximo & Mínimo \\
\hline Área $(\mathrm{A})\left(\mu \mathrm{m}^{2}\right)$ & 100 & 180 & 100 & 10 \\
\hline Diâmetro Feret (DF) $(\mu \mathrm{m})$ & 40 & 110 & 85 & 10 \\
\hline Circularidade (CIRC) & 0,84 & 0,16 & 1 & 0,29 \\
\hline Razão de Aspecto (RA) & 1,59 & 0,51 & 1,94 & 1 \\
\hline Arredondamento (A) & 0,67 & 0,17 & 0,98 & 0,11 \\
\hline
\end{tabular}

De forma geral, com base na Tabela 2, é possível observar que as partículas possuem um tamanho que varia de $10 \mu \mathrm{m}$ a $85 \mu \mathrm{m}$. A média dos valores de circularidade, razão de aspecto e área apontam pra uma tendência não circular na forma das partículas. Os altos valores nos desvio padrão indicam uma heterogeneidade na distribuição dos resultados. Para uma discussão detalhada desses parâmetros os resultados foram apresentados em forma de histograma, conforme se observa nas Figuras 3 e 4.

$\mathrm{Na}$ Figura 3, é apresentado os resultados referentes aos parâmetos de tamanho: área [Figura 3(a)] e diâmetro de Feret [Figura 3(b)] das partículas de granito. O parâmetro diâmetro médio de Feret (DF) é efetuado o cálculo dos maiores diâmetros horizontais e 
verticais de uma determinada partícula (FERREIRA \& RASBAND, 2011), sendo esta medição feita por intermédio dos eixos máximos de comprimentos que pertencem ao objeto analisado nas imagens de microscopia (SHAHIN et al. 2006; PARIN, 2003). Com base no histograma da Figura 3(a) a maioria das partículas concentram-se em um tamanho (diâmetro) de aproximadamente $0,01-0,04 \mathrm{~mm}^{2}$.

Figura 3 - (a) Gráfico 1: Histograma da Área das partículas do pó de granito; (b) Gráfico 2: Histograma de diâmetro de Ferret das partículas do pó de granito.

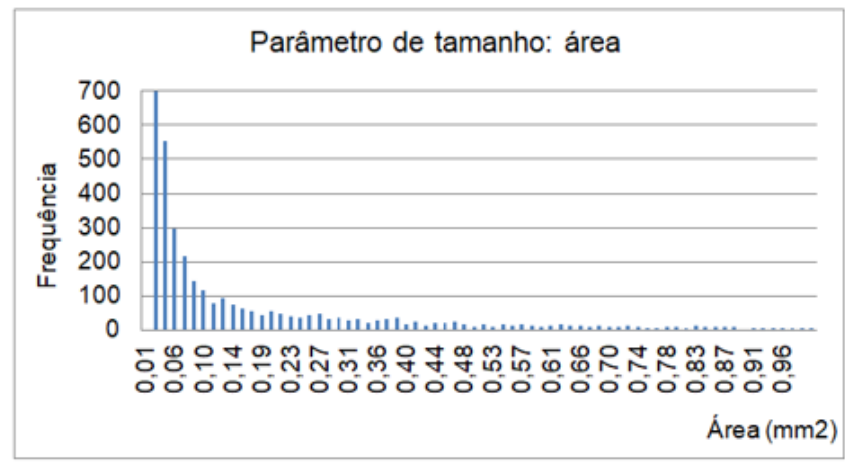

(a)

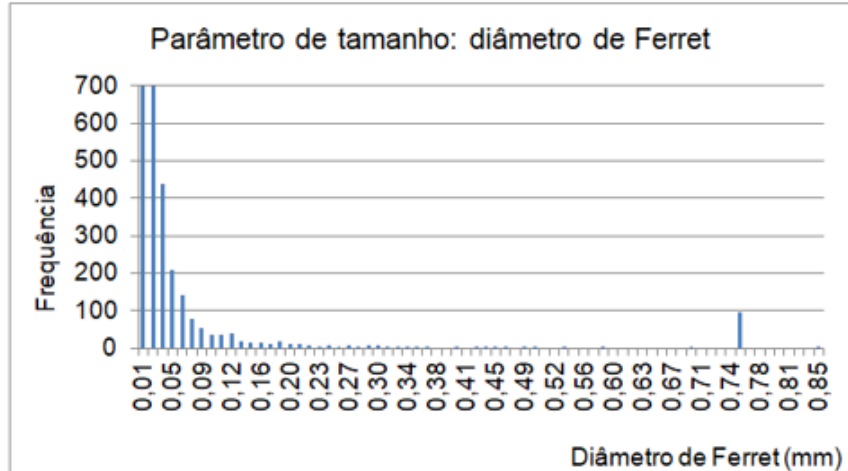

(b)

Para o cálculo estatístico da área é utilizado como base os números de pixels que estão contidos em um determinado objeto segmentado (IGATHINATHANE et al, 2008; FERREIRA \& RASBAND, 2011). Com base no histograma da Figura 3(b), pode-se comparar o comportamento da área em relação ao diâmetro de Feret. A comparação entre esses parâmetros já nos dão ideia de que as partículas não são assimétricas, visto que existe uma variação nos valores de área.

Os valores referentes aos parâmetros de forma são apresentados nos gráficos da Figura 4, são eles: circularidade [Figura 4(a)], razão de aspecto [Figura 4(b)] e arredondamento [Figura 4 (c)].

O parâmetro de circularidade nos possibilita avaliar o alongamento das partículas, isto é, quanto mais próximos do valor 1 , as partículas apresentam menos achatamento oval 
(IGATHINATHANE et al, 2008). Pode-se concluir que quando é encontrado partículas com medidas mais próximas de 1 os objetos são círculos perfeitos e, valores mais próximos de 0 são objetos mais alongadas e menos circulares (FERREIRA \& RASBAND, 2011). Os resultados de circularidade (variaram de 0,5 à 1,0 ) podem ser observados no histograma do Gráfico 3 [Figura 4(a)] e apontam que as partículas não são esfericas e tendem a ser ovais.

Para a Razão de Aspecto (AR), é preciso extrair algumas propriedades dimensionais das partículas, no qual se faz necessário a aplicação de uma determinada correção nos eixos maiores e menores. Com isso, por meio de ajustes na elipse das partículas, sendo estas caracterizadas por uma divisão entre os eixos maiores e menores (IGATHINATHANE et al. 2008; FERREIRA \& RASBAND, 2011). De acordo com os valores apresentados no histograma, é possível analisar que as partículas concentram-se em suma dentro de um intervalo de 0,91 a 0,98 [Figura 4(b)]. Perante a isso, é possível dizer que a maioria das partículas possuem características morfológicas arredondadas.

O parâmetro de arredondamento (A) é o inverso da Razão de Aspecto, pois seu cálculo é obtido através da razão entre a área da superfície da partícula e os maiores eixos pertencentes ao mesmo. Além disso, o valor máximo de arredondamento poderá ser igual a 1,00 [Figura 4(c)]. Sendo este valor caracterizado para partículas de máximo arredondamento (FERREIRA \& RASBAND, 2011; WADELL, 1932), isto é, partículas sem reentrâncias.

De acordo com o histograma da Figura 4(c), é possível observar que as partículas de granito apresentaram valores que variaram a partir de 0,35 a 1,00. Esse resultado aponta para a tendência de partículas com perímetro irregular e presença de reentrâncias. 
Figura 4 - (a) Gráfico 3: Histograma de Circularidade das partículas do pó de granito; (b) Gráfico 4: Histograma da Razão de Aspecto das partículas do pó de granito; (c) Gráfico 5: Histograma do Arredondamento das partículas do pó de granito.
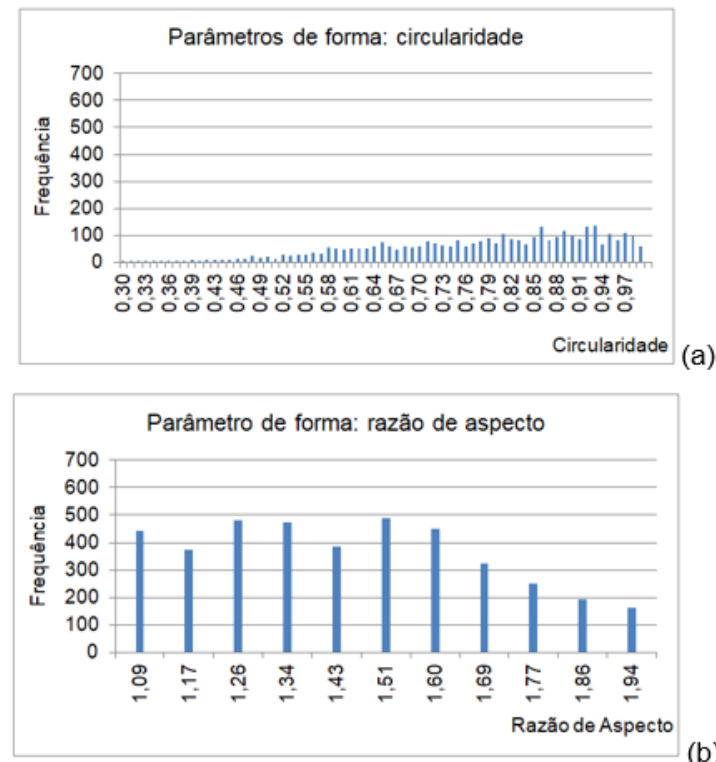

(b)

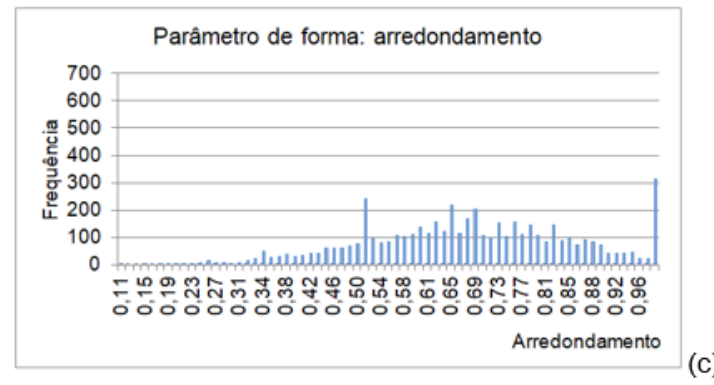

\section{CONCLUSÃO}

A metodologia proposta utilizando o processamento e análise de imagens para caracterização de tamanho e forma das partículas de granito mostrou-se viável e eficiente. As partículas de granito caracterizadas com a metodologia proposta apresentaram tamanho entre $10-40 \mu \mathrm{m}^{2}$ e tendem a ter formato oval com reentrâncias. Os resultados serão utilizados para otimizar o processo de obtenção de compósitos com uso de resina epóxi. Os resultados poderão ser usados no estudo das propriedades desses compósitos. 


\section{REFERÊNCIAS}

ALMEIDA T. F.; LEITE, F. H. G.; HOLANDA, J. N. F. Caracterização de Resíduo de Pó de Mármore para Aplicação em Materiais Cerâmicos. Universidade Estadual do Norte Fluminense Darcy Ribeiro-UENF/PPGECM, 28013-602, Campos dos Goytacazes RJ, 2015.

ALVES, J. O.; JUNCA, E.; ESPINOSA, D. C. R.; TENÓRIO, J. A. S. Resíduo do Corte de Granito: Inovação Tecnológica para a Destinação Final. Tecnol. Metal. Mater. Miner., São Paulo, v. 12, n. 2, p.123-128, abr./jun. 2015. http://dx.doi.org/10.4322/2176$\underline{1523.0856}$

AMARAL, L. F.; CARVALHO, J. P. R. G. DE; SILVA, B. M. DA; DELAQUA, G. C. G.; MONTEIRO, S. N.; VIEIRA, C. M. F. Development of ceramic paver with ornamental rock waste. Journal of Materials Research and Technology. 2018. https://doi.org/10.1016/j.jmrt.2018.05.009.

ATKINSON, H. V.; \& SHI, G. Characterization of inclusions in clean steels: a review including the statistics of extremes methods. Progress in Materials Science 2003; 48:457520. https://doi.org/10.1016/S0079-6425(02)00014-2

COELHO, J. M.; FARIA, E. L.; VIEIRA, L. V.; CORREIA, M. D.; ALBUQUERQUE, M. P.; ALBUQUERQUE, M. P.; BOM, C. R. Caracterização morfológica de grãos em lâminas delgadas por meio de técnicas de processamento de imagem. São Paulo, UNESP, Geociências, v. 38, n. 3, p. 735 - 750, 2019

CRUZ, T. G. Técnicas de Microscopia Óptica e Processamento Digital de Imagens na Caracterização Microestrutural de Cerâmicas Porosas Conformadas por Consolidação com Amido. Dissertação de Mestrado. Universidade Estadual Paulista Júlio de Mesquita Filho, UNESP, 2003.

IGATHINATHANE, C.; PORDESIMO, L. O.; COLUMBUS, E. P.; BATCHELOR, W. D.; METHUKU, S. R. Shape identification and particles size distribution from basic shape parameters using ImageJ. Computers and Electronics in Agriculture, 63(2), 168182. 2008. doi:10.1016/j.compag.2008.02.007.

FERREIRA, T.; \& RASBAND, W. The ImageJ User Guide - Version 1.44. February 2011. Disponível em: <http://imagej.nih.gov/ij/docs/user-guide.pdf>. Acesso em: 1 de maio de 2020.

JAIN, K. L.; SANCHETI, G.; GUPTA, L. K. Durability performance of waste granite and glass powder added concrete. Construction and Building Materials, 252, 119075. 2020. https://doi.org/10.1016/i.conbuildmat.2020.119075

MAINY, D. Morphological and analytical characterization of inclusions: Relation with processing parameters and properties of use. Materials Characterization, 36(4-5), 321 - 326. 1996. doi:10.1016/s1044-5803(96)00065-4. 
NALLUSAMY, S.; \& KARTHIKEYAN, A. Synthesis and Wear Characterization of Reinforced Glass Fiber Polymer Composites with Epoxy Resin Using Granite Powder. Journal of Nano Research, 49, 1-9. 2017. https://doi.org/10.4028/www.scientific.net/JNanoR.49.1.

PARIN, J. C. Estudo comparativo de métodos de determinação do tamanho de partícula. Instituto de Pesquisas Energéticas e Nucleares. São Paulo, 2003.

PAWAR, M. J.; PATNAIK, A.; NAGAR, R. Investigation on mechanical and thermomechanical properties of granite powder filled treated jute fiber reinforced epoxy composite. Polymer Composites. 2015. DOI 10.1002/pc.23633.

PINHEIRO, H. S.; NOGUEIRA, R. E. F. Q.; XAVIER, L. C. P.; LOBO, C. J. S.; CARNEIRO, F. O. M. Peças Cerâmicas fabricadas usando pó de granito com adição dos produtos da combustão do carvão mineral: Caracterização Mecânica. revista Matéria, v.24, n.1, 2019. doi: http://dx.doi.org/10.1590/s1517-707620190001.0700.

PIRATELLI-FILHO, A.; \& SHIMABUKURO, F. Characterization of compression strength of granite-epoxy composites using design of experiments. Materials Research, 11(4), 399-404. 2008. doi:10.1590/s1516-14392008000400003

SHAHIN, M. A.; SYMONS, S. J.; POYSA, V. W. Determining Soya Bean Seed Size Uniformity with Image Analysis. Biosystems Engineering, 94(2), 191-198. 2006. doi:10.1016/j.biosystemseng.2006.02.011.

SUBHASH, C.; KRISHNA, M. R.; RAJ, M. S.; SAI, B. H.; RAO, S. R. Development of granite powder reinforced epoxy composites. Materials Today: Proceedings, 5(5), 13010 13014. 2018. https://doi.org/10.1016/j.matpr.2018.02.286.

WADELL, H. Volume, Shape, and Roundness of Rock Particles. University of Chicago, The Journal of Geology 40, no. 5 (Jul. - Aug., 1932): 443-451.

ZAFAR, M. S.; JAVED, U.; KHUSHNOOD, R. A.; NAWAZ, A.; ZAFAR, T. Sustainable incorporation of waste granite dust as partial replacement of sand in autoclave aerated concrete. Construction and Building Materials, 250, 118878. 2020. https://doi.org/10.1016/j.conbuildmat.2020.118878. 


\section{EFEITO DA ADIÇÃO DE RESÍDUO DE VIDRO SODA-CAL EM MASSA CERÂMICA PARA INDÚSTRIA DE REVESTIMENTO CERÂMICO}

Felipe Werlick Velloso dos Santos

UFRRJ, DEQ, Seropédica, RJ

http://lattes.cnpq.br/2847098534215301

Lidiane Alves Franco

UFRRJ, DEQ, Seropédica, RJ

http://lattes.cnpq.br/3475185551017262

Jônatas de Oliveira Sousa

UFRRJ, DEQ, Seropédica, RJ

http://lattes.cnpq.br/6472167535387848

Simone Pereira Taguchi Borges

UFRRJ, DEQ, Seropédica, RJ

http://lattes.cnpq.br/8221926915555893

Belmira Benedita de Lima-Kühn

UFRRJ, DEQ, Seropédica, RJ

http://lattes.cnpq.br/2717561428282678

Antonio Renato Bigansolli

UFRRJ, DEQ, Seropédica, RJ

http://lattes.cnpq.br/5868109671445446

Informações sobre o

artigo:

Recebido em:

21/08/2020

Aceito em:

21/08/2020

Data de publicação:

$23 / 10 / 2020$

Palavras-chave:

Resistência a flexão

Argila amarela

Resíduo

Vidro soda-cal

\section{RESUMO}

O presente trabalho teve como principal objetivo, caracterizar e avaliar os efeitos da adição de resíduo de vidro soda-cal, na argila amarela, para possível aplicação na indústria de revestimento cerâmico. Foi utilizado difração de raios X (DRX) como método de caracterização nas amostras do pó do vidro e do pó da argila. Os corpos de prova foram preparados com a incorporação de 0 e $20 \%$ de resíduo de vidro em massa, ambos obtidos pelo método de prensagem uniaxial. $\mathrm{O}$ tratamento térmico foi realizado em forno mufla nas temperaturas de $1000^{\circ} \mathrm{C}$ e $1100^{\circ} \mathrm{C}$ durante 1 hora. Após a sinterização os materiais cerâmicos foram submetidos a ensaios de absorção de água, retração linear de secagem e de queima, perda ao fogo e resistência à flexão. A composição com adição de $20 \%$ de resíduo de vidro sinterizada a $1100^{\circ} \mathrm{C}$ atendeu às especificações da norma NBR 13818 para piso do tipo semi-grês, grupo BIIa para os ensaios de resistência à flexão e absorção de água. A composição com adição de $20 \%$ de resíduo de vidro sinterizada a $1100^{\circ} \mathrm{C}$ alcançou $27,94 \mathrm{MPa}$ de resistência à flexão, valor superior ao $22 \mathrm{MPa}$ estabelecido pela NBR 13818. Os resultados obtidos nesse trabalho evidenciaram uma boa alternativa para reciclagem do vidro de embalagens agregando-o 
como matéria-prima na indústria de revestimentos cerâmicos, uma vez que o mesmo atua como agente fundente em temperaturas acima de $1000^{\circ} \mathrm{C}$.

EFFECTS OF THE ADDITION OF SODA-LIME GLASS WASTE TO CERAMIC MASS FOR CERAMIC TILE INDUSTRY

\section{ABSTRACT}

The present work had as main objective, to characterize and to evaluate the effects of the addition of soda-lime glass waste, in the yellow clay, for possible application in the ceramic tile industry. Xray diffraction (XRD) was used as characterization method in the samples of glass powder and clay powder. The samples were prepared with the incorporation of 0 and $20 \%$ of glass residue by weight, both obtained by the uniaxial pressing method. The heat treatment was carried out in a muffle furnace at temperatures of $1000^{\circ} \mathrm{C}$ and $1100^{\circ} \mathrm{C}$ for 1 hour. After sintering the samples were subjected to water absorption test, linear drying and firing shrinkage, loss by fire and flexural strength. The composition with the addition of $20 \%$ of sintered glass residue at $1100^{\circ} \mathrm{C}$ met the specifications of standards according NBR 13818 for semistoneware flooring, group BIIa for the tests of flexural strength and water absorption. The composition with the addition of $20 \%$ of glass residue sintered at $1100^{\circ} \mathrm{C}$ reached $27.94 \mathrm{MPa}$ of flexural strength, a value higher than the $22 \mathrm{MPa}$ established by NBR 13818. The results obtained in this work showed a good alternative for recycling packaging glass, adding it as a raw material in the ceramic tile industry, since it acts as a melting agent at temperatures above $1000^{\circ} \mathrm{C}$.

\section{INTRODUÇÃO}

O desenvolvimento industrial ocasionou crescente aumento na quantidade de resíduos gerados, devido aos avanços tecnológicos que visam melhorar a qualidade de vida da população (TRENTIN, 2020). Esse crescente acúmulo de resíduos em depósitos, mesmo que adequadamente preparados, é uma solução cada vez menos aceita pela sociedade, devido à degradação ambiental da área entorno dos depósitos. O reaproveitamento do resíduo é uma maneira de remediar a disposição inadequada, eliminando a ocupação final de aterros sanitários (GODINHO, 2004).

Os vidros utilizados para embalagens é um material inerte não cristalino, não poroso e frágil, constituído principalmente de sílica. No fim de seu uso, os materiais a base de vidro são descartados, todavia, boa parte são totalmente recicláveis podendo ser 
reutilizados ou agregados em outros processos industriais (ZACCARON, 2019). Segundo a associação Compromisso Empresarial para Reciclagem - CEMPRE, o Brasil produz em média 980 mil toneladas de embalagens de vidro por ano, usando apenas 45\% de matéria-prima em formas de caco (CEMPRE, 2020).

Sabe-se que a indústria de cerâmica vem tendo destaque em relação à reciclagem, com a incorporação de diversos resíduos, proporcionando economia de energia e material (ZACCARON, 2019). O Brasil é o terceiro maior produtor de revestimento cerâmico do mundo, considerando dados da Associação Nacional dos Fabricantes de Cerâmica para Revestimentos, Louças Sanitárias e Congêneres - ANFACER. Em 2019, a produção de revestimentos cerâmicos foi de 900 milhões de metros quadrados (ANFACER, 2020). Nesses atuais volumes, a produção de revestimento cerâmico necessita de uma quantidade expressiva de matérias-primas (BIFF, 2016). Assim, é importante estudar métodos que busquem a substituição total ou parcial de algum componente da massa, sem que haja perda da propriedade do material final, reduzindo a demanda por matérias-primas convencionais. Dessa forma o presente trabalho busca avaliar o efeito da adição de resíduo de vidro em massa argilosa para possível aplicação na indústria de revestimento cerâmico.

\section{METODOLOGIA}

As matérias-primas utilizadas para promover este trabalho foram argila amarela, extraída do município de Seropédica - RJ- Brasil e o vidro de garrafa marrom de cerveja (300 ml) doado pela empresa Ambev. O trabalho foi feito em duas etapas: preparação, caracterização da argila e do vidro e produção de placas cerâmicas, conforme a Figura 1. 
Figura 1- Fluxograma do trabalho experimental

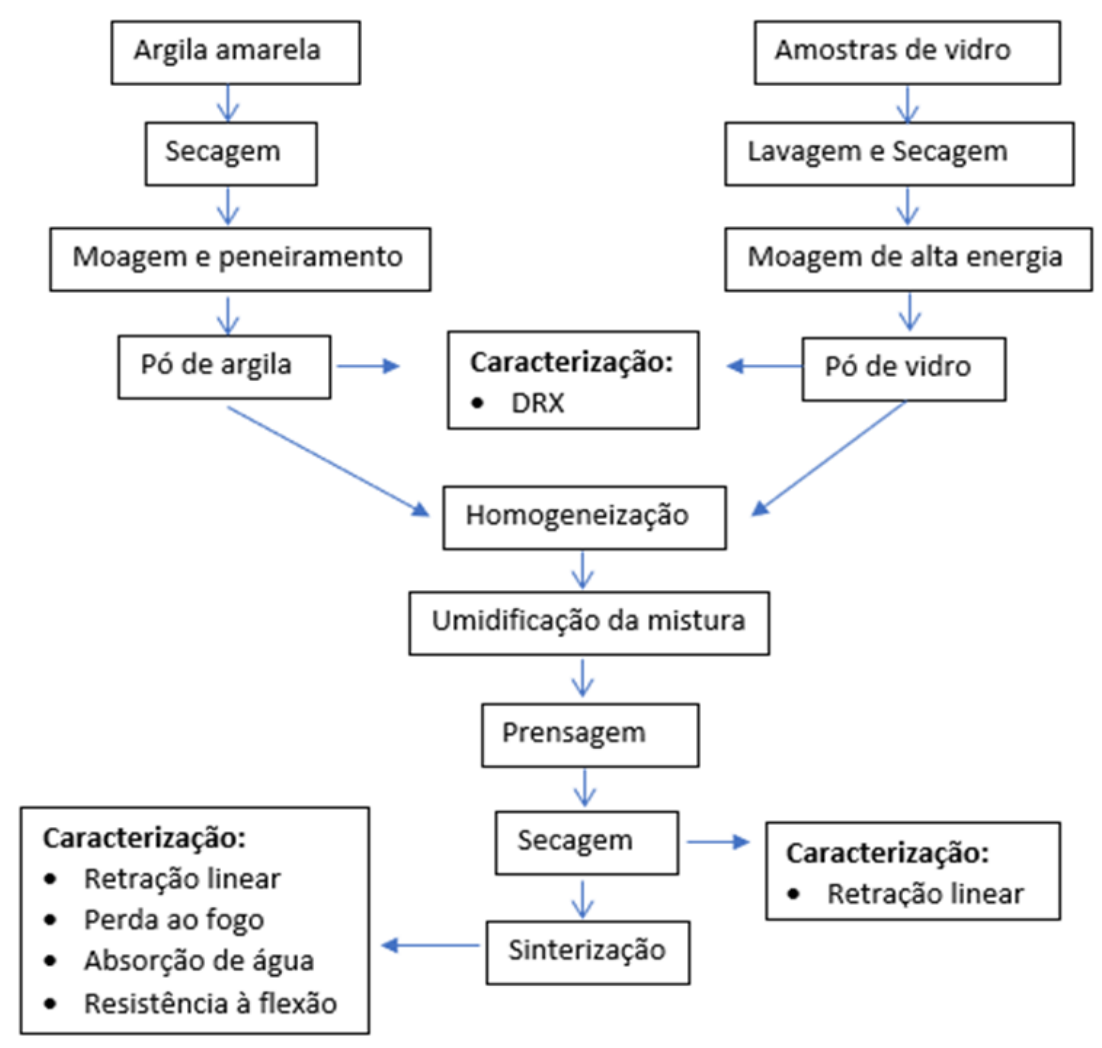

A argila foi seca, em estufa da marca Fanem modelo 515-C por 8 horas, passou pelo processo de cominuição em moinho tipo martelo da marca Tecnal modelo TE-330 e almofariz de porcelana, em seguida todo material foi peneirado.

O vidro foi lavado para retirada de impurezas e dos rótulos, depois foi fragmentado manualmente para ser cominuído no moinho de alta energia da marca Restsch do modelo PM100, com parâmetros de velocidade igual a 300 rpm e tempo total de moagem de 8 minutos com inversão de sentido ao atingir 4 minutos.

As análises de difração de raios $\mathrm{X}$ foram realizadas em difratômetro da marca Rigaku modelo MiniFlex II com radiação de $\mathrm{CuK} \alpha, 2 \theta$ variando de $5^{\circ}$ a $90^{\circ}$, passo angular de $0,02^{\circ}$ corrente de $15 \mathrm{~mA}$ e tensão de $30 \mathrm{kV}$.

Após o processo de obtenção da matéria-prima foram confeccionados corpos de prova de material cerâmico com a incorporação de 0 e $20 \%$ de resíduo de vidro em massa, sendo AR0 (argila pura) e AR20 (20\% de resíduo de vidro e $80 \%$ da argila amarela). Foram preparadas duas triplicatas para cada composição, resultando no total de 12 amostras, duas triplicatas com a composição AR0 e duas triplicatas com a composição AR20. 
Os corpos de prova foram conformados por intermédio de uma prensa hidráulica da marca Bovenau, o formato do corpo de prova utilizado no experimento foi de $120 \mathrm{~mm} x$ $30 \mathrm{~mm}$ x $5 \mathrm{~mm}$. A pressão de compactação realizada no processo de compactação foi de 2,5 t. Após a secagem, os corpos de prova foram submetidos ao processo de queima em forno mufla da marca Cienlab nas temperaturas de $1000^{\circ} \mathrm{C}$ e $1100^{\circ} \mathrm{C}$ por um período de 60 minutos para cada temperatura. As amostras foram caracterizadas quanto a retração linear, absorção de água e resistência à flexão.

\section{RESULTADOS E DISCUSSÃO}

A Figura 2 mostra os corpos de prova com a composição AR0 e AR20 após passar pelo processo de sinterização nas temperatuas de $1000^{\circ} \mathrm{C}$ e $1100^{\circ} \mathrm{C}$.

Figura 2- Corpos de prova sinterizados na temperatura de: (A) $1000^{\circ} \mathrm{C}$ e (B) $1100^{\circ} \mathrm{C}$.

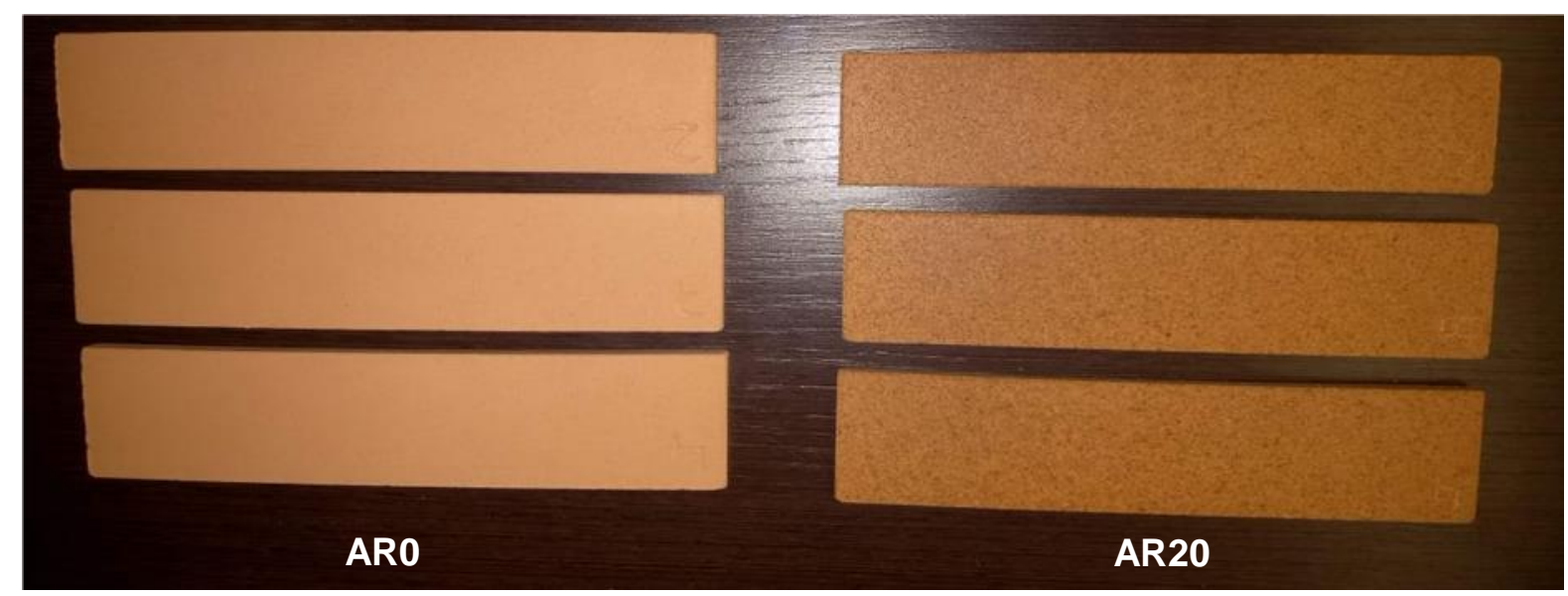

(A)

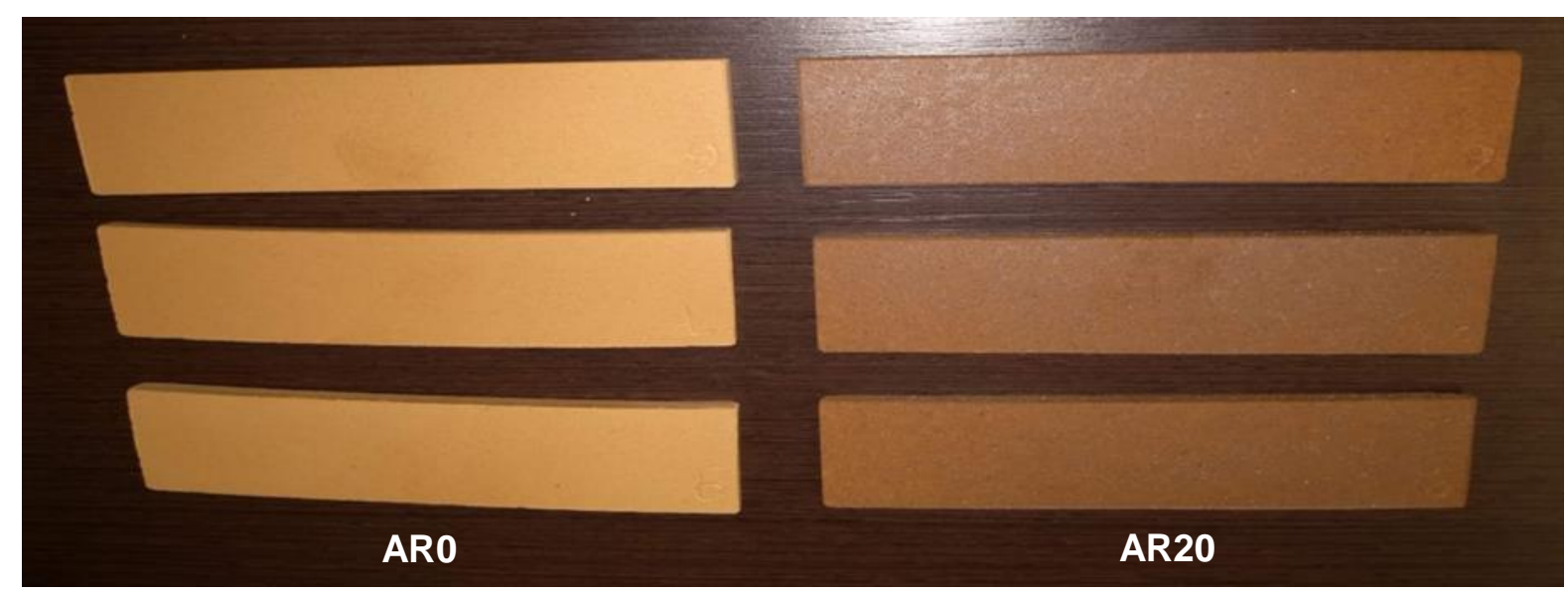

(B) 
As Figuras 3 e 4 mostram os difratogramas de raios $\mathrm{X}$ do resíduo de vidro e da argila amarela, respectivamente.

Na Figura 3 é possível perceber bandas de fase vítrea caracterizando-o como amorfo. Essa característica é adquirida pelo processo de resfriamento rápido para obtenção dos vidros.

Figura 3 - Difratograma de raios X do resíduo de vidro

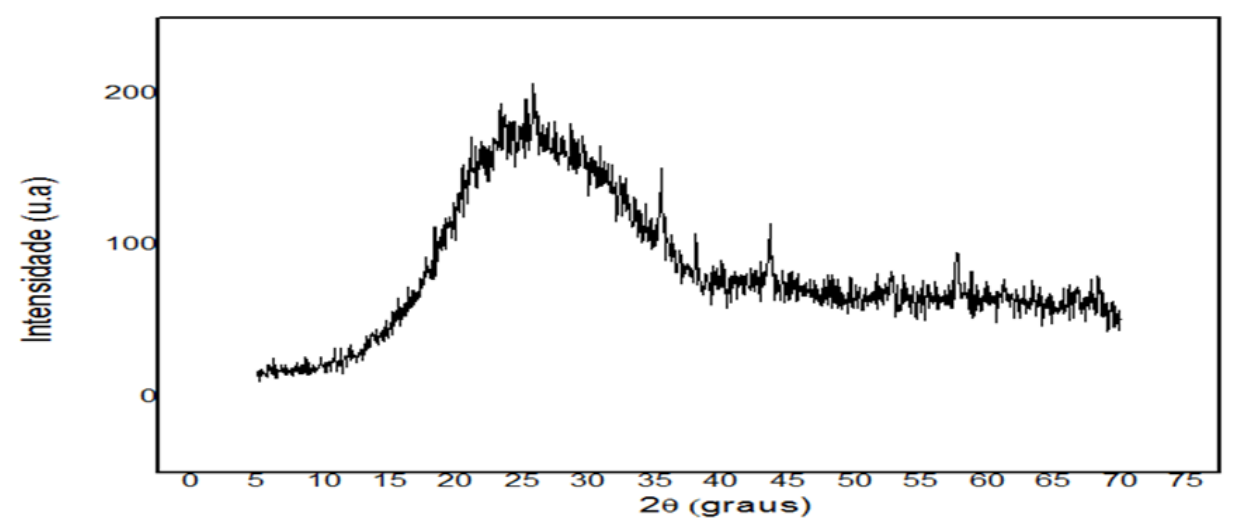

O difratograma da argila, ilustrado na Figura 4, revelaram a presença das reflexões características dos argilominerais caulinita $\left[\mathrm{Al}_{2}\left(\mathrm{Si}_{2} \mathrm{O}_{5}\right)(\mathrm{OH})_{4}\right]$, quartzo $\left(\mathrm{SiO}_{2}\right)$, feldspato sódico $\left[\mathrm{NaAl}\left(\mathrm{SiO}_{4}\right)\right]$, magnetita $\left(\mathrm{Fe}_{3} \mathrm{O}_{4}\right)$, microclínio ou feldspato potássico ( $\left.\mathrm{KAlSi}_{3} \mathrm{O}_{8}\right)$. O argilomineral com maior predominância nessa argila é caulinita, evidenciado pelos seus picos característicos bem intensos e de forma definida. A caulinita é o argilomineral mais abundante em argilas usadas para produtos cerâmicos, sendo a responsável pela plasticidade. Já o quartzo atua como componente não plástico. O feldspato sódico e potássico são fontes de óxidos alcalinos que atuam como fundentes no processo de sinterização (BUSH, 2016).

Figura 4 - Difratograma de raios X da argila amarela

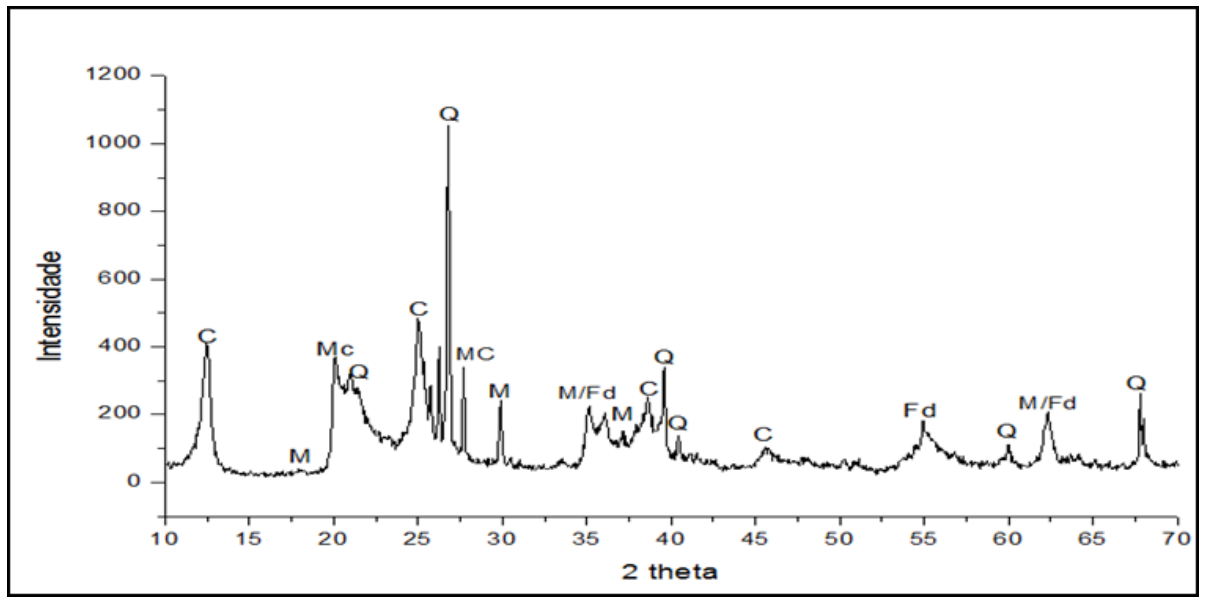


A Tabela 1 apresenta os valores de perda ao fogo, retração linear de secagem e de queima das amostras com a incorporação de 0 e $20 \%$ de resíduo, nas temperaturas de $1000^{\circ} \mathrm{C}$ e $1100^{\circ} \mathrm{C}$.

Tabela 1 - Propriedades de retração linear de secagem e queima, perda ao fogo.

\begin{tabular}{ccc}
\hline Experimento & \multicolumn{2}{c}{ Amostras } \\
\cline { 2 - 3 } & AR0 $(\%)$ & AR20 (\%) \\
\hline RL de secagem & $8,0 \pm 0,01$ & $6,4 \pm 0,03$ \\
RL de queima a $1000^{\circ} \mathrm{C}$ & $4,70 \pm 0,04$ & $8,70 \pm 0,18$ \\
RL de queima a $1100^{\circ} \mathrm{C}$ & $11,38 \pm 0,29$ & $10,97 \pm 0,09$ \\
Perda ao fogo a $1000^{\circ} \mathrm{C}$ & $14,21 \pm 0,07$ & $11,62 \pm 0,11$ \\
Perda ao fogo a $1100^{\circ} \mathrm{C}$ & $14,97 \pm 0,52$ & $11,75 \pm 0,12$ \\
\hline
\end{tabular}

Onde: AR0 (Argila pura); AR20 (Argila com a adição de 20\% de resíduo)

$\mathrm{Na}$ amostra com $20 \%$ de resíduo a retração linear de secagem é menor, pois as partículas do pó do vidro não absorvem água quanto a argila.

Segundo Caldas (2012), a retração linear de queima está associada com a composição da massa, densidade da peça prensada a seco e das condições de sinterização. $\mathrm{Na}$ Tabela 1, observa-se que o aumento da temperatura de sinterização aumentou a retração linear para as amostras AR0 e AR20. A incorporação de $20 \%$ de resíduo a $1000^{\circ} \mathrm{C}$ houve um aumento na retração linear, favorecida pela formação da fase líquida proveniente dos fundentes presentes na argila. Já nas amostras sinterizadas á $1100^{\circ} \mathrm{C}$ o processo de retração linear das amostras AR20 competem com a expansão causada pelas transformações de fase devido ao excesso de sílica na composição, mas estes valores de retração são semelhantes quando consideramos o desvio padrão.

A perda ao fogo diminuiu com a adição de $20 \%$ do resíduo de vidro comparado com a argila pura nas duas temperaturas de sinterização.

A Figura 5 apresenta a absorção de água das amostras após a sinterização Verificase que com a incorporação de $20 \%$ do resíduo de vidro ocorre uma redução na absorção de água de $25 \%$ a $10 \%$ para uma sinterização à $1000^{\circ} \mathrm{C}$ e com o aumento da temperatura de sinterização para $1100^{\circ} \mathrm{C}$ mostra uma diminuição no teor de absorção de água para valores próximo a $5 \%$, o que pode ser explicado pelo preenchimento dos poros durante a fusão 
com óxidos fundentes presentes na massa, ocasionando uma redução na porosidade (Oliveira, 2000).

Figura 5 - Absorção de água das amostras após a sinterização

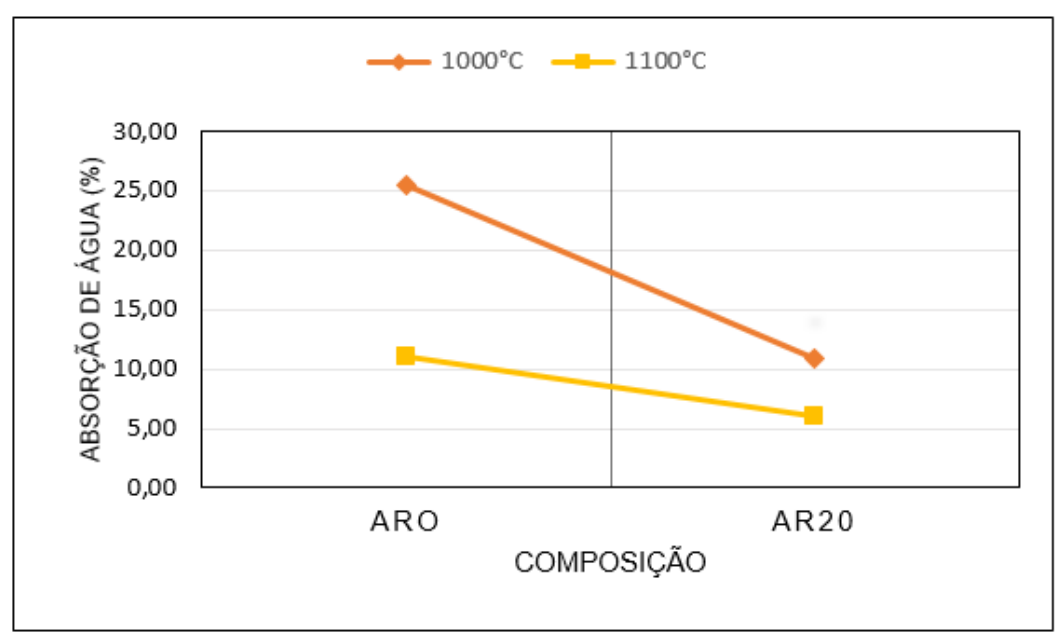

O melhor resultado foi obtido para amostra $\mathrm{AR} 20$ a $1100^{\circ} \mathrm{C}$ que se enquadra nas especificações conforme a norma NBR 13818 para piso do tipo semi-grês, grupo BIIa, com absorção de água entre 3,0 \% < AA $\leq 6,0 \%$. O resultado da amostra AR20 a $1000^{\circ} \mathrm{C}$ também se enquadra na norma, porém no grupo BIII com absorção de água AA $>10 \%$.

A Figura 6 apresenta a resistência mecânica à flexão das amostras. Observa-se um aumento nos valores de tensão de ruptura máxima com a adição do resíduo e com o incremento da temperatura. Os valores encontrados para as amostras sinterizadas a $1000^{\circ} \mathrm{C}$ foram de 3,98 MPa para amostra AR0 e 14,76 MPa para amostra AR20, as sinterizadas à $1100^{\circ} \mathrm{C}$ foram 13,02 MPa para amostra AR0 e 27,94 MPa para amostra AR20. Porém, apenas a amostra AR20 a $1100^{\circ} \mathrm{C}$ alcançou o valor exigido para cerâmica de revestimento estando dentro da especificação para piso semi-grês, grupo BIIa, com a tensão de ruptura $\geq 22 \mathrm{MPa}$. 
Figura 6- Tensão de ruptura á flexão das amostras

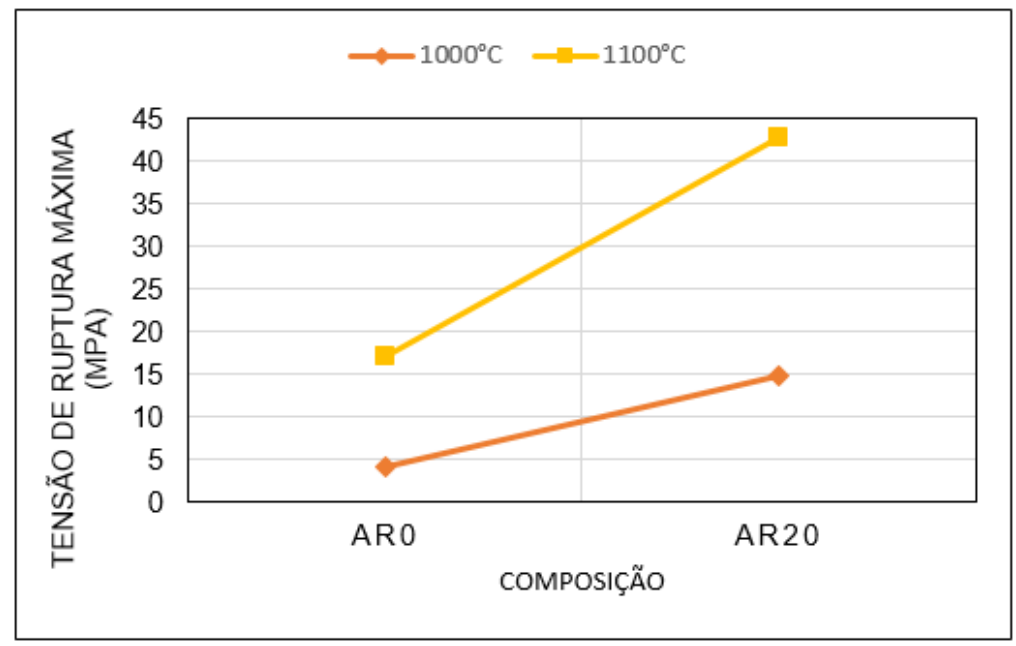

Segundo Andrade (2009), o aumento da tensão máxima de ruptura das amostras com incremento do vidro pode estar relacionado a presença de $\mathrm{CaO}, \mathrm{Na}_{2} \mathrm{O}$ e $\mathrm{MgO}$ nos resíduos vítreos (co4 nforme análise química) que se combinam com o quartzo, já que este se comporta como um "esqueleto" durante a formação da fase líquida, contribuindo para o aumento da resistência mecânica do material.

\section{CONCLUSÃO}

A adição de $20 \%$ do pó de vidro proveniente de garrafas de cerveja á argila amarela contribuiu para obtenção de uma cerâmica com melhores propriedades quando comparada à cerâmica obtida a partir da argila pura, utilizada como referência.

Os resultados obtidos no ensaio de absorção de água para amostra sinterizada a $1100^{\circ} \mathrm{C}$ estão em conformidade com as especificações da norma NBR 13818 para piso do tipo semi-grês, grupo BIIa, enquanto a amostra sinterizada a $1000^{\circ} \mathrm{C}$ apresenta propriedades que a classifica no grupo BIII, todavia, no ensaio de flexão apenas a amostra sinterizada a $1100^{\circ} \mathrm{C}$ alcançaram a resistencia exigida para cerâmica de revestimento, encontrando-se dentro da especificação para piso semi-grês, grupo BIIa.

Os resultados obtidos nesse trabalho mostram uma alternativa para a reciclagem do vidro de embalagens agregando-o como matéria-prima na indústria de revestimento cerâmico. 


\section{REFERÊNCIAS}

ANDRADE, F. L. F., VARELA, M. L.; DUTRA, R. P. S.; NASCIMENTO, R. M.; MELO, D. M. A.; PASKOCIMAS, C. A. Avaliação da potencialidade de uso do resíduo proveniente da indústria de beneficiamento do caulim na produção de piso cerâmico. Cerâmica Industrial, v, 14, jan/fev, p.41-47, 2009.

ASSOCIAÇÃO BRASILEIRA DE NORMAS TÉCNICAS, NBR 13818, Placas Cerâmicas - Especificações e Métodos de Ensaios. Rio de Janeiro ,1997.

ASSOCIAÇÃO NACIONAL DOS FABRICANTES DE CERÂMICA PARA REVESTIMENTOS, LOUÇAS SANITÁRIAS E CONGÊNERES, ANFACER, https://www.anfacer.org.br/numeros-do-setor. Acesso em 12/08/2020.

BIFF, S.; SILVA, M.R. Uso do resíduo sólido proveniente do processo de beneficiamento de areia na indústria de revestimentos cerâmicos e sua influência nas propriedades físicas dos produtos cerâmicos. Revista Matéria, Rio de Janeiro v.21, n.4, pp. 853- 865, 2016

BUSCH, P. F. Efeito da incorporação de resíduo de processamento de lapidação de vidro sodo-cálcicos nas propriedades físicas e mecânicas de cerâmica vermelha. 2016. 97 f. Dissertação (Mestrado em Engenharia e Ciências de Materiais) - Centro de Ciência e Tecnologia, Universidade Estadual do Norte Fluminense Darcy Ribeiro, Campos dos Goytacazes, Rio de Janeiro, 2016. Cap. 1 e 4.

CALDAS, T. C. C. Reciclagem de resíduo de vidro plano em cerâmica vermelha. 2012. 89 f. Dissertação (Mestrado) - Curso de Engenharia e Ciência dos Materiais, Centro de 58 Ciência e Tecnologia, Universidade Estadual do Norte Fluminense Darcy Ribeiro, Campos dos Goytacazes, 2012. Cap. 3.

CEMPRE, compromisso empresarial para reciclagem. Fichas técnicas. Disponível em: http://cempre.org.br/artigo-publicacao/ficha-tecnica/id/6/vidro. Acesso em: 12/08/2020.

GODINHO, K.O., RABELO, T.R., HOLANDA, J.N.F., et al. Incorporação de resíduo de vidro em cerâmica vermelha, In: Anais do $48^{\circ}$ Congresso Brasileiro de Cerâmica. p.110, Curitiba, PR, Julho, 2004.

OLIVEIRA, I. R.; STUDART, A. R.; PILEGGI; R. G.; PANDOLFELLI. V. C. Dispersão e empacotamento de partículas - princípios e aplicações em processamento cerâmico. São Paulo: Fazendo Arte Editorial, 2000.

TRENTIN, P. O.; MANICA, J.; VANZETTO, S. C., et al. Substituição parcial de agregado miúdo por resíduo de vidro moído na produção de argamassa. Revista Matéria, Rio de Janeiro v.25, n.1, 2020

ZACCARON, A.; FRIZZO, R.G.; ZANONI, E.T; et al. Efeito da adição de resíduo de vidro em massa de cerâmica de alvenaria. Revista Matéria, Rio de Janeiro v.24, n.4, 2019. 


\section{ESTUDO DAS PROPRIEDADES TÉRMICAS E DA INTERAÇÃO COM A ÁGUA NAS BLENDAS DE AMIDO/PBAT E AMIDO/PBAT/PLA}

\section{Amanda de Sousa Martinez de Freitas}

Federal University of São Paulo (UNIFESP), São José dos Campos, SP http://lattes.cnpq.br/9739345065523926

\section{Ana Paula da Silva}

Federal University of São Paulo (UNIFESP), São José dos Campos, SP http://lattes.cnpq.br/8719042515485740

\section{Cristiane Carla Maciel}

Institute of Science and Technology, São Paulo State University (UNESP), Sorocaba, SP http://lattes.cnpq.br/8846411014725252

\section{Iury Araújo Nogueira}

Federal University of São Paulo (UNIFESP), São José dos Campos, SP http://lattes.cnpq.br/1610547731540507

\section{Ana Paula Lemes}

Federal University of São Paulo (UNIFESP), São José dos Campos, SP http://lattes.cnpq.br/4529102387970131

\section{Informações sobre o}

artigo:

\section{Recebido em:}

$21 / 08 / 2020$

Aceito em:

$24 / 08 / 2020$

Data de publicação:

$23 / 10 / 2020$

Palavras-chave:

Polímeros

biodegradáveis

Molhabilidade

Solubilidade

DCS e fotodegradação

\section{RESUMO}

Blendas de amido plastificado com outros polímeros biodegradáveis foram preparadas visando obter materiais de fácil biodegradação, com melhores propriedades mecânicas e de processamento, em relação ao amido. $\mathrm{O}$ presente trabalho preparou blendas $70: 30 \mathrm{~m} / \mathrm{m}$ de amido/PBAT e $70: 15: 15 \mathrm{~m} / \mathrm{m}$ amido/PBAT/PLA. As análises de DSC, mostraram que as blendas eram imiscíveis; porém o amido apresentou interação com as cadeias PBAT, onde foi observada diminuição na temperatura de fusão do amido na blenda de amido/PBAT e na blenda de amido/PBAT. Em ambas as blendas foi possível verificar um decréscimo na quantidade de material solubilizado e na capacidade de absorver água em relação ao amido plastificado puro. $\mathrm{O}$ amido e as blendas (amido/PBAT/PLA e amido/PBAT) apresentaram decaimento de ângulo de contato de 57; 25,6 e 30\%, respectivamente, comparando a análise inicial com a medição da gota após 5 minutos. Também foi observada uma diminuição da molhabilidade em relação ao PBAT e ao PBAT/PLA puros, de 8 e 5,37\% após 5 minutos de permanência da gota, apresentando caráter mais hidrofóbico em relação as amostras de amido puro e nas blendas. O ângulo de contato também foi analisado após a exposição das blendas a fotodegradação por 144 horas, onde foi possível observar um caráter mais hidrofílico após a degradação. 


\section{STUDY OF THERMAL PROPERTIES AND INTERACTION WITH WATER IN THE BLENDS OF STARCH/PBAT AND STARCH/PBAT/PLA}

\section{ABSTRACT}

Blends of plasticized starch with other biodegradable polymers were prepared in order to obtain materials of easy biodegradation, with better mechanical and processing properties, in relation to starch. For this, blends of 70:30 w/w of starch/PBAT and 70:15:15 w/w of starch/PBAT/PLA were prepared. DSC analyzes showed that the blends were immiscible; however, the starch showed interaction with the PBAT chains, where a decrease in the starch melting temperature was observed in the starch blend/PBAT and in the starch blend/PBAT. In both blends, it was possible to verify a decrease in the amount of solubilized material and in the ability to absorb water in relation to pure plasticized starch. Starch and blends (starch/PBAT/PLA and starch/PBAT) showed a decay of contact angle of $57 ; 25.6$ and 30\%, respectively, comparing the initial analysis with gout measurement after 5 minutes. It was also observed a decrease in wettability in relation to pure PBAT and PBAT/PLA, of 8 and $5.37 \%$ after 5 minutes of permanence of the drop, presenting a more hydrophobic character in relation to pure starch samples and blends. The contact angle was also analyzed after the blends were exposed to photodegradation for 144 hours, where it was possible to observe a more hydrophilic character after the degradation.

\section{INTRODUCTION}

Starch is a polysaccharide that can be obtained from several natural and renewable sources, in addition to having a low cost. Despite its biodegradability and potential use for packaging production, films produced using only granular starch present high fragility and low mechanical properties, due to the presence of hydrogen bonds in its structure (REN et ali., 2009; ZULLO et al., 2009). The existence of these connections makes it difficult to process the starch, due to the high temperature required for its fusion, $220-240^{\circ} \mathrm{C}$. In order to obtain a starch with better processability, plasticizers are commonly used, which act to break the bonds between the starch macromolecules, originating the thermoplastic starch which presents high flexibility and greater processing ease. The main plasticizers are polyols, such as glycerol and sorbitol. These plasticizers have a hydrophilic nature, which makes the films produced susceptible to the action of the environment, such as moisture, directly impacting their resistance to water vapor permeation (ZULLO et al., 2009; DA RÓZ et ali., 2006). 
To circumvent this problem, the production of blends with other biodegradable polymers has been studied, in order to obtain a material with better mechanical properties and processing, in addition to improving stability against moisture. The poly (butylene adipate co-terefatalate) - PBAT, is a synthetic and hydrophobic biodegradable copolyester, which has high flexibility and mechanical properties like those of polyethylene, being commonly used in blends with biopolymers to enhance its mechanical properties and resistance to water vapor permeation due to the presence of hydrogen bonds in its structure (REN et ali., 2009; BRANDELERO et ali., 2011; PAN et ali., 2016). Another possible blend is that with poly (lactic acid) - PLA, a natural, hydrophobic and biodegradable polyester, which has good processability and mechanical properties (MULLER et ali., 2017). Blends of starch using PBAT and PLA have the potential to improve the mechanical properties and stability of starch. In addition, they promote the use of low-cost raw materials obtained from natural sources, thus reducing the environmental impact caused (PAN et ali., 2016; SHIRAI et ali, 2013).

This study aimed to prepare blends of thermoplastic starch, with PBAT and PLA, and to compare the properties of the blends compared to pure source materials, in terms of interaction with water and thermal properties.

\section{METHODOLOGY}

\subsection{Materials}

The materials used were, potato starch, soluble, of the Dinâmica brand, minimum content of 85\%; Glycerin PA (Glycerol) of the Dinâmica brand; Deionized water; ECOFLEX ${ }^{\circledR}$ BASF copolyester of poly (butylene adipate co-terefatalate) - PBAT. ECOVIO® BASF blend composed of 45\% PBAT and 55\% PLA poly (lactic acid).

\subsection{Methods}

To produce plasticized starch, a concentrated solution was prepared with $30 \mathrm{~g}$ of starch, $110 \mathrm{~g}$ of water and $10 \mathrm{~g}$ of glycerol, under constant stirring and heating to approximately $80{ }^{\circ} \mathrm{C}$. The highly viscous solution was divided into Falcon tubes and frozen 
for $24 \mathrm{~h}$, afterwards the material was lyophilized, producing granulated plasticized starch (Figure 1). The PBAT and PBAT/PLA samples were used as purchased.

Figure 1 - Schematic of the granular plasticized starch process.

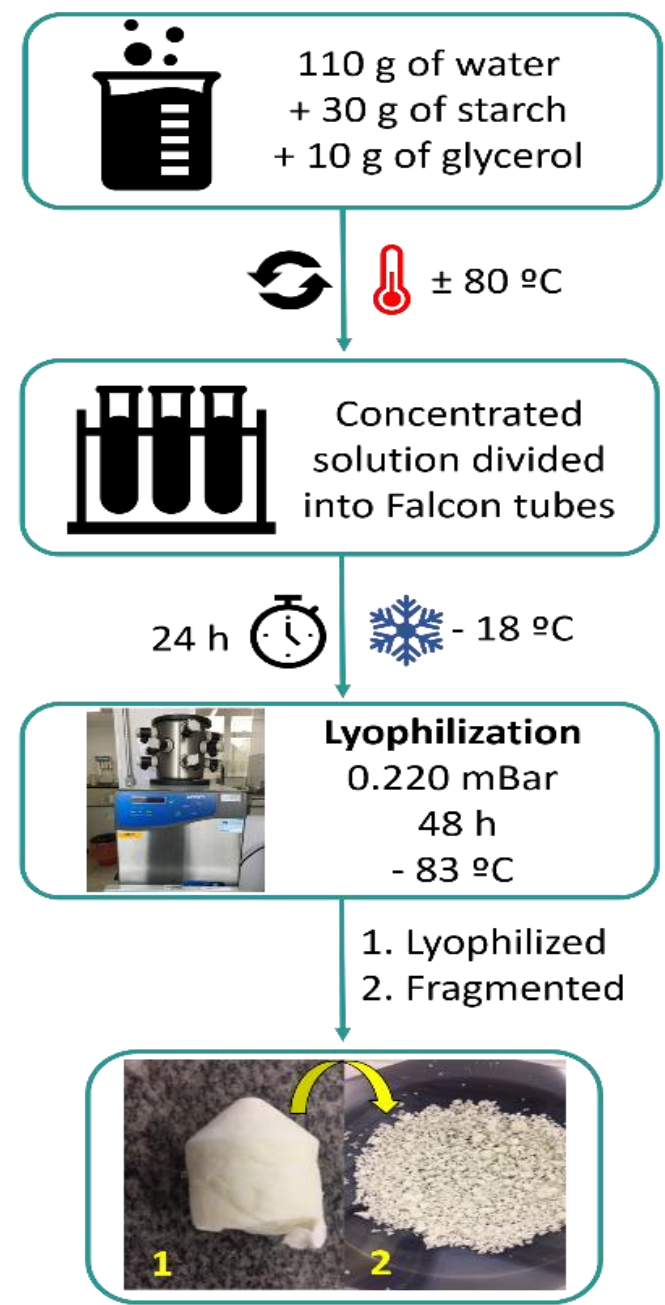

The materials were dried in an oven and passed individually in a homogenizer followed by hot molding in a hydraulic press, with a temperature of $190^{\circ} \mathrm{C}$. The same process was repeated for the 70:30 w/w blends of starch/PBAT and 70:15:15 of starch/PBAT/PLA (Figure 2). 
Figure 2 - Schematic of materials processing.

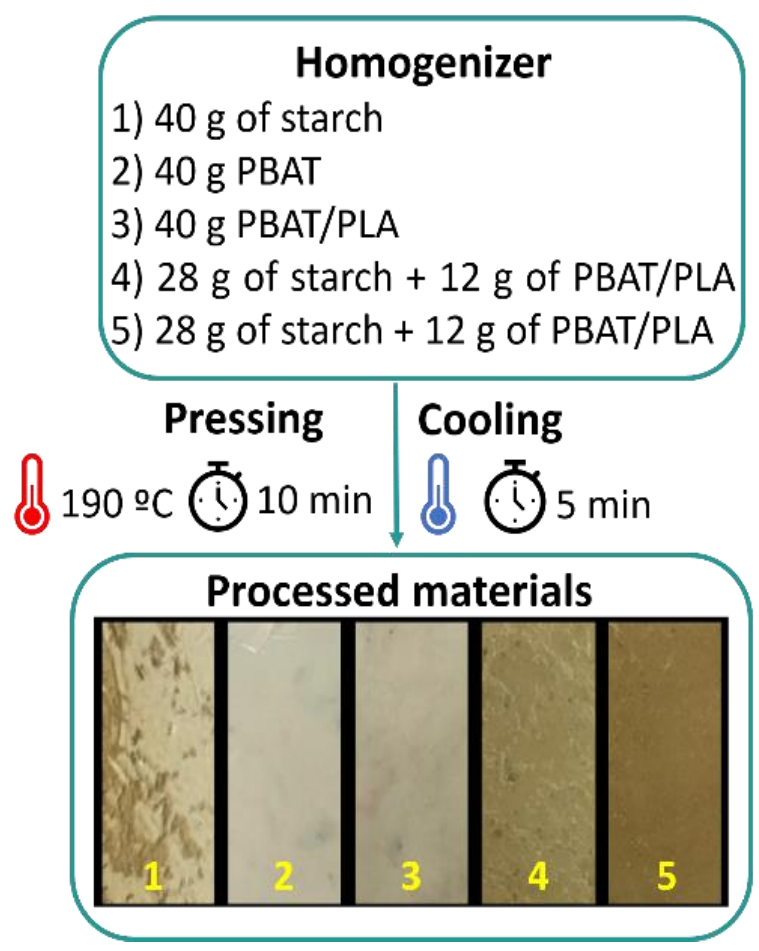

The thermal proprieties of samples were characterized by Differential Scanning Calorimetry (DSC) on a Netzsch Phoenix DSC 204 F1. The samples were heated from room temperature to $240{ }^{\circ} \mathrm{C}$ to $10{ }^{\circ} \mathrm{C} \mathrm{min}^{-1}$ in a sealed aluminum DSC pan, under nitrogen atmosphere with a flow rate of $20 \mathrm{~mL} \cdot \mathrm{min}^{-1}$. The thickness measurements were performed with a digital micrometer, from 5 readings from different areas. To determine the water absorption, 3 discs with $2 \mathrm{~cm}$ in diameter were cut and weighed, each sample was immersed in $50 \mathrm{~mL}$ of deionized water and kept for 48 hours under slight agitation at room temperature and weighed. Subsequently to determine the solubilized dry material, the same samples were dried in an oven for 1 hour at $100{ }^{\circ} \mathrm{C}$ and weighed after being at room temperature. For the analysis of the wettability of the materials, the contact angle was measured by the sessile drop method, using the Ramé-Hart goniometer, model 250 Standard. The photodegradation of the samples was performed by exposure to UV-C ultraviolet light, which, being the most energetic, accelerated the aging of the samples during 144 hours of exposure. 


\section{RESULTS AND DISCUSSIONS}

The plates had an average thickness of $1.20272 \pm 0.05097 \mathrm{~mm}$, Table 1 , showing that there was no great variation in thickness between the points on the plate itself, being a uniform pressing that generated plates of homogeneous thickness.

Table 1 - Percentage of solubilized dry material absorbed water and average thickness of the samples.

\begin{tabular}{lccc}
\cline { 2 - 4 } & $\begin{array}{c}\text { Solubilized Dry } \\
\text { Material (\%) }\end{array}$ & $\begin{array}{c}\text { Absorbed Water } \\
\mathbf{( \% )}\end{array}$ & Average Thickness (mm) \\
\hline Starch & 39,54 & 223,44 & $1.39 \pm 0.05$ \\
Starch/PBAT/PLA & 32,80 & 54,31 & $1.25 \pm 0.04$ \\
Starch/PBAT & 27,60 & 46,27 & $1.16 \pm 0.07$ \\
PBAT/PLA & 1,67 & 47,16 & $1.09 \pm 0.07$ \\
PBAT & 0,18 & 44,78 & $1.16 \pm 0.07$ \\
\hline & - & - & $\mathbf{1 . 2 0} \pm \mathbf{0 . 0 5}$ \\
\hline
\end{tabular}

Being that the thermoplastic starch had the highest thickness value among all the compositions, since the starch after processed presented high viscosity and rigidity, making it difficult to fill the mold. The films of PBAT/PLA and PBAT had a thickness less than that of thermoplastic starch because polyesters result in films with greater flexibility, a behavior also observed for the Starch/PBAT and Starch/PBAT/PLA blends due to the contribution of PBAT and PLA, thus easing the stiffness of starch films, as also observed in other study (RENATA et ali., 2011).

Despite the apparent homogeneity, DSC analyzes showed that the mixtures were immiscible. The polymers and blends were subjected to Differential Scanning Calorimetry analysis to determine the melting behavior (Figure 3). 
Figure 3 - DSC curves of the first heating: Starch, PBAT and starch/PBAT (70:30 w/w) blend and Starch, PBAT/PLA and starch/PBAT/PLA (70:15:15 w/w) blend.
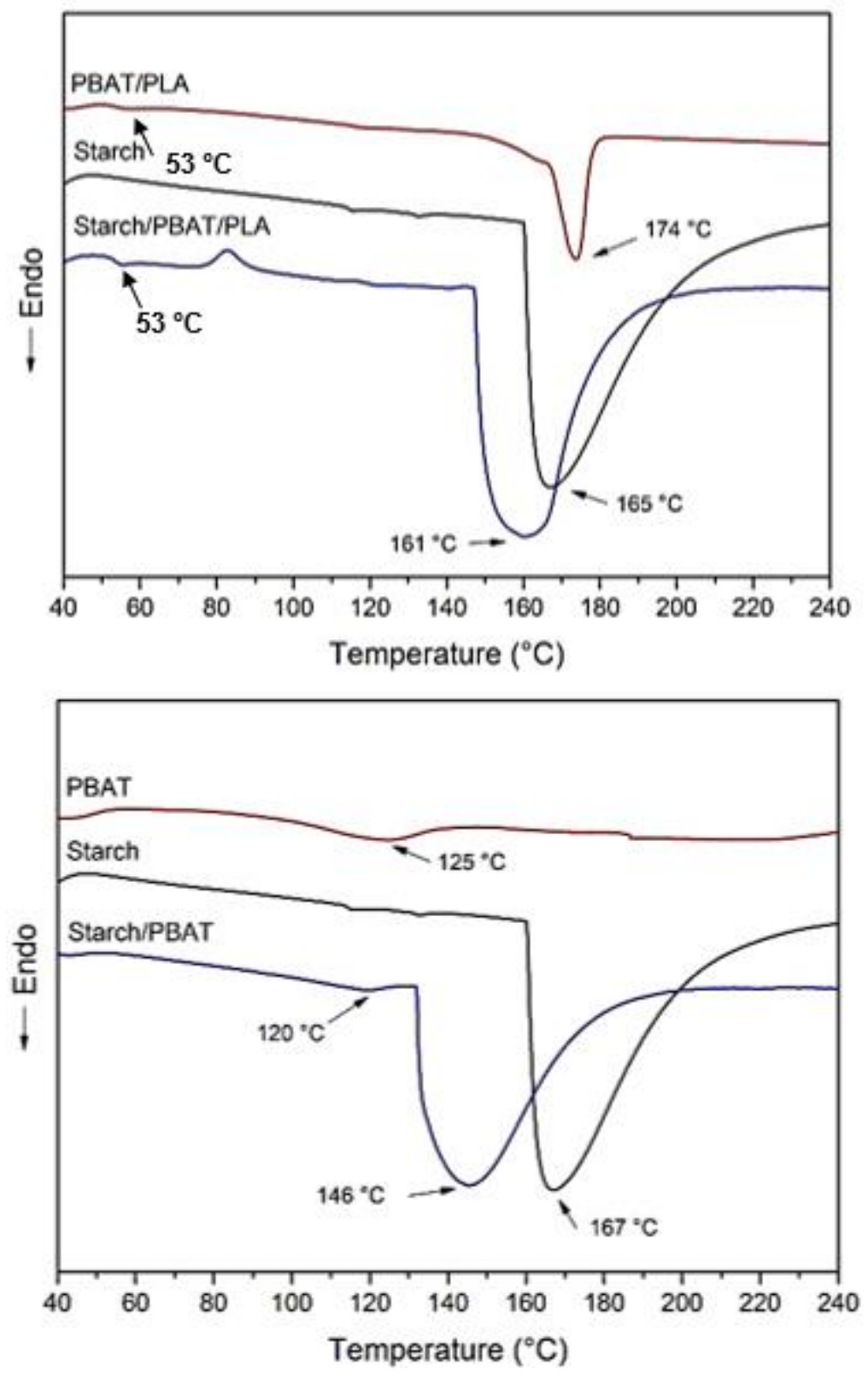

The glass transition temperature ( $\mathrm{Tg}$ ), cold crystallization temperature (Tcc) and melting temperature $(\mathrm{Tm})$ values obtained in the first heating scans are shown in the Table 2. 
Table 2 - Values of transition temperature (Tg), cold crystallization temperature (Tcc) and melting temperature (Tm) determined by DSC analysis of the polymers and blends Starch/PBAT (70:30 w/w) e Starch/PBAT/PLA (70:15:15 w/w).

\begin{tabular}{lcccc}
\cline { 2 - 5 } & $\operatorname{Tg}\left({ }^{\circ} \mathbf{C}\right)$ & $\operatorname{Tcc}\left({ }^{\circ} \mathbf{C}\right)$ & $\operatorname{Tm}\left({ }^{\circ} \mathbf{C}\right)$ & $\operatorname{Tm}_{2}\left({ }^{\circ} \mathbf{C}\right)$ \\
\hline Starch & - & - & 167 & - \\
PBAT & - & - & 125 & - \\
PBAT/PLA & 53 & - & 174 & - \\
Starch/ PBAT & - & - & 120 & 146 \\
Starch/PBAT/PLA & 53 & 83 & 161 & - \\
\hline
\end{tabular}

As can be seen in Table 2 the starch showed its Tm in $167^{\circ} \mathrm{C}$, PBAT in $125^{\circ} \mathrm{C}$ and PBAT/PLA in $174{ }^{\circ} \mathrm{C}$, similar values have been observed in literature (CORRADINI et ali., 2007; MATOS et ali., 2019). The starch/PBAT blend present two melting temperature values, corresponding to each polymer. The melting temperature of each polymer in the starch/PBAT blend had a small shift in the DSC curve, the Tm for starch $\left(146^{\circ} \mathrm{C}\right)$ decreased by $21^{\circ} \mathrm{C}$ and the $\mathrm{Tm}$ for PBAT $\left(120^{\circ} \mathrm{C}\right)$ decreased by $5{ }^{\circ} \mathrm{C}$. The significant decrease in the melting temperature value of starch can be due to defects in the crystals because to the influence of the interaction between PBAT chains and starch chains, even though the blend is immiscible.

A glass transition temperature $(\mathrm{Tg})$ value of $53{ }^{\circ} \mathrm{C}$ was observed in the starch/ PBAT/PLA blend, whose this value belong to PLA present in the PBAT/PLA blend, confirming that the blend is immiscible (DECOL et ali., 2019; GERARD et ali., 2014; HESAMI et ali., 2017). The polymers of starch/PBAT/PLA blend exhibited the same range of Tm values, which in the blend causes the values to overlap and thus a single Tm value at $161^{\circ} \mathrm{C}$

However, a small displacement at the peak and a decrease in the Tm value of the blend can be observed in comparison with the Tm values of the polymers. This decrease can be due to the interaction between PBAT chains (present in the PBAT/PLA blend) and starch chains, which can cause defects in starch crystals and thus decrease the Tm range of the starch/PBAT/PLA blend.

As the interaction of starch with PLA is less, the peak has a smaller displacement when compared to the displacement observed in the DSC curve of the starch/PBAT blend. However, the starch chains influences in the formation of the crystals of the PLA that present a cold crystallization, thus appearing the peak of cold crystallization temperature (Tcc) at $83^{\circ} \mathrm{C}$ in the curve of the starch/PBAT/PLA blend that belongs to the PLA (LI et ali., 2007; QUERO et ali., 2012). 
To evaluate the interaction of processed materials with water, the percentage of solubilized dry material (\%SDM) was calculated, according to Equation 1 (GONTARD et al., 1992):

$$
\% \mathbf{S D M}=\frac{\mathrm{IM}-\mathrm{MD}}{\mathrm{IM}} \times \mathbf{1 0 0} \%(1)
$$

Where: $\mathrm{IM}=$ Initial mass and $\mathrm{MD}=$ Mass of dry material after solubilization. The percentage of water absorbed (\%WA) by the samples was also calculated, using Equation 2:

$$
\% \boldsymbol{W A}=\frac{(\boldsymbol{W} \boldsymbol{M}-\boldsymbol{I} \boldsymbol{M})}{\boldsymbol{I} \boldsymbol{M}} \times \mathbf{1 0 0} \%(2)
$$

Where: $\mathrm{WM}=$ Wet sample mass and IM = Initial mass. The calculated values (Table 1) are shown that the thermoplastic starch showed the highest percentage of solubilized material and absorbed water. The result was already expected due to the hydrophilic nature of the starch and plasticizer used, originated by the presence of $\mathrm{OH}$ groups in the structure of the materials, which enable the formation of hydrogen bonds with water. The PBAT and PBAT/PLA polymers exhibited much lower percentages of solubility and water absorption when compared to thermoplastic starch, since both polymers are hydrophobic in nature. In both blends it was possible to verify a decrease in the amount of solubilized material in relation to the pure plasticized starch, demonstrating the efficiency of the chosen polymers in decreasing the water solubility due to the hydrophobic character of both PBAT and PLA. The manufacture of blends considerably decreased the ability of thermoplastic starch to absorb water, as also observed in PBAT composites with starch nanoparticles study (DA SILVA et al., 2017).

The analysis of the wettability shows the contact angle value for each sample, with the measurement at the exact moment that the drop is dripped ( 0 min) and after $5 \mathrm{~min}$ in that the drop was dripped, (Figure 4).

Figure 4. Analysis of contact angle to the samples measurement at the exact moment that the drop is dripped (0 min) and after $5 \mathrm{~min}$ in that the drop was dripped: (A) Starch, (B) PBAT, (C) PBAT/PLA, (D) Starch/PBAT/PLA (70:15:15 w/w) and (E) Starch/PBAT(70:30 w/w).
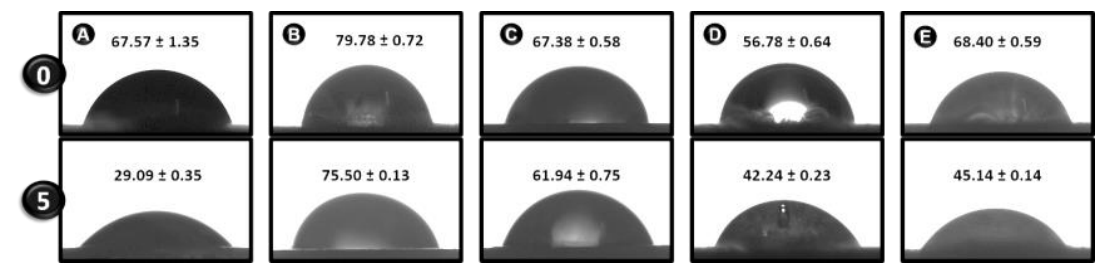

The mean values and their respective standard deviations from the contact angle analysis show significant differences between the samples. Starch (Figure 4 A) has a value of 
$67.57^{\circ}$ at the first moment, and after 5 minutes of rest the drop presents almost half of the initial value, $29.09^{\circ}$, this behavior reveals a material with hydrophilic behavior. The samples of the commercial polymers PBAT/PLA and PBAT (Figure $4 \mathrm{~B}$ and $\mathrm{C}$ ), have a more hydrophobic behavior, considering that after the 5 minutes of rest, the polymers did not show great variation in the contact angle, that is, the $67.38^{\circ}$ PBAT/PLA went to $61.94^{\circ}$, while the $79.78^{\circ}$ PBAT went to $75.50^{\circ}$.

The introduction of thermoplastic starch in commercial polymers allowed a more hydrophilic surface, changing the behavior of the angles in relation to the resting time (LUCHESE et ali., 2018). At first the contact angle of the Amido/PBAT/PLA and Amido/PBAT blends, Figure $4 \mathrm{D}$ and E respectively, showed a decrease in the angle compared to pure commercial polymers. After 5 minutes of rest, the Starch/PBAT/PLA blend decayed from $56.78^{\circ}$ to $42.24^{\circ}$ and the Starch/ PBAT blend from $68.40^{\circ}$ to $45.14^{\circ}$, it was possible to verify that the processing of the commercial polymers with thermoplastic starch showed good interaction between the materials, verified through the behavior of the angle and their behaviors according to the drop time of the drop, the hydrophilic nature is due to the starch and plasticizer used that have $\mathrm{OH}$ groups in their structures, which allow the formation of hydrogen bonds (GUPTA et ali., 2019).

The analysis of the contact angle was also performed for the samples after the interval of 144 hours of exposure to UV-C light, the results obtained are shown in figure 5.

Figure 5 - Analysis of the measured contact angle of the samples with variation in the light exposure intervals of 0 and 144 hours for samples of: starch, PBAT, PBAT/PLA and samples of starch/PBAT (70:30 w/w), starch/PBAT/PLA (70:15:15 w/w)

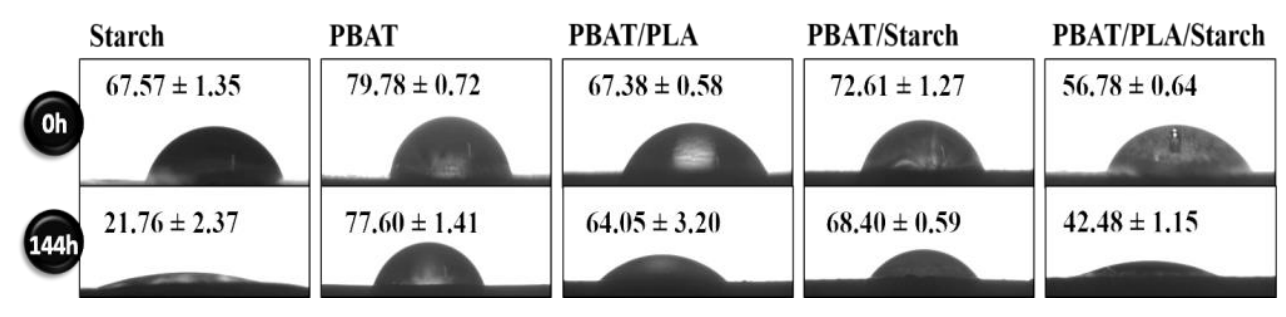

With the exposure of the samples to photodegradation it was possible to observe that all surfaces become more hydrophilic, this result was more pronounced for the starch samples and their blends This observed behavior was attributed to the formation of polar groups during the photodegradation process, which decrease the surface energy and provide places for intermolecular interaction with water by hydrogen bonds (CACURO et ali., 2018). 


\section{CONCLUSION}

The decrease in Tm of starch in the starch/PBAT and starch/PBAT/PLA blends revealed that, although the blends are immiscible, the starch has a good interaction with the PBAT in the two blends. It is also observed a decrease in the amount of solubilized material and in the water absorption capacity in both blends in relation to pure plasticized starch. Starch and blends showed a decrease in the value of the contact angle in relation to the instant analysis of the drop and after 5 minutes of contact with the surface, in addition to a reduction in wettability in relation to PBAT and pure PBAT/PLA. The photodegradation of the samples also significantly altered the surface wettability of the samples, which in general became more hydrophilic.

\section{ACKNOWLEDGMENTS}

This study was financed in part by the Coordenação de Aperfeiçoamento de Pessoal de Nivel Superior - Brasil (CAPES) - Finance Code 001.

\section{REFERENCES}

BRANDELERO R. P. H.; GROSSMANN M. V. E.; YAMASHITA F. Effect of the method of production of the blends on mechanical and structural properties of biodegradable starch films produced by blown extrusion. Carbohydrate Polymers, 86, 1344-1350, 2011.

CACURO T.; FREITAS, A.S.M.; WALDMAN W.R. Demonstration of Polymer Photodegradation using a simple apparatus. Journal of Chemical Education, 22, 22222226, 2018.

CORRADINI, E.; DE CARVALHO, A. J. F.; CURVELO, A. A. DA S.; AGNELLI, J. A. M.; MATTOSO, L. H. C. Preparation and characterization of thermoplastic starch/zein blends. Materials Research, 10(3), 227-231, 2007.

DA RÓZ, A. L.; CARVALHO, A. J. F.; GANDINI, A.; CURVELO, A. A. S. The effect of plasticizers on thermoplastic starch compositions obtained by melt processing. Carbohydrate Polymers, 63(3), 417-424, 2006.

DA SILVA, N. M. C.; CORREIA, P. R. C.; DRUZIAN, J. I.; FAKHOURI, F. M.; FIALHO, R. L. L.; DE ALBUQUERQUE, E. C. M. C. PBAT/TPS Composite Films Reinforced with Starch Nanoparticles Produced by Ultrasound. International Journal of Polymer Science, 10, 2017. 
DECOL, M.; PACHEKOSKI, W. M.; BECKER, D. Enhancing thermal conductivity and near-infrared radiation reflectance of poly( $\varepsilon$-caprolactone)/poly (lactic acid)-based nanocomposites by incorporating hexagonal boron nitride. Polymer Composites, 40(9), 3464-3471, 2019.

GERARD, T.; BUDTOVA, T.; PODSHIVALOV, A.; BRONNIKOV, S. Polylactide/poly(hydroxybutyrate-co-hydroxyvalerate) blends: Morphology and mechanical properties. Express Polymer Letters, 8(8), 609-617, 2014.

GONTARD, N.; GUILBERT, S.; CUQ, J. -L. Edible Wheat Gluten Films: Influence of the Main Process Variables on Film Properties using Response Surface Methodology. Journal of Food Science, 57(1), 190-195, 1992.

GUPTA, H.; KUMAR, H.; KUMAR, M.; GEHLAUT, A. K.; GAUR, A.; SACHAN, S.; PARK, J.-W. Synthesis of biodegradable films obtained from rice husk and sugarcane bagasse to be used as food packaging material. Environmental Engineering Research, 25(4), 506-514, 2019.

HESAMI, M.; JALALI-ARANI, A. Cold crystallization behavior of poly (lactic acid) in its blend with acrylic rubber; the effect of acrylic rubber content. Polymer International. 66, 1564-1571, 2017.

LI, H.; HUNEAULT, M. A. Effect of nucleation and plasticization on the crystallization of poly (lactic acid). Polymer, 48(23), 6855-6866, 2007.

LUCHESE, C. L.; BENELLI, P.; SPADA, J. C.; TESSARO, I. C. Impact of the starch source on the physicochemical properties and biodegradability of different starch-based films. Journal of Applied Polymer Science, 135(33), 1-11, 2018.

MATOS COSTA, A. R.; NORYUKI ITO, E.; CAVALHO, L. H.; CANEDO, E. L. Nonisothermal melt crystallization kinetics of poly(3-hydroxybutyrate), poly (butylene adipateco-terephthalate) and its mixture. Polímeros, 29(1), 1-16, 2019.

MULLER, J.; GONZÁLEZ-MARTÍNEZ, C.; CHIRALT, A. Combination of Poly(lactic) acid and starch for biodegradable food packaging. Materials, 10(8), 1-22, 2017.

PAN, H.; JU, D.; ZHAO, Y.; WANG, Z.; YANG, H.; ZHANG, H.; DONG, L. Mechanical properties, hydrophobic properties and thermal stability of the biodegradable poly (butylene adipate-co-terephthalate)/maleated thermoplastic starch blown films. Fibers and Polymers, 17(10), 1540-1549, 2016.

Polymers, B., \& Information, P. Ecovio ${ }^{\circledR}$ T2308 - Biodegradable compound for compostable films or sheets with high biobased content. Biodegradable Polymers. February 1-4, 2019.

QUERO, E.; MÜLLER, A. J.; SIGNORI, F.; COLTELLI, M. B.; BRONCO, S. Isothermal cold-crystallization of PLA/PBAT blends with and without the addition of acetyl tributyl citrate. Macromolecular Chemistry and Physics, 213(1), 36-48, 2012. 
REN, J.; FU, H.; REN, T.; YUAN, W. Preparation, characterization and properties of binary and ternary blends with thermoplastic starch, poly (lactic acid) and poly (butylene adipateco-terephthalate). Carbohydrate Polymers, 77(3), 576-582, 2009.

SHIRAI, M. A.; GROSSMANN, M. V. E.; MALI, S.; YAMASHITA, F.; GARCIA, P. S.; MÜLLER, C. M. O. Development of biodegradable flexible films of starch and poly (lactic acid) plasticized with adipate or citrate esters. Carbohydrate Polymers, 92(1), 19-22, 2013.

ZULLO, R.; IANNACE, S. The effects of different starch sources and plasticizers on film blowing of thermoplastic starch: Correlation among process, elongational properties and macromolecular structure. Carbohydrate Polymers, 77(2), 376-383, 2009. 


\section{SISTEMA AUTOMATIZADO PARA MONITORAMENTO DO NÍVEL DE ÁGUA NAS CISTERNAS UTILIZANDO PLATAFORMA ARDUINO}

Isabela Rodrigues Magalhães

Universidade Federal dos Vales do Jequitinhonha e Mucuri, MG http://lattes.cnpq.br/2190260405525454

\section{Letícia Lopes da Silva}

Universidade Federal dos Vales do Jequitinhonha e Mucuri, MG http://lattes.cnpq.br/4371770900202219

\section{Patricia Soares Borges}

Universidade Federal dos Vales do Jequitinhonha e Mucuri, MG http://lattes.cnpq.br/4277069604908387

\section{Priscila Rodrigues de Souza Amador}

Universidade Federal dos Vales do Jequitinhonha e Mucuri, MG http://lattes.cnpq.br/8879084079139517

\section{Daniel Moraes Santos}

Universidade Federal dos Vales do Jequitinhonha e Mucuri, MG http://lattes.cnpq.br/2800973010325998

\section{Alcino de Oliveira Costa Neto}

Universidade Federal dos Vales do Jequitinhonha e Mucuri, MG http://lattes.cnpq.br/0015122954424304

Informações sobre o

artigo:

Recebido em:

$28 / 08 / 2020$

Aceito em:

$29 / 08 / 2020$

Data de publicação:

$23 / 10 / 2020$

Palavras-chave:

Captação

Água da chuva

Eficiência

Sustentabilidade

\section{RESUMO}

No momento atual, devido a crescente escassez de água, torna-se indispensável a implantação de cisternas de captação de água da chuva, bem como o controle e monitoramento das mesmas. Diante disso, no presente artigo foi apresentado um sistema que gerencie de maneira automatizada e eficiente o nível de água das cisternas fazendo o uso de um microcontrolador Arduino. Deste modo, elaborou-se um software através de programação do tipo c/c ++ que identifica quando o nível desejável de água é atingido, e consequentemente realiza o desligamento ou acionamento da bomba de distribuição. O projeto tem por objetivo viabilizar o uso de cisternas de forma mais eficiente aos moradores de locais carentes desse recurso, de modo que o mesmo tenha maior controle e aproveitamento da água e ainda uma economia de tempo e custo no uso da mesma. Para tal finalidade, desenvolveu-se um protótipo e a partir do mesmo foi possível analisar a eficiência e limitações na utilização do sistema para o monitoramento de cisternas em regiões secas. 


\section{AUTOMATED SYSTEM FOR WATER LEVEL MONITORING IN CISTERNS USING THE ARDUINE PLATFORM}

\section{ABSTRACT}

At the present time, due to the increasing water scarcity, it is essential to install rainwater catchment cisterns, as well as their control and monitoring. Given this, in this article was presented a system that manages in an automated and efficient way the water level of the cisterns using an Arduino microcontroller. In this way, software was developed through programming of type $\mathrm{c} / \mathrm{c}++$ which identifies when the desired level of water is reached, and consequently performs the shutdown or drive of the distribution pump. The project aims to enable the use of cisterns more efficiently to residents of deprived places of this resource, so that it has greater control and use of water and also a saving of time and cost in its use. For this purpose, a prototype was developed and from it was possible to analyze the efficiency and limitations in the use of the system for monitoring cisterns in dry regions.

\section{INTRODUÇÃO}

$\mathrm{Na}$ atualidade é fácil observar que as inovações tecnológicas conduzem a análises cada vez mais modernas e complexas de automação. Elas podem ser aplicadas em diferentes tarefas e otimizam as atividades e serviços tomados, assim como reduzem gastos e desperdícios.

O Arduino é uma placa eletrônica controlada por um tipo de programação responsável por manipular os dados coletados e utilizá-los para diversas finalidades através de uma linguagem de programação do tipo $\mathrm{c} / \mathrm{c}++$. A placa apresenta uma tecnologia de baixo custo, podendo ser utilizada na concepção de projetos baseados em microcontroladores (MONK, 2013).

Em muitos projetos desenvolvidos em conjunto com o Arduino, a utilização de sensores é indispensável. Esses aparelhos são responsáveis pela realização de leituras de determinadas características do meio e de criar sistemas capazes de interagir com o ambiente (CAMPOS, 2014).

A chuva é uma fonte valiosa de água doce e essencial à vida. Diante disso, sua captação é de extrema importância, principalmente porque a água é um recurso finito e vulnerável. Um ótimo local para captação desse recurso é no semiárido nordestino, pois tratase da região mais chuvosa do planeta, com pluviosidade média de $750 \mathrm{~mm} /$ ano. Entretanto 
apresenta longos períodos de escassez e mau armazenamento desse recurso (ECOCASA, 2017).

Assim, lidar com a dificuldade no semiárido não corresponde a extinguir a seca, mas adaptar-se ao ambiente de forma inteligente, que corresponde principalmente na captação da água no período de chuva e reserva da mesma com o impedimento de sua evaporação (MINISTÉRIO DE CIDADANIA, 2019).

Considerando o problema relatado acima e a grande abrangência da utilização do Arduino, o projeto consiste na aplicação desse microcontrolador para realização de medições do nível de água da cisterna, possibilitando sua distribuição e reutilização. Visto que em diversas regiões do Brasil observa-se uma gradativa e intensa variação nos índices pluviométricos, que associados ao uso irracional da água têm afetado na oferta da mesma para o abastecimento público.

\section{METODOLOGIA}

O presente trabalho foi desenvolvido em 4 etapas, as quais consistiram: pesquisas bibliográficas sobre o Arduino, sensor de nível de água e cisternas; montagem do sistema através da plataforma Arduino, onde dispositivos foram instalados, programados e configurados; montagem final do protótipo e por fim coleta e análise dos dados. Para confecção do protótipo foram necessários os dispositivos:

- 1 Placa Arduino UNO R3;

- 1 Protoboard;

- 1 Sensor de nível de água;

- 2 Leds;

- Cabos macho;

- Cabos fêmea;

- 1 Balde;

- 1 Módulo de relé 5V;

- 1 Bomba;

- 1 Mangueira;

- 1 proveta graduada $2 \mathrm{~L}$;

- Água. 
Através do software Arduino a criação de aparelhos eletrônicos é feita de forma mais fácil. Trata-se de uma placa controladora composta por diversas ferramentas de prototipagem eletrônica open source. Ele possui uma série de sensores que possibilitam a integração e interação com outros dispositivos. Além disso, o Arduino pode ser conectado a um computador com um cabo USB ou ligado a uma fonte adaptadora ou bateria (GOMES, 2015).

O protoboard, também conhecido como placa de ensaio ou matriz de contato, é uma placa que contém orifícios e ligações condutoras. Através dele pode-se realizar a montagem experimental de circuitos elétricos (ARAÚJO, 2014).

Os sensores de nível são dispositivos que têm por finalidade detectar o nível de um líquido em reservatórios, tanques e silos (SOUZA et al., 2017). Já o relé é um constituinte eletromecânico, que possibilita ligar e desligar um sinal a partir de outro sinal, sendo que os dois sinais são isolados. Dessa maneira, este dispositivo possibilita converter sinais que não se misturam, deixando-os eletricamente isolados um do outro (PATSKO, 2006).

Tendo em mãos os materiais apresentados, realizou-se a montagem do sistema. Inicialmente, o sensor de nível de água, o relé e os leds foram instalados à placa Arduino e ao protoboard por meio dos cabos. Posteriormente, realizou-se a programação e configuração do conjunto através da linguagem de programação do tipo c/c ++ . Subsequentemente, efetuou-se a montagem final do protótipo, a qual consistiu no acoplamento do sensor nível de água ao reservatório (balde), para obter a informação de que o mesmo estava no nível desejável. Essa informação foi transmitida através dos leds instalados, estes que informaram a quantidade de água do recipiente (cheio/vazio) para a bomba, a fim de acionar a mesma quando o reservatório estivesse cheio, e desligá-lo quando estivesse vazio. A instalação dos LEDs e da bomba foi feita em conjunto com a utilização do relé $5 \mathrm{~V}$. Por fim, utilizou-se uma mangueira para esvaziar o reservatório quando estivesse cheio. Essa mangueira foi acoplada ao recipiente e a bomba.

\section{RESULTADOS E DISCUSSÃO}

$\mathrm{Na}$ figura 1 abaixo, observa-se o processo inicial de montagem do Arduino. A imagem apresenta como foi realizada a instalação dos fios macho, fêmea e do sensor, bem como dos LEDs e relé na placa, sendo todos estes acoplados ao protoboard. 
Figura 1 - Placa Arduino montada

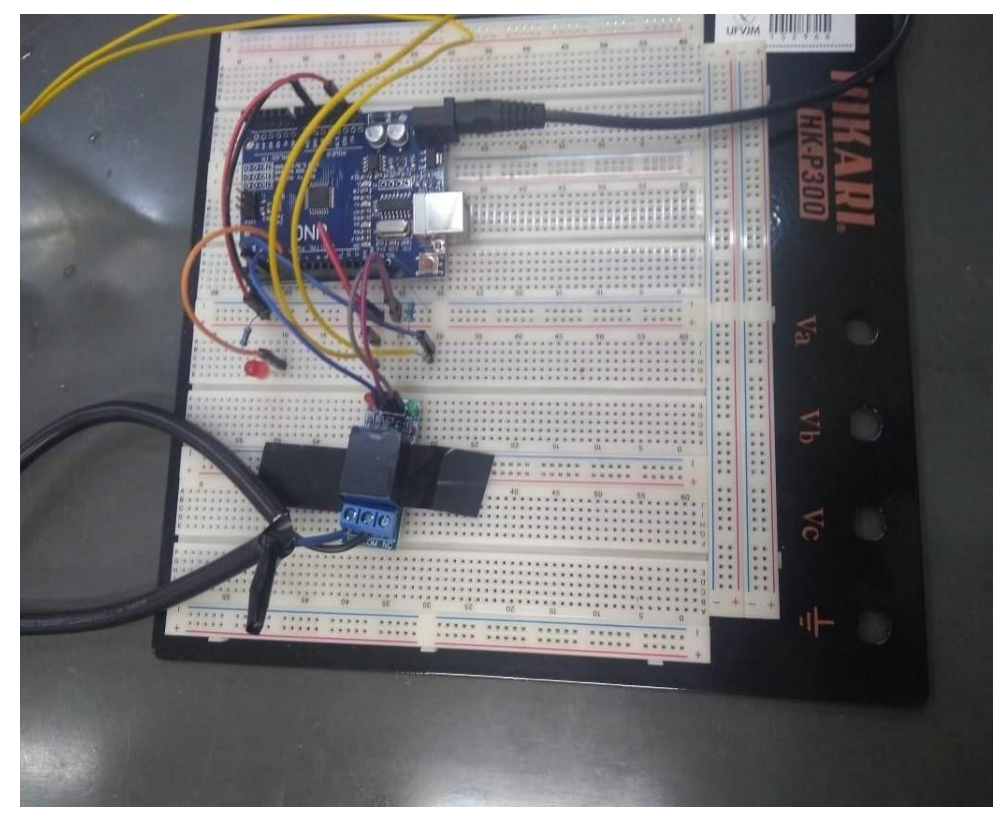

Fonte: Elaborada pelos autores

O sensor de nível de água escolhido pela equipe era de um modelo mais simples, por esse motivo o mesmo teve que ser acoplado na parte inferior do reservatório. Assim, quando o recipiente encontra-se cheio ou com o nível acima do sensor, o led vermelho e os dois leds do relé são acesos, fazendo com que a bomba seja acionada, e subsequentemente ocorre a distribuição de água do reservatório para o local desejado. Conforme observado na figura 2:

Figura 2 - Protótipo em funcionamento com reservatório acima do nível.

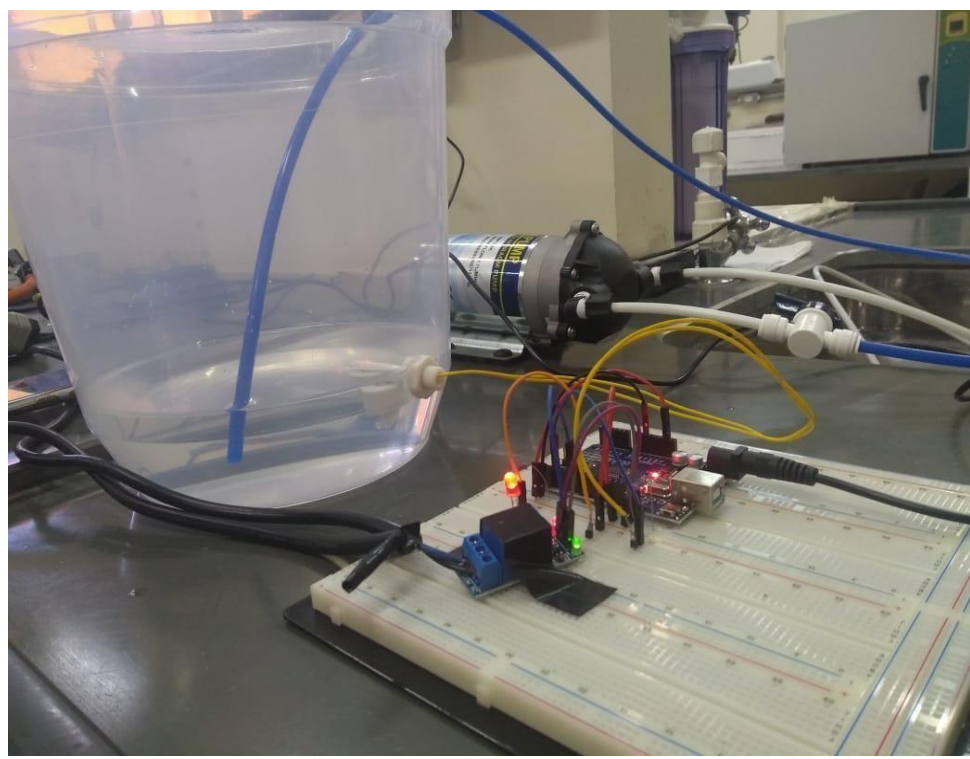

Fonte: Elaborada pelos autores 
O sensor de nível de água indica que o reservatório encontra-se vazio quando a altura da coluna de água é inferior ao mesmo. No entanto, percebe-se que ainda existe um pequeno volume de água abaixo do dispositivo, este é conhecido como volume morto, visto que abaixo deste nível a bóia não trabalha. $\mathrm{O}$ volume morto é necessário para que não ocorra a queima do dispositivo e da bomba.

No momento em que o recipiente se esvazia, o sensor envia um sinal para a placa, no qual desliga o led verde do relé e aciona o vermelho, fazendo com que a bomba desligue, e assim finalizando a distribuição. O que pode ser notado na figura 3.

Figura 3 - Sistema quando nível de água está abaixo do sensor.

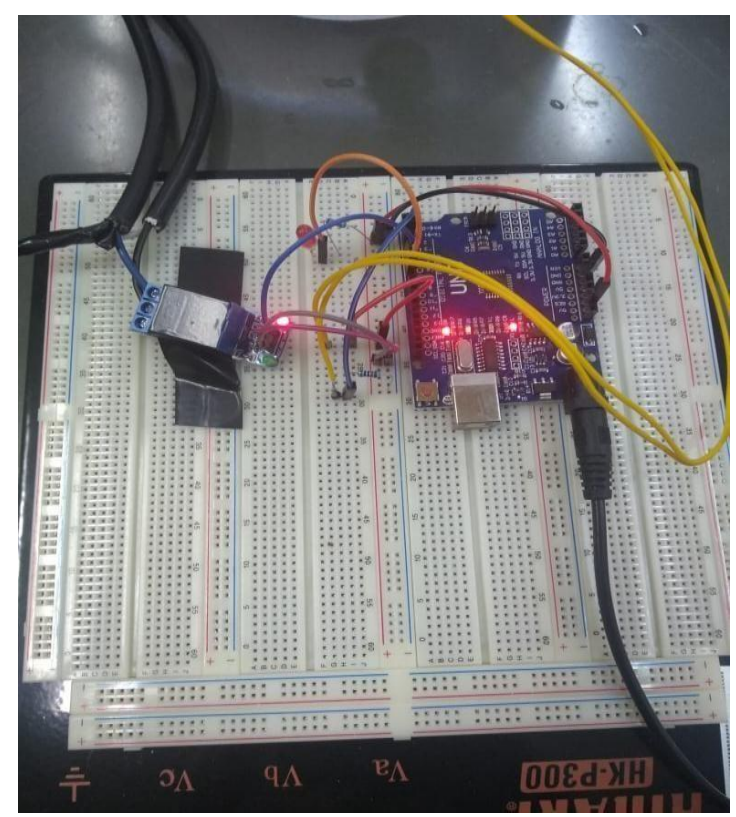

Fonte: Elaborada pelos autores

No presente trabalho, foram realizados testes sobre o tempo em que a bomba leva para esvaziar o reservatório com diferentes volumes. Conforme representado nas tabelas $1 \mathrm{e}$ 2:

- Utilizando $\mathrm{V}=2 \mathrm{~L}$ de água:

Tabela 1 - Medição do tempo utilizando-se o volume de 2L de água.

\begin{tabular}{cc}
\hline NÚMERO DE TESTES & TEMPO (minutos) \\
\hline 1 & 0,750 \\
2 & 1,067 \\
3 & 1,117 \\
4 & 1,017 \\
\hline
\end{tabular}


- Utilizando $\mathrm{V}=3 \mathrm{~L}$ de água:

Tabela 2 - Medição do tempo utilizando-se o volume de 3L de água.

\begin{tabular}{cc}
\hline NÚMERO DE TESTES & TEMPO (minutos) \\
\hline 1 & 2,000 \\
2 & 1,400 \\
3 & 1,418 \\
4 & 2,067 \\
\hline
\end{tabular}

Outro ponto importante é volume morto, sendo que abaixo desse valor a bóia não trabalha:

Tabela 3 - Volume morto.

\begin{tabular}{cc}
\hline NÚMERO DE TESTES & Volume $(\mathrm{mL})$ \\
\hline 1 & 980 \\
2 & 960 \\
3 & 960 \\
4 & 970 \\
\hline
\end{tabular}

\section{CONCLUSÃO}

A partir da observação dos aspectos analisados, conclui-se que os resultados obtidos foram satisfatórios, uma vez que o projeto obteve sucesso tanto na parte da programação, quanto em sua execução. Entretanto, para maior eficiência do mesmo, observa-se que o uso de um sensor de nível ultrassônico possibilitaria a instalação na parte superior do reservatório, uma vez que possui funcionamento baseado na emissão de pulsos de ultrassom, o que promove medições contínuas e precisas a qualquer nível de água em um reservatório. Além disso, nota-se a vantagem da utilização do sistema em cisternas das residências rurais já existentes, o que possibilitará ao morador a automatização do seu reservatório e distribuição da água coletada para irrigação.

Essa utilização controlada pelo software proporcionará ao usuário uma maior economia de água, pois quando a cisterna estiver cheia, o próprio sistema realizará a distribuição desse bem para outro reservatório, de acordo com o desejo do proprietário, sem necessidade de desperdício. Essa aplicação também trará benefícios aos órgãos públicos, visto que haverá uma economia no custo de transporte desse recurso, uma vez que a população vivente em regiões secas teria água em suas residências. 


\section{REFERÊNCIAS}

ARAÚJO, W. C. Montagem de circuitos eletrônicos. Curso técnico de eletrônica, ETEC Albert Einstein. SP 2014.

CAMPOS, R. A. F. Automação residencial utilizando Arduino e aplicações WEB. Trabalho de Conclusão de Curso (Bacharelado em Engenharia de Computação), Centro Universitário de Brasília, Brasília. DF 2014.

ECOCASA. Captação de água da chuva: por onde começar?. 2017. Disponível em: <https://www.ecocasa.com.br/agua-da-chuva-por-onde-comecar>. Acesso em: 13 mar. 2019.

GOMES, P. C. T. Entenda o que é Arduíno e como funciona a sua aplicação!. 2015. Disponível em: <https://www.opservices.com.br/o-que-e-o-arduino/>. Acesso em: 13 mar. 2019.

MINISTÉRIO DE CIDADANIA. Programa cisternas. 2019. Disponível em: $<$ http://mds.gov.br/assuntos/seguranca-alimentar/acesso-a-agua-1/programa-cisternas $>$. Acesso em 20 jul. 2019.

MONK, S. Programação com Arduino: começando com sketches. Bookman Editora LTDA, Porto Alegre. RS 2013.

PATSKO, L. F. Aplicações, Funcionamento e Utilização de Sensores. 2006. Disponível em: <https://www.maxwellbohr.com.br/downloads/robotica/mec1000_kdr5000/tutorial_ele tronica_-_aplicacoes_e_funcionamento_de_sensores.pdf>. Acesso em: 12 mar. 2019.

SOUZA, L. K. et al. Juice Machine. Monografia (Técnico em Automação Industrial), ETEC Jorge Street, São Caetano do Sul. SP 2017. 
COMPARATIVO ENTRE ANÁLISES LINEAR E NÃO-LINEAR NA OBTENÇÃO DE FLECHAS EM VIGAS DE CONCRETO ARMADO COM A UTILIZAÇÃO DE SOFTWARE

\section{Amâncio da Cruz Filgueira Filho}

Faculdade de Integração do Sertão (FIS), Serra Talhada, PE

http://lattes.cnpq.br/6353170691331354

\section{Lucíolo Victor Magalhães e Silva}

Instituto Federal do Sertão Pernambucano, Campus Salgueiro, PE

http://lattes.cnpq.br/3239088236416834

\section{Antônio Oscar Cavalcanti da Fonte}

Universidade Federal de Pernambuco, Recife, PE http://lattes.cnpq.br/2603293658379177

Informações sobre o

artigo:

Recebido em:

09/10/2020

Aceito em:

$17 / 10 / 2020$

Data de publicação:

$23 / 10 / 2020$

Palavras-chave:

Flexas

Vigas

Concreto armado

Não-linearidade física

Análise estrutural

\section{RESUMO}

O intuito deste trabalho é analisar a influência da não-linearidade física no comportamento de vigas de concreto armado a partir de modelagem computacional de um edifício. Para isso, considerouse um modelo de um pavimento de uma edificação, com características típicas de construções encontradas no mercado imobiliário. As análises foram realizadas a partir de um comparativo entre modelos estruturais de grelha linear elástica e não-linear para ações em serviço. Foram realizadas análises de flechas, com a consideração da fissuração e fluência. De posse das análises conclui-se que a análise não-linear deve ser levada em conta para verificações de serviço para que os projetos possam ser elaborados de maneira mais eficiente.

COMPARATIVE BETWEEN LINEAR AND NON-LINEAR ANALYSIS IN OBTAINING VERTICAL DISPLACEMENT IN REINFORCED CONCRETE BEAMS WITH THE USE OF SOFTWARE

\section{ABSTRACT}

The aim of this work is to analyze the influence of physical nonlinearity on the behavior of reinforced concrete beams from computational modeling of a building. For this, a model of a floor of a building was considered, with typical characteristics of buildings found in the real estate market. The analyses were 
Keywords:

Vertical displacement

Beams

Reinforced concrete

Physical non-linearity

Structural analyses performed from a comparison between structural models of elastic linear and non-linear grid for in service actions. Vertical displacement analyzes were performed, taking into account cracking and creep. Based on the analysis, it is concluded that the non-linear analysis must be taken into account for service checks so that the projects can be developed more efficiently.

\section{INTRODUÇÃO}

Freitas (2015) cita que os modelos matemáticos utilizados para o comportamento linear de estruturas reticuladas são descritos por equações diferenciais, existindo diversos métodos para resolvê-las através de um sistema de equações algébricas equivalentes. Freitas (2015) ainda comenta que os métodos mais utilizados para esse tipo de análise são o método das forças e o método dos deslocamentos.

A consideração da não-linearidade física dos materiais é essencial para que seja estabelecida de forma mais precisa a capacidade resistente das estruturas de concreto armado (BUCHAIM, 2001), isso se torna preponderante, pois vários fatores conferem esse comportamento como a fissuração, fluência, processos construtivos, cargas aplicadas corretamente em serviço e os efeitos do tempo (ARAUJO, 2002).

Segundo Carvalho (2014) o estado limite de serviço é aquele relacionado à durabilidade das estruturas, à aparência, ao conforto do usuário e à boa utilização funcional das mesmas, seja em relação aos usuários como às máquinas e equipamentos utilizados.

Estas análises estão ligadas principamente a verificações das estruturas quanto a deslocamentos, fissurações e vibrações, e as mesmas são muito sensíveis a diversos fatores para estimar os valores através de metodologias de cálculo. Daí a necessidade de análises que considerem o comportamento do material como realmente ele é.

Conforme a ABNT NBR 6118:2014, item 15.7.3, uma maneira aproximada para considerar a não-linearidade física em uma estrutura, para análise de esforços globais de $2^{a}$ ordem, é alterar diretamente o valor da rigidez dos elementos que a compõe. Quando reduzimos, por exemplo, as rigidezes de seus elementos: lajes $\left(0,3 \mathrm{E}_{\mathrm{ci}} \mathrm{I}_{\mathrm{c}}\right)$, vigas $(0,4$ ou 0,5 $\left.\mathrm{E}_{\mathrm{ci}} \mathrm{I}_{\mathrm{c}}\right)$ e pilares $\left(0,8 \mathrm{E}_{\mathrm{ci}} \mathrm{I}_{\mathrm{c}}\right)$, sendo $\mathrm{E}_{\mathrm{ci}} \mathrm{O}$ valor de $90 \%$ do módulo de elasticidade tangente do concreto, e $\mathrm{I}_{\mathrm{c}} \mathrm{O}$ momento de inércia da seção bruta de concreto, conforme demonstrado na figura 1 a seguir: 
Figura 1 - Consideração aproximada da não-linearidade física.

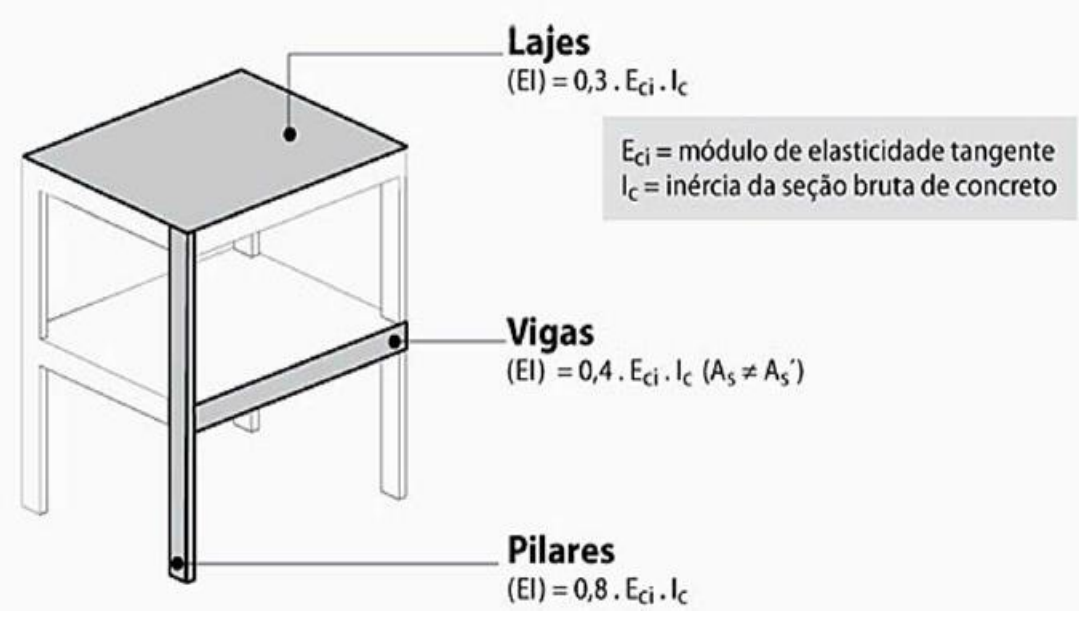

Fonte: Kimura (2007)

Uma maneira de obter valores mais precisos de rigidez, e consequentemente ter uma consistência maior nos valores obtidos considerando a não-linearidade física, é pelos diagramas de momentos-curvatura $(M \times 1 / r)$. A curvatura como mostra a figura 2, é a variação de um ângulo num determinado seguimento $(\mathrm{d} \theta / \mathrm{ds})$, que também é o inverso do raio que a forma ao longo do seguimento, sendo $\mathrm{d} \theta / \mathrm{ds}=1 / \mathrm{r}$.

Figura 2 - Seguimentos curvos representando a curvatura e seus elementos
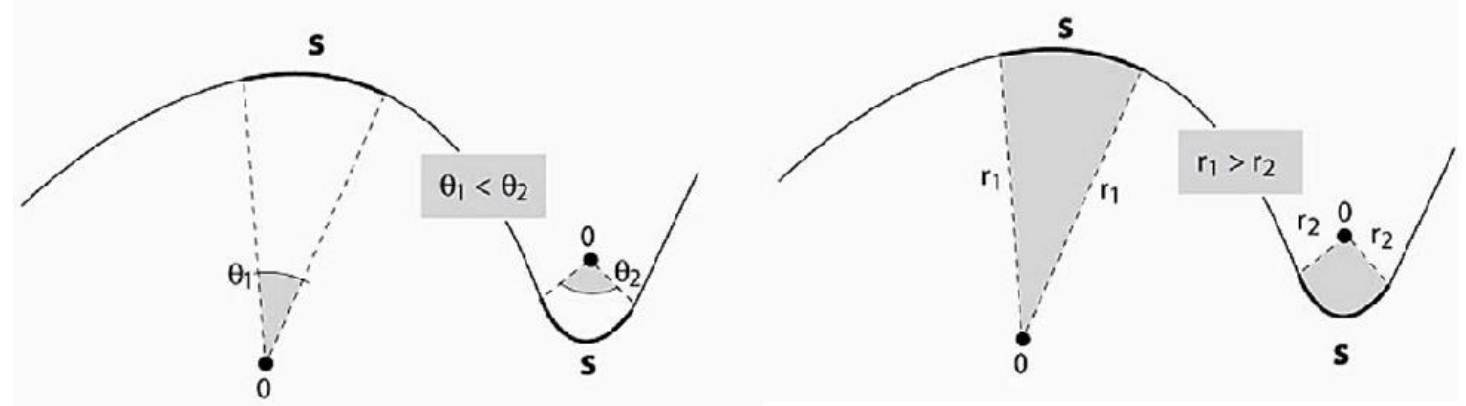

Fonte: Kimura (2007)

A curvatura pode ser considerada em seções de concreto armado, desde que admitirmos que a seção continue plana após as deformações conforme a figura 3, relacionando ela com as deformações ocorrentes nos materiais (concreto e aço) e a sua altura útil $(1 / \mathrm{r}=(\varepsilon c-\varepsilon s) / d)$. A partir essa equação, que foi igualada a curvatura, pode ser admitido que exista uma relação direta entre momento e curvatura, segundo Carvalho (1994), a partir 
de modelos que consideram flexão simples pura atuando em um trecho de peça na qual a seção está contida.

Figura 3 - Curvatura representada em seção de concreto armado.

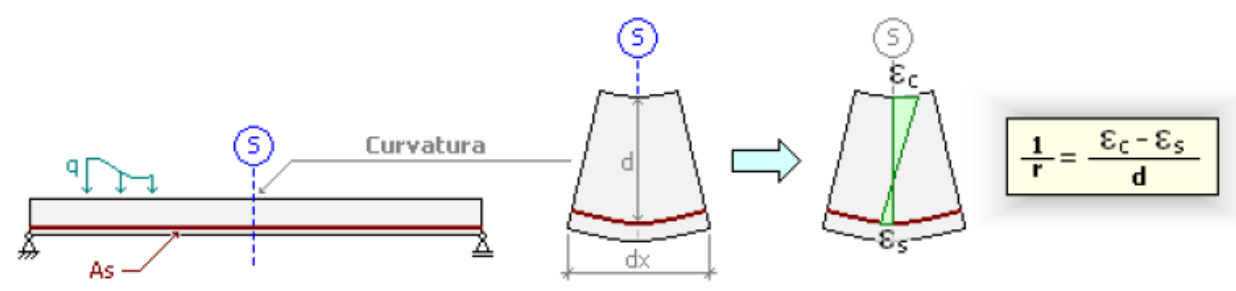

Fonte - TQS Informática LTDA (2010)

A rigidez é o fator que relaciona o momento com a curvatura, como pode ser observado na Figura 04. Kimura (2007) cita que o diagrama de momento-curvatura é análogo ao diagrama tensão x deformação $(\sigma \times \varepsilon)$.

Figura 4 - Relação de curvatura numa seção com o momento fletor atuante na mesma

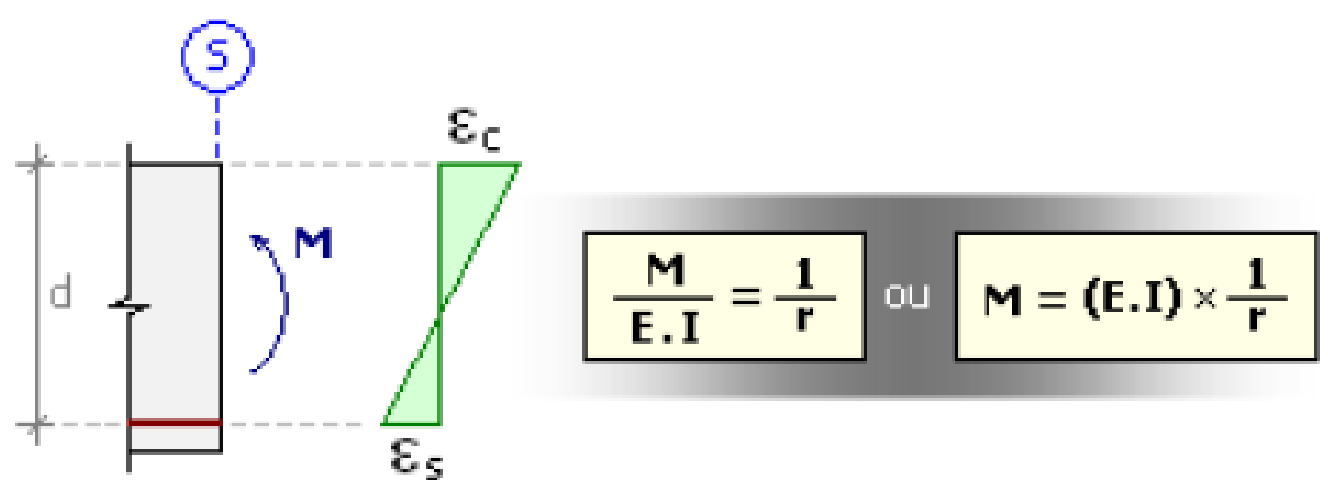

Fonte - TQS Informática LTDA (2010)

O objetivo deste trabalho é utilizar um programa computacional voltado para área de engenharia estrutural, descrevendo suas funções, vantagens, cuidados e limitações. Comparar os resultados obtidos nas análises linear e não-linear no comportamento estrutural de um pavimento de um edifício. 


\section{METODOLOGIA}

O software utilizado nesta pesquisa foi o CAD/TQS, que utiliza, em suas formulações de cálculo, as prescrições da ABNT NBR 6118:2014.

O projeto consiste em um edifício em concreto armado, de quatro pavimentos, sendo três pavimentos tipo e uma cobertura, totalizando $11,2 \mathrm{~m}$ de altura (pé direito $=2,8 \mathrm{~m}$ para todos os pavimentos). O pavimento consiste em um modelo usual em edifícios residenciais, consistindo em quatro apartamentos por andar, dois elevadores e escada. Sua estrutura é composta por 12 lajes (considerando uma da escada), 24 vigas e 22 pilares. Conforme explicitado na planta de formas da figura 05. A seguir estão apresentados as seções transversais dos elementos estruturais.

•Pilares - 24/65, 110x24, 24/290, 20x90, 20/40, 20/140 e 20/160 em cm.

-Vigas - 24x55, 14x55 e 16/55 em cm.

-Lajes - espessura $=12 \mathrm{~cm}$.

A planta de formas do pavimento tipo está apresentada na figura 05 , em conjunto com a forma da estrutura.

Figura 5 - Planta de formas do pavimento tipo

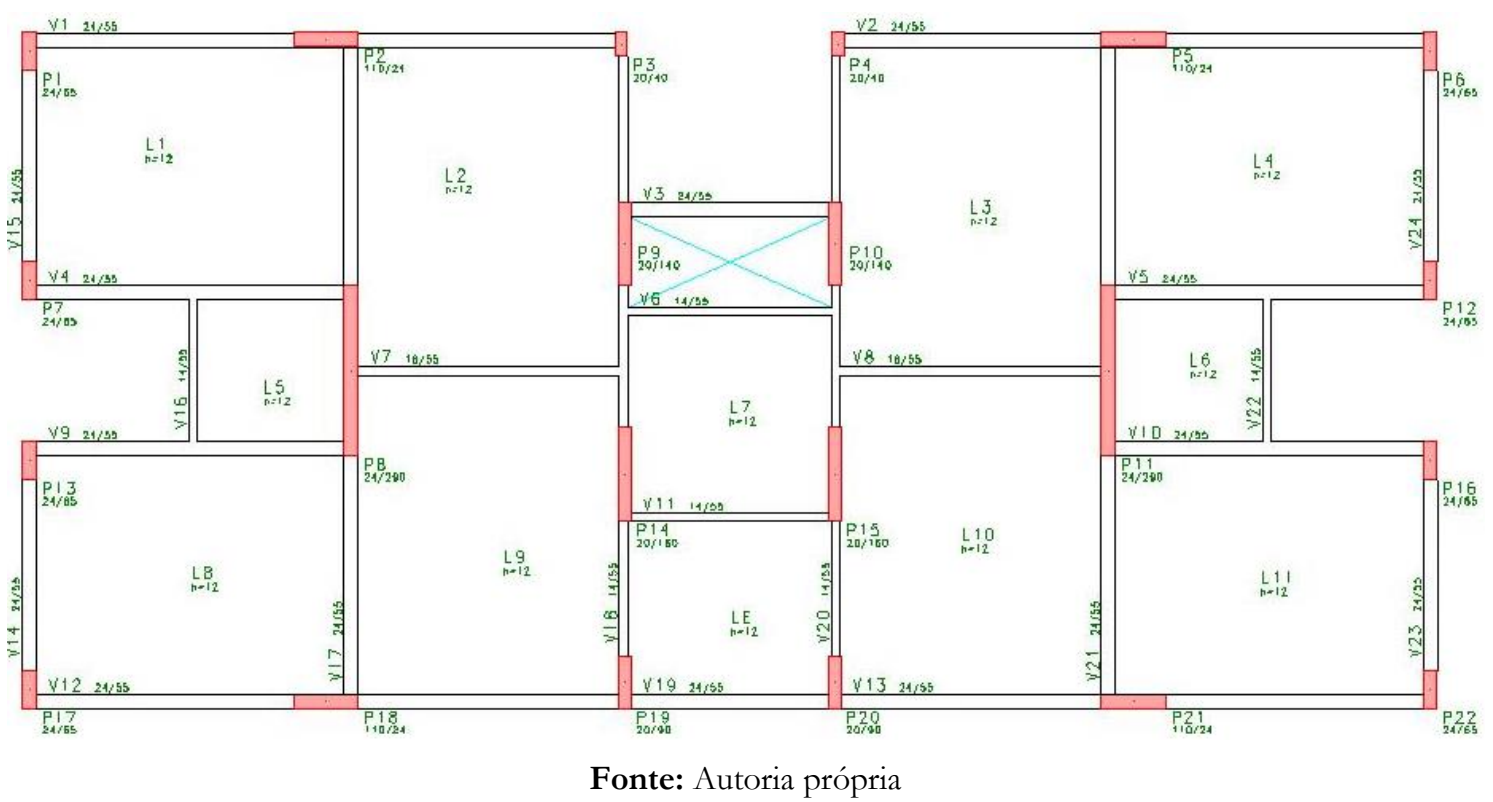

Toda a base de cálculo deste trabalho será realizada no modelo de grelha. Realizar análise estrutural de um pavimento utilizando grelha para cálculo é muito comum na engenharia estrutural, sendo este modelo bem indicado para esta atividade, pois, segundo 
Carvalho (2014) leva em consideração a influência da flexibilidade dos apoios e da rigidez à torção tanto das lajes como das vigas, além de possibilitar a inclusão da não-linearidade física do concreto armado. Serão exibidos resultados obtidos considerando grelhas elásticas lineares e não-lineares fisicamente.

A combinação para estado limite de serviço será considerada com estrutura já projetada com armações de modo a atender o estado limite último. Considerar a totalidade das cargas variáveis seria um equívoco, pois para uma análise ELS deve-se ponderar a carga variável reduzindo pelo coeficiente relativo à simultaneidade das ações $\gamma \mathrm{f} 2$ (através dos redutores $\psi 1$ e $\psi 2$ ), conforme recomendações da ABNT NBR 6118:2014.

Quanto à classificação, foi determinada a combinação quase permanente, conforme o item 11.8.3.1 da NBR 6118, no qual sugere que a análise de flechas (deformações excessivas) seja realizada com este tipo de combinação, definido pela equação 1 a seguir:

$$
\text { CELS-DEF: }_{1,0} \cdot\left(\mathrm{g}_{1}\right)+1,0 \cdot\left(\mathrm{g}_{2}\right)+\psi_{2} \cdot(\mathrm{q})
$$

Sendo:

g: Carregamento devido ao peso próprio dos elementos estruturais;

g2: Carregamento devido à sobrecarga permanente;

q : Carregamento devido a sobrecarga variável;

$\psi_{2}$ : Coeficiente ponderador de ações variáveis, adotando-se para este trabalho o valor de 0,6.

$\mathrm{Na}$ análise não-linear, o carregamento total definido no pavimento é subdividido em incrementos de cargas, de tal forma que a rigidez em cada ponto dos elementos estruturais possa ser corrigida gradativamente à medida que a fissuração se propaga, sendo este metodologia obtida por processos computacionais. Quanto maior o número de incrementos, mais precisos serão os resultados obtidos, porém o esforço computacional será superior. $\mathrm{O}$ número de incrementos de carga nesta pesquisa foi definido em 12.

Quanto à consideração da fluência (deformação lenta) do concreto as parcelas de carga foram majoradas pelos coeficientes $\alpha_{\mathrm{f}}$. Nos quatro primeiros incrementos (peso próprio) por $\alpha_{\mathrm{f}}=1,5$. Nos seis incrementos seguintes (cargas permanentes) por $\alpha_{\mathrm{f}}=1,3$. Para as cargas variáveis não há majoração.

Outra análise também será feita do pavimento a qual consiste no cálculo chamado de Rigidez Final, que consiste em majorar a flecha elástica resultante da aplicação do 
carregamento total em serviço por um coeficiente que relaciona as rigidezes integral (estádio I) e fissurada (estádio II), semelhante ao que é feito em processos manuais.

O modelo utilizado para calcular a rigidez final vai ser obtido a partir do último incremento da análise incremental, esta é a grande diferença deste modelo com o modelo de análise incremental (o qual possui parcelas de carga). O carregamento estará sendo aplicado de maneira total só que com a estrutura apresentando configuração de rigidez variável. A análise por rigidez final se configura como uma análise linear com uma variação de rigidez na estrutura.

As flechas imediatas são as que correspondem a o estado de deformações logo após a estrutura ter sido construída, sem consideração das variáveis que acontecem ao longo do tempo, caso da fluência. O resultado das análises será obtido sem a consideração da fluência.

As flechas na estrutura geram esforços em elementos não estruturais que estão sobre ela, como paredes e divisórias, podendo ocasionar possíveis manifestações patológicas nestes elementos, como fissuras que são causadas principalmente devido à fluência, cargas das alvenarias e das cargas variáveis. Serão calculadas as flechas após a construção de alvenarias, através do processo utilizado para análise da fluência baseado no coeficiente $\alpha f$, do item 17.3.2.1.2 da NBR 6118. Assim o cálculo elástico linear não será feito na análise.

As flechas totais consistem na soma das flechas imediatas mais as diferidas, ou seja, constituem nas flechas geradas pelas cargas permanentes iniciais, permanentes restantes e da sobrecarga acidental, considerando os efeitos ao longo do tempo. Para as flechas na análise elástica linear será considerado um coeficiente de 2,5 para considerar a fluência, para as demais análises serão utilizados os coeficientes $\alpha_{\mathrm{f}}$.

\section{RESULTADOS E DISCUSSÃO}

As flechas imediatas máximas obtidas na análise elástica linear majorada foram de $0,18 \mathrm{~cm}$ nas vigas V16 e V22, na análise não-linear incremental as maiores foram de $0,20 \mathrm{~cm}$ nas vigas V7, V8 e V22, e para análise por rigidez final a maior flecha foi de $0,48 \mathrm{~cm}$ na viga V7. As diferenças de flechas entre as análises elástica linear e não-linear são muito pequenas, chegando a valores de 0,04 cm maiores na análise não-linear, na viga V7 e V8. Em geral as vigas mais solicitadas foram as que tiveram maiores diferenças no deslocamento, devido à perda de rigidez por fissuração nas mesmas ser mais atenuante. 
Situação que também acontece quando se analisam as diferenças de valores da análise elástica linear com a análise de cálculo por rigidez final. Flechas com maiores diferenças nas regiões onde houve maior solicitação e preponderância de momentos positivos. A maior diferença ocorre na viga V7 (0,32 cm), chegando a uma variação de $200 \%$.

Quanto às flechas após a construção de alvenarias, foram obtidas flechas máximas na análise não-linear incremental nas vigas V7 e V8 no valor de $0,26 \mathrm{~cm}$, enquanto que no cálculo da rigidez final o maior valor foi de $0,64 \mathrm{~cm}$ na viga V7. A maior diferença entre as análises foi na viga $\mathrm{V} 7$, num aumento de $0,38 \mathrm{~cm}$ na rigidez final, ocasionando um aumento de $146,15 \%$.

Para as flechas totais, logo a princípio, o que se pode observar nos resultados obtidos, é que uma análise puramente linear, sem a consideração da fluência e da fissuração tem valores bem abaixo dos demais no qual estes foram levados em conta por algum tipo de parâmetro. A fissuração e a fluência não podem ser descartadas, sua não consideração torna este método inviável em nível de projeto, pois tornará a estrutura mais suscetível a manifestações patologicas em serviço.

As flechas máximas obtidas nas análises foram de $0,45 \mathrm{~cm}$ nas vigas V16 e V22 na análise elástica linear majorada, de $0,40 \mathrm{~cm}$ nas vigas V7, V16 e V22 na análise não-linear incremental e de 1,03 cm nas vigas V7 e V8 no cálculo pela rigidez final. A diferença entre os resultados das flechas da análise elástica linear majorada com a da análise não-linear são muito pequenas, e todas sendo com valores maiores na análise linear, atingindo valores de 0,05 cm nas vigas V4, V5, V9, V10, V16 e V22.

Em comparação com os resultados obtidos com o cálculo da rigidez final se podem observar diferenças consideráveis, as vigas nas demais análises que mais deformaram foram as mesmas, porém se observa que estas comparadas com todas as análises tiveram um aumento bastante significativo, como no caso das vigas V7 e V8 com uma flecha máxima de $1,03 \mathrm{~cm}$, que apresentaram uma grande diferença com a análise linear majorada no valor de $0,63 \mathrm{~cm}$, um aumento de $157,50 \%$. As vigas com menos deformação tiveram os valores bem semelhantes às demais, como no caso da viga V15 que teve flecha máxima de 0,04 cm, mesmo valor obtido na análise não-linear incremental e $0,01 \mathrm{~cm}$ menor que na análise elástica linear majorada.

Essa explicação se dá devido à maneira como a análise por rigidez final é calculada, no qual se aplica a carga total com a situação final de rigidez. Há preponderância da variação dos valores obtidos nas vigas mais deformadas, pois estas foram as que atingiram o estádio 
II de cálculo, em outras palavras são as barras que sofreram fissuração tiveram suas rigidezes reduzidas. Podem-se observar na figura 06 as vigas mais deformadas para este tipo de análise.

A tabela 1 e a tabela 2 apresentam, respectivamente, os resultados das análises da viga V7 e V22 que também podem ser vistos nos gráficos 1 e 2.

Figura 6 - Diagrama de deslocamentos totais do cálculo da rigidez final do pav. Tipo.

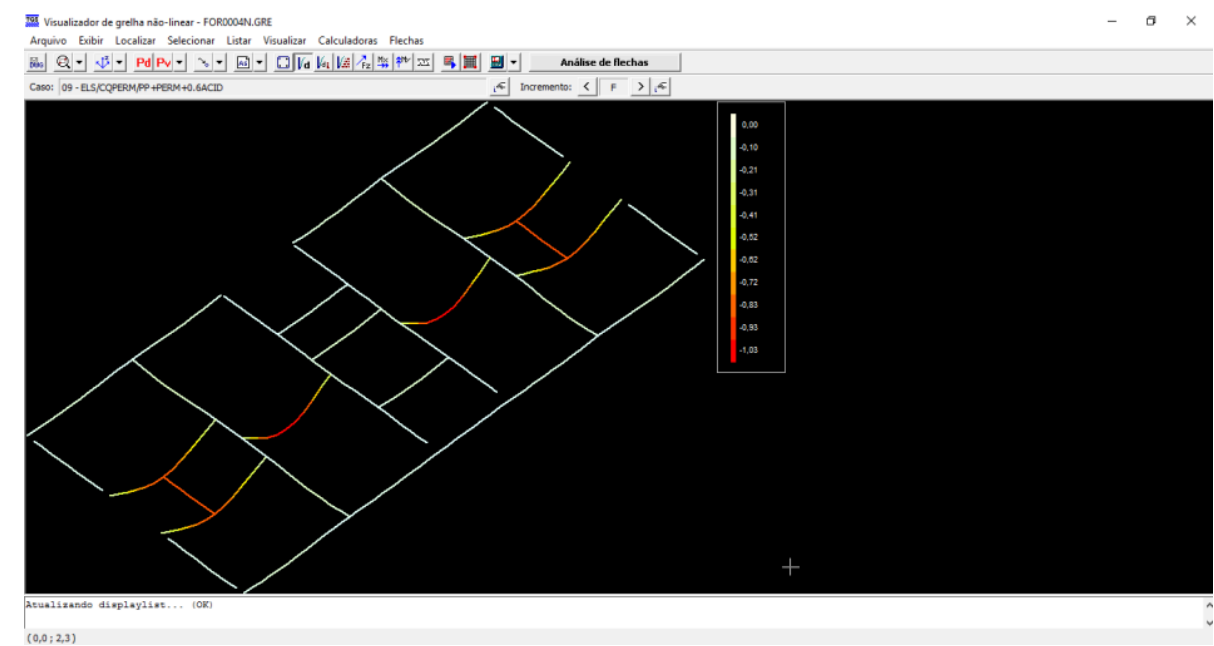

Fonte: Autoria própria

Tabela 1 - Flechas máximas em cada análise da viga V7

\begin{tabular}{c|c|c|c|c}
\hline \multicolumn{5}{|c}{ Viga V7 } \\
\hline Flechas & Linear & Linear majorada & Não-linear & Rigidez final \\
\hline Imediatas & 0,16 & - & 0,20 & 0,48 \\
\hline Após const. das alvenarias & - & - & 0,26 & 0,64 \\
\hline Totais & - & 0,40 & 0,40 & 1,03 \\
\hline
\end{tabular}

Fonte: Autoria própria

Tabela 2 - Flechas máximas em cada análise da viga V22

\begin{tabular}{c|c|c|c|c}
\hline \multicolumn{5}{|c}{ Viga V22 } \\
\hline Flechas & Linear & Linear majorada & Não-linear & Rigidez final \\
\hline Imediatas & 0,18 & - & 0,20 & 0,40 \\
\hline Após const. das alvenarias & - & - & 0,25 & 0,54 \\
\hline Totais & - & 0,45 & 0,40 & 0,87 \\
\hline
\end{tabular}

Fonte: Autoria própria

Gráfico 1 - Flechas máximas em cada análise da viga V7 


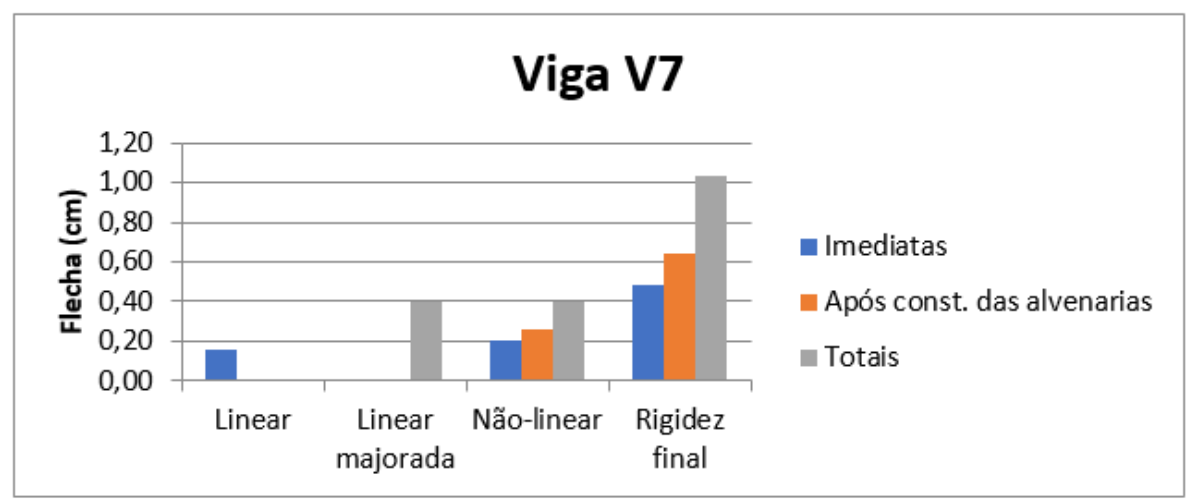

Fonte: Autoria própria

\section{CONCLUSÃO}

A perda gradativa da rigidez é calculada de uma maneira mais próxima da realidade na análise não-linear incremental, pois a rigidez vai diminuindo devido à fissuração do material pelo incremento de cargas. No cálculo por rigidez final, o qual utiliza a rigidez em seu estado final em serviço, apesar de considerá-la já diminuída, não considera sua perda gradativa, uma situação que se torna "irreal”, pois as cargas não são aplicadas de uma única vez numa estrutura com sua rigidez em situação final em serviço.

Outro fator importante são as deformações que acontecem ao longo do tempo devido à fluência do material. Estas não deverão ser desprezadas, pois seu efeito mostra aumentos significantes nos resultados. Na análise não-linear a flecha máxima da viga V7 considerando a fluência foi de $0,40 \mathrm{~cm}$, e não considerando esse critério foi de $0,20 \mathrm{~cm}$.

Uma observação a se fazer é que na ABNT NBR 6118:2014 recomenda se utilizar para a consideração da fluência os coeficientes af ou $\varphi$, porém esses coeficientes só poderiam ser considerados no software utilizado nesta pesquisa para análise não-linear e para rigidez final. Daí para se fazer algumas comparações foi necessário se utilizar de um coeficiente de majoração para análise elástica linear, que foi utilizado o fator 2,5, este que atendeu bem a majoração nas flechas que deram valores satisfatórios comparando com as demais. Este valor é recomendado pelo próprio sóftware para esta utilização.

Uma desvantagem do software é de só se poder fazer a análise não-linear física de um pavimento de concreto armado pelo modelo em serviço. Apesar da estrutura está armada para não acontecer seu colapso total, uma análise em Estado Limite Ultimo pelo grelha não-linear seria interessante devido a poder visualizar a grande variabilidade de esforços e deformações dos modelos linear e não-linear. 
Enfim, qual modelo se deve escolher? Essa resposta continua sendo algo intrigante. Não existe ainda um modelo no qual possamos definir como $100 \%$ condizente com a realidade. $\mathrm{O}$ que se pode observar ao longo de pesquisas e trabalhos feitos nesta área é que a análise não-linear incremental possui uma maior quantidade de resultados em serviço satisfatórios com os condizentes em obra e laboratório, o que já se devia prever pois ésta considera grande parte dos comportamentos e características do material, como a perda de rigidez gradativamente com a aplicação de cargas, fluência e fissuração. Mesmo assim não se devem desprezar os demais modelos, pois apesar das vantagens obtidas com o processo incremental não se pode afirmar sua plena certeza. Quanto mais modelos de cálculo em mãos mais comparações para se atingir um parecer final em projeto.

\section{REFERÊNCIAS}

ABNT - ASSOCIAÇÃO BRASILEIRA DE NORMAS TÉCNICAS. NBR 6118: Projeto de estruturas de concreto - Procedimento. Rio de Janeiro, 2014.

ARAÚJO, J. M. Modelos de previsão da fluência e da retração do concreto. Série Estruturas de Concreto, n. 4, Ed. Dunas, Rio Grande, Abril, 2002., 26.p.

BUCHAIM, R. - A influência da não-linearidade física do concreto armado na rigidez à flexão e na capacidade de rotação plástica. 2001. 260 f. Tese (Doutorado em Engenharia). Departamento de Engenharia de Estruturas e Fundações, Escola Politécnica da Universidade de São Paulo, São Paulo.

CARVALHO, R. C. - Análise não-linear de pavimentos de edifícios de concreto através da analogia de grelha. 1994. 208 p. Tese (Doutorado em Engenharia). Departamento de Estruturas, Universidade de São Paulo, São Carlos.

CARVALHO, R. C. , FILHO, J. R. F. - Cálculo e Detalhamento de Estruturas Usuais de Concreto Armado Segundo a NBR 6118:2014. 2014. 416 p. Editora EduFSCar, São Carlos.

FREITAS, J. A. T. , TIAGO, C. - Análise Elástica de Estruturas Reticuladas. 2015. 248 f. Instituto Superior Técnico, Universidade de Lisboa, Lisboa.

KIMURA, A. E. Informática aplicada em estruturas de concreto armado. 2007. 624 p. Editora PINI, São Paulo.

TQS Informática Ltda, Análise Estrutural. Manuais TQS v.18. n. 3. 2015. 280 p. São Paulo 


\section{PROCEDIMENTOS ADOTADOS PARA EXECUÇÃO EM REFORMA DE REVESTIMENTOS INTERNOS EM UM AMBIENTE HOSPITALAR}

\section{Amâncio da Cruz Filgueira Filho}

Faculdade de Integração do Sertão (FIS), Serra Talhada, PE http://lattes.cnpq.br/6353170691331354

\section{Thiago Sette Santos}

Faculdade de Integração do Sertão (FIS), Serra Talhada, PE http://lattes.cnpq.br/4851463673696736

\section{Lucíolo Victor Magalhães e Silva}

Instituto Federal do Sertão Pernambucano, Campus Salgueiro, PE http://lattes.cnpq.br/3239088236416834

Informações sobre o

artigo:

Recebido em:

$09 / 10 / 2020$

Aceito em:

$17 / 10 / 2020$

Data de publicação:

$23 / 10 / 2020$

Palavras-chave:

Revestimento interno

Hospital

Sala de cirurgia

Reforma

\section{RESUMO}

As atividades de revestimento interno, que dependem de decisões tomadas nas diversas etapas do processo de acabamento das edificações, têm por objetivo maximizar o desempenho de cada subsistema que o constitui. A manutenção de cada um desses subsistemas está associada a uma série de atividades programadas que devem prolongar sua vida útil e minimizar a um custo compensador o processo de manutenção. Os materiais usados no acabamento de estabelecimentos assistenciais de saúde devem ser escolhidos de uma maneira diferente do convencional, pois não serão apenas observadas as questões de estética, iluminação, ventilação acústica e custo. Segundo Sampaio (2005), ao se realizar o projeto de um ambiente hospitalar devem ser levadas em consideração a satisfação e o bem-estar de todos os seus usuários, pois os edifícios hospitalares, estando diretamente ligados a saúde do homem, requerem conforto, qualidade, eficiência e manutenção de um entorno saudável. Devido a esses possuírem áreas que são considerados área de risco, e exigirem total higienização, tendo em vista que quanto mais crítica for a área, maiores serão as exigências. O que se busca de uma maneira geral são materiais que tornem os revestimentos resistentes, lisos, impermeáveis, facilitando assim a higienização. Tanto em áreas críticas quanto nas semicríticas, devem ser sempre usados materiais de acabamento que tornem as superfícies lisas, monolíticas e com menor número possível de frestas, podendo após suas frequentes limpezas e manutenções, manterem suas características. No desenvolvimento deste trabalho se abordará o procedimento de execução de uma obra de revestimentos internos num ambiente de risco (hospital), conceituação do tema, a inserção do engenheiro e suas responsabilidades e citações as normas vigentes. 


\section{PROCEDURES ADOPTED FOR EXECUTION IN REFORM OF INTERNAL COATINGS IN A HOSPITAL ENVIRONMENT}

\begin{tabular}{|c|c|}
\hline & ABSTRACT \\
\hline $\begin{array}{l}\text { Keywords: } \\
\text { Internal coating } \\
\text { Hospital } \\
\text { Surgery room } \\
\text { Reform }\end{array}$ & $\begin{array}{l}\text { The internal coating activities, which depend on decisions taken in } \\
\text { the various stages of the building finishing process, aim to } \\
\text { maximize the performance of each subsystem that constitutes it. } \\
\text { The maintenance of each of these subsystems is associated with a } \\
\text { series of scheduled activities that should extend its useful life and } \\
\text { minimize the maintenance process at a cost. The materials used in } \\
\text { the finishing of health care establishments must be chosen in a } \\
\text { different way from the conventional one, as the issues of aesthetics, } \\
\text { lighting, acoustic ventilation and cost will not be observed. } \\
\text { According to Sampaio (2005), when carrying out the design of a } \\
\text { hospital environment, the satisfaction and well-being of all its users } \\
\text { must be taken into account, as hospital buildings, being directly } \\
\text { linked to men's health, require comfort, quality, efficiency and } \\
\text { maintenance of a healthy environment. Because they have areas } \\
\text { considered to be at risk, and require total hygiene, considering that } \\
\text { the more critical the area, the greater the requirements. What are } \\
\text { generally sought are materials that make the coatings resistant, } \\
\text { smooth, impermeable, thus facilitating hygiene. In both critical and } \\
\text { semi-critical areas, finishing materials should always be used that } \\
\text { make surfaces smooth, monolithic and with the least possible } \\
\text { number of cracks, and after their frequent cleaning and } \\
\text { maintenance, they can maintain their characteristics. In the } \\
\text { development of this work, the procedure for executing a work of } \\
\text { internal coatings in a risky environment (hospital) will be } \\
\text { approached, conceptualization of the theme, the insertion of the } \\
\text { engineer and his responsibilities and citations to the current rules. }\end{array}$ \\
\hline
\end{tabular}

\section{INTRODUÇÃO}

Para a escolha correta de um revestimento é necessária uma análise do local que se deseja revestir e qual o seu uso. Alguns fatores foram determinantes na seleção de materiais do revestimento, tais como a durabilidade, a segurança, a estética, acústica, a facilidade de limpeza e manutenção. Para tanto, é preciso ficar atento ao desempenho técnico do revestimento em questão, o que significa conhecer suas características e propriedades. Existe, no mercado, uma grande diversidade de materiais que proporcionam ao usuário conforto e facilidade na manutenção dos revestimentos, cabe-se escolher o material mais adequado para a determinada situação (SOARES, 2002). 
A Resolução da Diretoria Colegiada $n^{\circ}$ 50, em vigor na Agência Nacional de Vigilância Sanitária, descreve que nas áreas críticas devem ser utilizados materiais de acabamento que tornem as superfícies monolíticas, com o menor número possível de ranhuras ou frestas, mesmo após o uso e limpeza frequente. Estes que não podem possuir índice de absorção de água superior a 4\% individualmente ou depois de instalados no ambiente, além do que, o rejunte de suas peças, quando existir, também deve ser de material com esse mesmo índice de absorção $\mathrm{O}$ uso de cimento sem qualquer aditivo antiabsorvente para rejunte de peças cerâmicas ou similares deve ser vedado tanto nas paredes quanto nos pisos das áreas críticas.

Para Bicalho \& Barcellos (2002), não existe material ideal para revestimento em hospitais, todos possuem suas vantagens e desvantagens, o que deve ser observado é qual atividade será desenvolvida no ambiente especificado, pois determinado material pode ser bom para uma determinada área, mas pode não servir para outra.

O presente trabalho tem como objetivo o acompanhamento e avaliação da aplicação de revestimentos internos hospitalares, restringida a uma área crítica, uma sala de grandes cirurgias. O acompanhamento foi feito ao âmbito das manifestações patológicas encontradas, as condições de limpabilidade, além do fluxo de equipamentos hospitalares e pessoas. Coordenação na execução e programação de serviços, dando orientações com a mão de obra terceira. Acompanhamento e verificação dos serviços, como também, a parte do setor administrativo da obra, com ajuda no acompanhamento físico da obra, levantamentos de materiais e medições de empreiteiros.

De maneira objetiva, foi descrita tal experiência adquirida, onde se podem relatar os procedimentos adotados na execução dos projetos, quando vivenciado em um canteiro de obras, tratando-se diretamente com atividades na execução de uma obra de reforma.

\section{METODOLOGIA}

Trata-se de um trabalho descritivo das etapas de acompanhamento de reforma de revestimentos internos em um hospital, cabendo a esta dar a orientação correta de quais materiais deveriam ser postos em cada situação, levando em conta ser uma área de risco, pois os revestimentos que nesse ambiente devem ser minunciosamente escolhidos, sendo 
indispensável esta consultoria devido a necessidade de uma futura aprovação desta sala cirúrgica.

Ao começar o acompanhamento da obra foi observado que as instalações elétricas e eletrônicas, como também as de climatização e fluído-mecânicas já estavam todas devidamente instaladas. Tendo em vista também que são dispensadas instalações hidráulicas e sanitárias. A fiscalização e orientação seriam feito em toda a obra de revestimentos internos, piso, parede, teto, portas e pintura. A sala possui área de $37 \mathrm{~m}^{2}$, dimensão mínima de $5 \mathrm{~m}$ e pé direito de $2,70 \mathrm{~m}$.

O trabalho se inicia, na retirada das portas das suas dobradiças, visto que estas serão reaproveitadas, sua retirada é apenas para facilitar no percurso da obra. Logo em seguida a sala foi totalmente isolada das demais sendo toda coberta de tapumes e telas, para evitar que os demais pacientes de outras salas terem o contato com a poeira e resíduos da obra, evitando-se possíveis infecções por esta causa.

O contrapiso foi minunciosamente verificado, visto que neste terá aplicação por cima de um piso do tipo condutivo, pois este é o mais indicado para salas cirúrgicas pela tentativa de eliminação de cargas eletrostáticas, pois estas podem causar explosões ou choques nos pacientes devido a baixa taxa de umidade em função do uso de ar condicionado e onde se usam anestésicos ou produtos químicos de limpeza.

Antes de começar a raspagem das paredes e teto foram quebradas partes do reboco dos quais estavam danificados pela umidade e salinidade, e logo após a quebra é feito um chapisco. Depois então é dado início a raspagem das paredes para aplicação de um novo revestimento, que deve ser específico para sala de cirurgia. Daí, com o auxílio da ABNT NBR 11.702, foi visto que existiriam três opções as quais eram epóxi a base de água, poliuretano e PVC. Foi constatada que a opção mais viável seria a tinta de epóxi a base de água, pois apesar de ser mais oneroso juntamente do poliuretano, se diferenciava deste devido a confiabilidade desta, pois é vastamente utilizada no mercado de engenharia em hospitais sendo esta específica para centros cirúrgicos. Outro fator importante na escolha é de ser de baixíssimo odor, o que futuramente não geraria constrangimento aos pacientes.

Antes da aplicação das tintas foi iniciada a execução de reboco nas partes danificadas, feito manualmente, chapando a massa na parede, com espessura média de 15 $\mathrm{mm}$ e traço de 1:5 (1 parte de cimento para 5 partes de areia). Foi utilizado aditivo plastificante de argamassa de reboco de $50 \mathrm{ml}$ para cada saco de cimento. Depois de sua aplicação esperamos 60 minutos para a argamassa entrar em fase de endurecimento. Após isto, foi iniciado o sarrafeamento com a régua de alumínio de $2,50 \mathrm{~m}$. Iniciando o 
sarrafeamento de cima para baixo seguindo as mestras e cruzando a régua entre as mestras para que o pano de reboco fique no prumo e bem acabado. Com a desempenadeira de pedreiro iniciou o desempeno e acabamento da massa em movimentos circulares retirando os excessos que a régua de alumínio não conseguir remover. Com a trincha foi aspergido um pouco de água nos pontos onde a argamassa já está atingiu o endurecimento, tornando-se difícil de passar a desempenadeira até o reboco ficar liso e bem acabado.

Após todo o reboco estar por completo foi passada uma lixa grossa para retirar todos os ressaltos existentes nas paredes, logo após é aplicado a massa corrida de três demãos até o nivelamento da superfície com uma desempenadeira. O mesmo processo feito nas paredes é feito no teto, porém este é aplicado gesso para execução de seu forro, utilizando orientações da ABNT NBR 13.867. A escolha do gesso se deve ao fato dele quando contínuo além de ter ótima estanqueidade é de ótima limpeza, além de que o forro removível para esta área é vedado e bem mais oneroso. Daí então se pode aplicar a tinta, misturando-a bem antes e durante a aplicação. Aplica-se o produto por igual com pistola, evitando repasses excessivos com cerca de 30\% de água limpa. Com secagem final após 4 horas.

Com isto se pode dar o início a colocação do novo piso condutivo manta de $2 \mathrm{~mm}$ x 2 m, o qual está em conformidade com a ABNT NBR 14.917-1. Removeu - se inicialmente as saliências superiores a $3 \mathrm{~mm}$, para que o piso tenha um perfeito acabamento nesta área e espaço para dilatação seguindo as descrições da ABNT NBR 14.917-2, ver Figura 1.

Figura 1 - Sala em estado de colocação do piso.

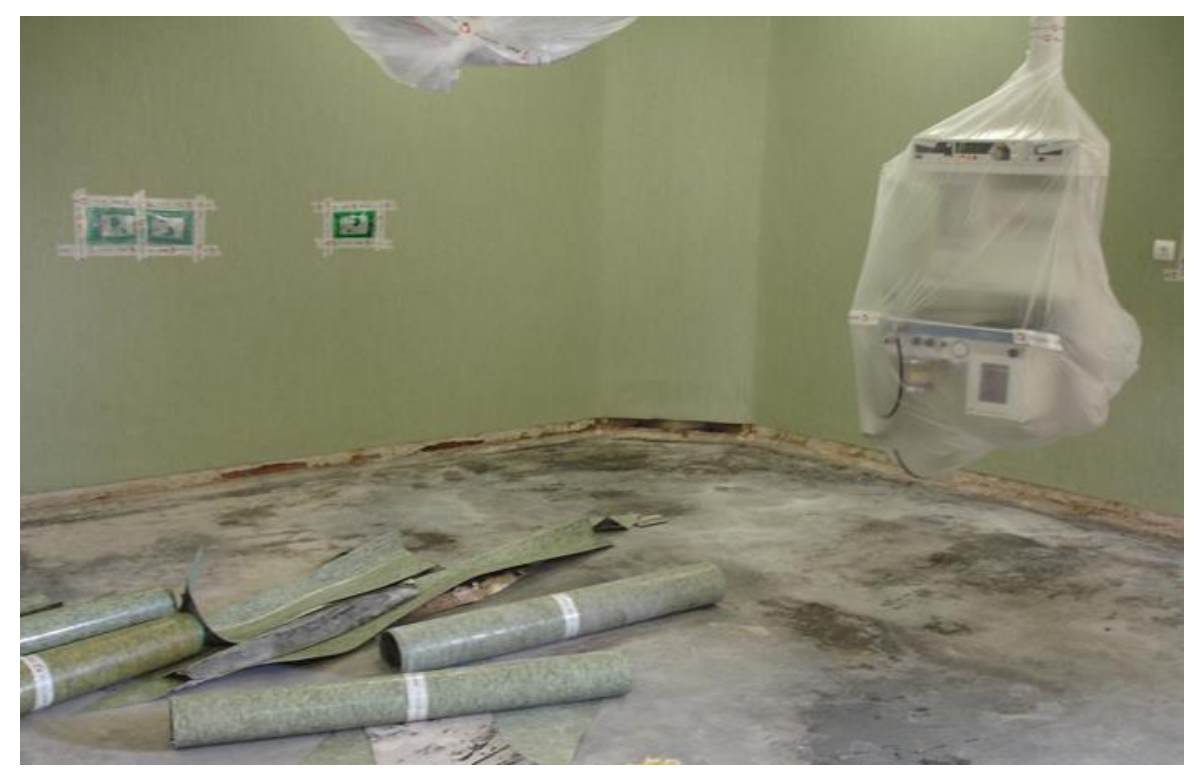

Fonte: Autor 
Com o auxílio de uma régua de piso sobre a manta foi marcado no batente da porta um corte de profundidade de $15 \mathrm{~mm}$ utilizando-se de uma serra manual. Dispondo a manta, com filme plástico voltado para baixo, como mostra a Figura 2, de forma que as emendas não coincidam com as juntas longitudinais do piso. Como o piso de manta condutiva é um material flexível foi feito uma leve curvatura de $1,5 \mathrm{~cm}$ de raio na junção do piso com a parede para implantação do rodapé, pois parede e rodapé devem estar perfeitamente alinhados, evitando o tradicional ressalto do rodapé que permite o acumulo de substancias e é de difícil limpeza. O rodapé é estendido $8 \mathrm{~cm}$ para cima alinhado com a parede.

Figura 2 - Medição do piso para colocação das mantas

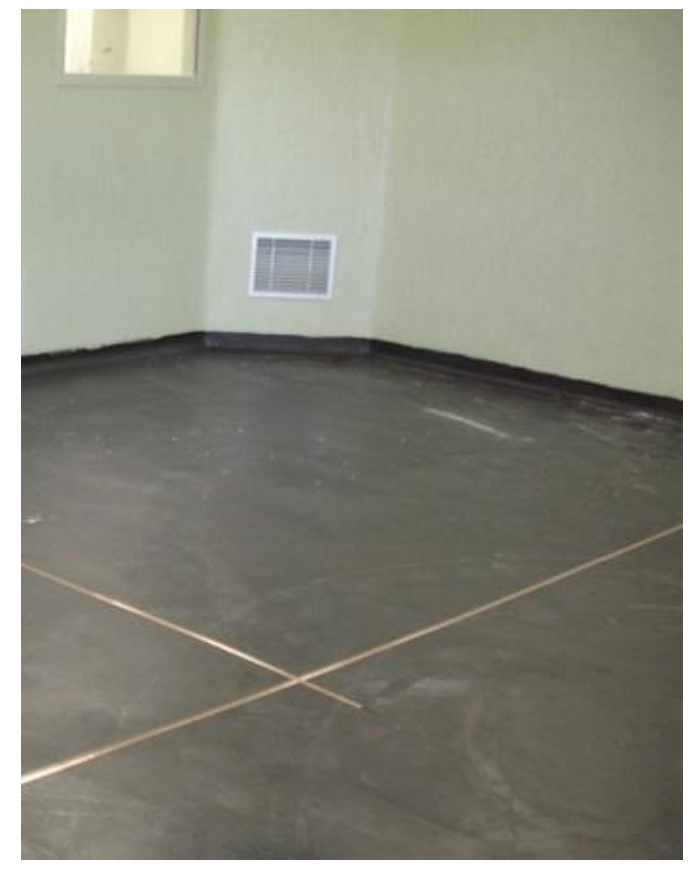

Fonte: Autor

Depois de instalar a manta, foi posicionado as réguas de medição definindo previamente o sentido delas para melhor aproveitamento do material para não haver recortes, entre fileiras, inferiores a $20 \mathrm{~cm}$ e fechamentos não inferiores a $5 \mathrm{~cm}$. Após todas as medições foi aplicada a cola PVA no lado fêmea do encaixe de forma contínua e homogênea em quantidade suficiente para verter o excedente à superfície, após a junção das réguas. Dessa forma, o excedente da cola fará a selagem da superfície, evitando a penetração de líquidos. Após 24 horas, todo processo de colagem foi concluído, conforme a Figura 3, daí se pôde dar a disposição dos equipamentos na sala. 
Figura 3 - Sala com os revestimentos de piso, parede e teto concluídos

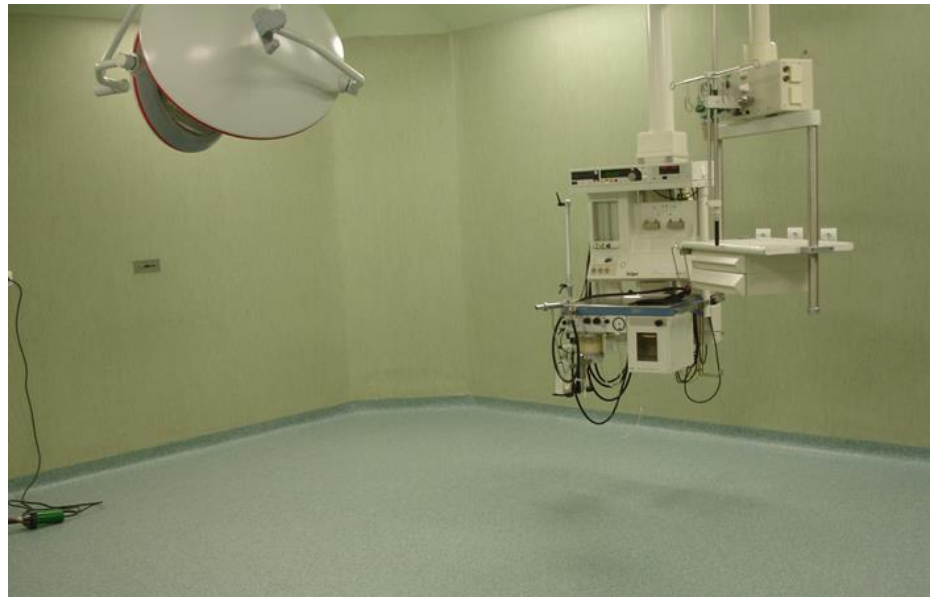

Fonte: Autor

Como havia antes sido retirada a porta da sala para facilitar na movimentação da obra, esta foi devidamente recolocada nas suas dobradiças, tendo em vista que a obra estava dada como concluída. A porta é de madeira tipo vai e vêm com duas folhas, ambas com visores, revestida com pintura de esmalte sintético, com dimensões cada uma de 70 x 2,10 m, ver Figura 4.

Figura 4 - Vista de fora da sala de cirurgia após a recolocação da porta, ainda em isolamento

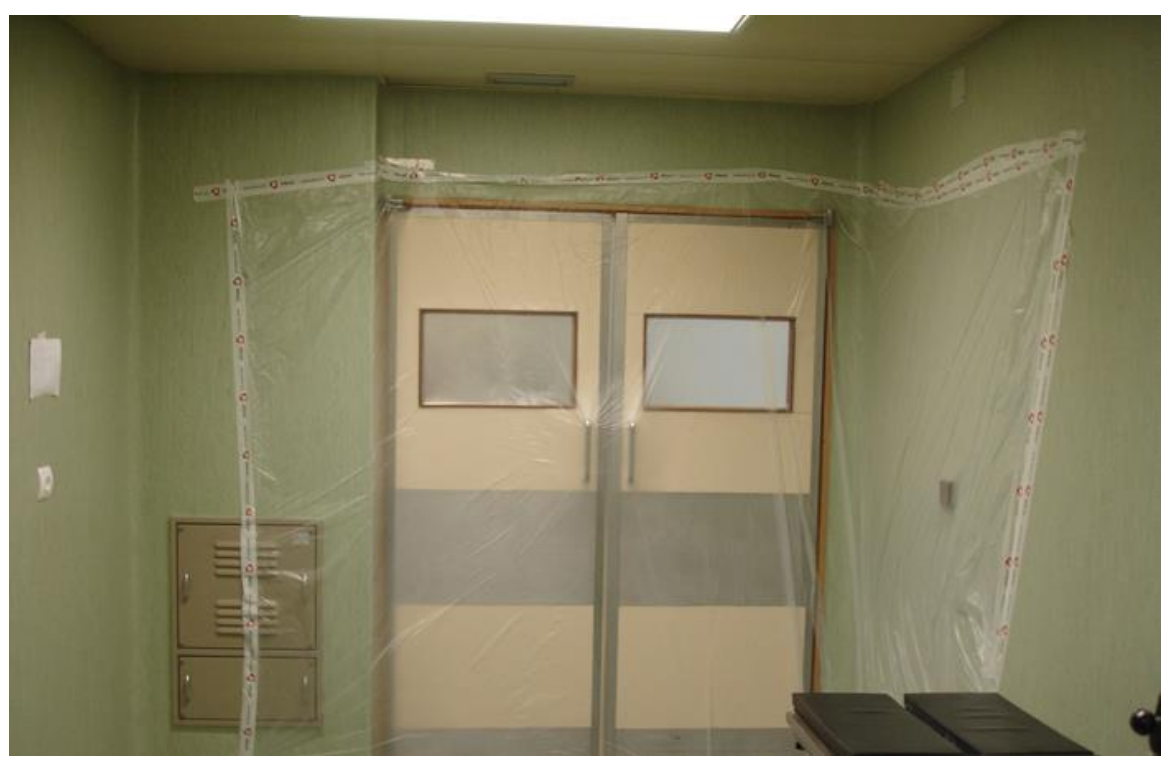

Fonte: Autor 


\section{RESULTADOS E DISCUSSÃO}

As atividades realizadas durante o período de dois meses, foram desenvolvidas no canteiro de obras e tomada de decisões das etapas em escritório.

As atividades de campo desenvolvidas foram divididas em: controle de produção, vistoria técnica, medições e distribuição de efetivos. As demais atividades realizadas em escritório foram: consulta prévia do projeto arquitetônico, emitir parecer técnico, elaboração de procedimentos de execução de serviços, elaboração de programações semanais e mensais. Permitindo o acompanhamento direto das atividades e proporcionando um conhecimento amplo da administração e controle da obra.

O fator de classificação do ambiente quanto ao seu risco de transmissão de infecções, definido pela RDC $\mathrm{n}^{\circ} 50$ da Agência Nacional de Vigilância Sanitária, foi de extrema importância no momento da escolha do materiais serem utilizados, tendo-se em vista que quanto mais crítica for a área, maior deverá ser a atenção destinada aos materiais de acabamento. Como a obra foi realizada numa sala de grandes cirurgias de um hospital, ambiente o qual é classificado como crítico teve-se que tomar cuidados minuciosos tanto para escolha dos materiais como para execução da reforma.

O que se foi observado é que não há uma norma técnica que especifique os tipos de revestimentos em hospitais, daí o trabalho foi baseado em definições das características dos revestimentos prescritos na Resolução RDC no 50 da Agência Nacional de Vigilância Sanitária e no manual Processamento de artigos e Superfícies em estabelecimentos de Saúde, do Ministério da Saúde.

A tinta de epóxi a base de água respondeu bem as expectativas, pois além de ser resistente a lavagem e ao uso de desinfetantes, possui baixo odor o que agilizaria a abertura da sala para sua utilização.

As tintas elaboradas a base de epóxi, PVC, poliuretano ou outras destinadas a áreas molhadas, podem ser utilizadas nas áreas críticas tanto nas paredes, tetos quanto nos pisos, desde que sejam resistentes à lavagem, ao uso de desinfetantes e não sejam aplicadas com pincel. Quanto utilizadas no piso, devem resistir à abrasão e impactos a que serão submetidas. 


\section{CONCLUSÃO}

O presente trabalho mostra uma aplicação prática de procedimentos e verificações as quais devem ser feitos em obras de reformas, como também explicita os cuidados os quais devem ser verificados em ambientes de risco como também os materiais os quais devem ser utilizados neste determinado ambiente.

Os revestimentos são de grande importância nas edificações, visto que contribuem para um bom acabamento e funcionalidade dos ambientes. Os hospitais como toda a edificação, devem ser projetados pensando no bem estar dos seus usuários; desse modo os revestimentos devem ser adequados ao uso que lhes será destinado. Ao se especificar os revestimentos para os ambientes hospitalares deve ser levado em consideração o risco de contaminação a que esse tipo de local está sujeito e, a partir disso, projetar revestimentos que possam minimizar a proliferação de infecções.

O trabalho com mão de obra terceira é de extrema importância para ambos, pois ai existe o intercâmbio de experiências e conhecimentos, os quais quando compartilhados entre as partes geram um crescimento de ambos na área de atuação, além de conquistar um produto final de maior qualidade. A cooperação de ambas as partes proporciona maior ganho de tempo e satisfação de estar nesta área de atuação. Por fim o ganho maior futuro é a sociedade, pois a sala receberá diversos tipos de pacientes os quais poderão tratar de sua cirurgia necessária num ambiente o qual está totalmente de acordo com o que se é destinado para ele.

\section{REFERÊNCIAS}

ASSOCIAÇÃO BRASILEIRA DE NORMAS TÉCNICAS (ABNT). NBR 11.702. Tintas para construção civil - Tintas, vernizes, texturas e complementos para edificações não industriais - Classificação e requisitos. Rio de Janeiro, 2019.

ASSOCIAÇÃO BRASILEIRA DE NORMAS TÉCNICAS (ABNT). NBR 13.867. Revestimento interno de paredes e tetos com pasta de gesso - Materiais, preparo, aplicação e acabamento. Rio de Janeiro, 1997.

ASSOCIAÇÃO BRASILEIRA DE NORMAS TÉCNICAS (ABNT). NBR 14.917-1. Revestimentos resilientes para pisos - Manta (rolo) ou placa (régua) vinílica flexível homogênea ou heterogênea em PVC; Parte 1: Requisitos, características e classes. Rio de Janeiro, 2017. 
ASSOCIAÇÃO BRASILEIRA DE NORMAS TÉCNICAS (ABNT). NBR 14.917-2. Revestimentos resilientes para pisos - Manta (rolo) ou placa (régua) vinílica flexível homogênea ou heterogênea em PVC; Parte 2: Procedimentos para seleção, utilização, instalação, conservação e limpeza. Rio de Janeiro, 2017.

BICALHO, F. C.; BARCELLOS, R. M. Materiais de Acabamento em Estabelecimentos Assistenciais de Saúde. In: CARVALHO, A. P. A. (Org.). Temas de Arquitetura de Estabelecimentos Assistenciais de Saúde. Faculdade de Arquitetura. Universidade Federal da Bahia, Salvador, 2002.

BRASIL, Ministério da Saúde. Agência Nacional de Vigilância Sanitária. Resolução da Diretoria Colegiada 50, de 21 de fevereiro de 2002. Apresenta: regulamento técnico para planejamento, programação, elaboração e avaliação de projetos físicos de estabelecimentos assistenciais de saúde. Brasília, 2002.

BRASIL. Ministério da Saúde. Coordenação de Controle de Infecção Hospitalar. Processamento de Artigos e Superfícies em Estabelecimentos de Saúde. -- 2. ed. -Brasília,1994. 50 p.

SAMPAIO, A.V.C.F. Arquitetura hospitalar: projetos ambientalmente sustentáveis, conforto e qualidade - proposta de um instrumento de avaliação. 2006. $402 \mathrm{f}$. (Doutorado em Estruturas Ambientais Urbanas) - Faculdade de Arquitetura e Urbanismo. Universidade de São Paulo, 2005.

SOARES, T. N. Revestimentos de pisos hospitalares: Avaliação das condições de uso em Porto Alegre. 2009. 87 f. (Trabalho de Conclusão do Curso de Engenharia Civil) Universidade Federal do Rio Grande do Sul, Porto Alegre, 2009. 


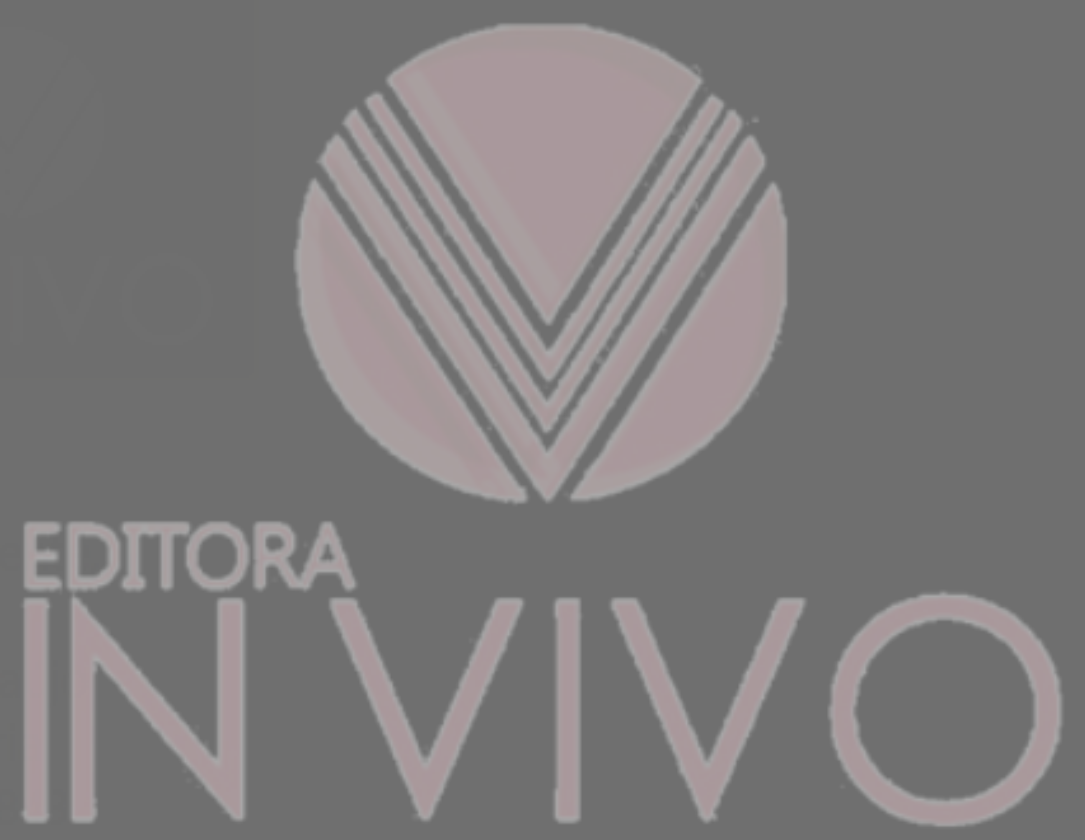

www.editorainvivo.com

Avance na ciência! Venha ser In Vivo! 